\title{
WestVirginiaUniversity
}

THE RESEARCH REPOSITORY @ WVU

Graduate Theses, Dissertations, and Problem Reports

2005

\section{Recycling baler material properties for safer baler operation}

Tracy A. Mick

West Virginia University

Follow this and additional works at: https://researchrepository.wvu.edu/etd

\section{Recommended Citation}

Mick, Tracy A., "Recycling baler material properties for safer baler operation" (2005). Graduate Theses, Dissertations, and Problem Reports. 1637.

https://researchrepository.wvu.edu/etd/1637

This Thesis is protected by copyright and/or related rights. It has been brought to you by the The Research Repository @ WVU with permission from the rights-holder(s). You are free to use this Thesis in any way that is permitted by the copyright and related rights legislation that applies to your use. For other uses you must obtain permission from the rights-holder(s) directly, unless additional rights are indicated by a Creative Commons license in the record and/ or on the work itself. This Thesis has been accepted for inclusion in WVU Graduate Theses, Dissertations, and Problem Reports collection by an authorized administrator of The Research Repository @ WVU. For more information, please contact researchrepository@mail.wvu.edu. 


\title{
Recycling Baler Material Properties for Safer Baler Operation
}

\author{
Tracy A. Mick
}

Thesis submitted to the

College of Engineering and Mineral Resources

at West Virginia University

in partial fulfillment for the requirements

for a degree of

Master of Science
in
Mechanical Engineering

Kenneth H. Means, Ph.D.,Chair

John R. Etherton, Ph.D.

Gary J. Morris, Ph.D.

Morgantown, WV

2005

keywords: recycling baler, safety device, strain gage, jam control 


\section{ABSTRACT \\ Recycling Baler Material Properties for Safer Baler Operation \\ Tracy A. Mick}

Between 1986 and 2002, there were 43 fatalities in the United States to operators of recycling industry balers. Of these fatalities, 29 involved horizontal balers that were baling paper and cardboard (Taylor, 2002). Balers often become jammed while the baling process is occurring, and the only way to remove the jam is manually. This requires an employee to place a limb of their body into the jamming area and remove the material that is causing the jam. While lockout and tagout procedures reduce the risk of hazardous energy being released, they can still be easily bypassed, ignored, or forgotten. Recent efforts to reduce machine-related injury and death involve the development of a control system for these machines that automatically detect hazardous operating conditions and responds accordingly. The system is being developed at the National Institute for Occupational Safety and Health (NIOSH) in Morgantown, WV. This system, JamAlert, automatically terminates the power to the machine when a jam is detected. JamAlert detects a jam by observing the strain that is experienced by the shear bar of the baler and the hydraulic pressure at which the ram is operating. The strain that is experienced by the baler shear bar when a jam is initiated was calculated in this study through laboratory testing and finite element modeling. Design recommendations are presented on how best to tune the JamAlert's operating program to most effectively control the jam-clearing hazard. 


\section{Acknowledgements}

There are many people that contributed to the process that lead to the completion of this thesis. I would like to thank them all for their help and guidance throughout the research, design, experimentation, and writing process. First of all I would like to thank Dave Edgell for all of the work that he did in the shop at NIOSH to fabricate the pieces that I needed to complete my testing. I would also like to thank Doug Cantis for his help with transporting equipment to the engineering building from NIOSH and for his assistance in dulling the shear bar. Also I would like to thank Cliff Judy for his help in designing and making components at the engineering building for the testing apparatus. The testing would not have been possible without those vital supports.

I also wish to thank all of the members of my graduate committee for offering me guidance and motivation throughout my entire graduate career. I want to thank Dr. Gary Morris for agreeing to be on my committee at such short notice. Also I wish to thank Dr. John Etherton for continually guiding me throughout my graduate career and making sure that I was continually on track. I also want to thank Dr. Kenneth Means for being the chairman on my graduate committee. I also want to thank him for assisting me in all of my testing and offering guidance throughout the thesis writing process. Without the help and guidance from all of these individuals, this entire task could not have been completed. 


\section{Table of Contents}

Abstract

Acknowledgements

Table of Contents iv

List of Tables $\quad \mathrm{V}$

List of Figures vi

Chapter 1 - Overview

1.1 Introduction 1

1.2 Literature Review

$\begin{array}{ll}1.3 \text { Objectives } & 7\end{array}$

Chapter 2 - Force Determination Experiment

2.1 Experiment Overview $\quad 8$

2.2 Equipment Setup and Description $\quad 10$

2.3 Experimental Procedure $\quad 23$

2.4 Experimental Results $\quad 29$

2.5 Experiment Results Discussion 34

Chapter 3 - Finite Element Modeling

3.1 ANSYS Overview $\quad 39$

3.2 Model Description $\quad 39$

3.3 Finite Element Modeling Results 43

3.4 Discussion of Finite Element Model Results $\quad 50$

Chapter 4 - Validation of Finite Element Model

4.1 Description of Recycling Baler 52

4.2 Validation Overview $\quad 53$

4.3 Results of Validation $\quad 54$

4.4 Discussion of Validation Results $\quad 56$

Chapter 5 - Conclusions and Recommendations

5.1 Conclusions $\quad 58$

$\begin{array}{ll}5.2 \text { Recommendations } & 59\end{array}$

$\begin{array}{ll}\text { Bibliography } & 62\end{array}$

Appendix A - Shear Bar Assembly Drawings 63

$\begin{array}{ll}\text { Appendix B - Cardboard Property Data } & 70\end{array}$

$\begin{array}{ll}\text { Curriculum Vitae } & 74\end{array}$ 


\section{List of Tables}

Table 1: Properties of Test Material Bundles 23

Table 2: Average Experimental Maximum Force (lbs.) for Three Shear 45

Bar Radii and Three Materials

Table 3: Maximum Strain (in/in) in y-direction for different shear bar edge radii and materials

Table 4: Average Maximum Strain and Pressure Caused by Cardboard,

Magazines, and Newspaper

Table 5: Experimental and Theoretical Average Maximum Strains 58

Table 6: Ranges of Strains for Limit Value and Corresponding Voltages 59 for JamAlert System

Table 7: Mechanical Properties of Combined Boards and Boxes 71

Table 8: Common U.S. Grades of Liner and Medium 73 


\section{List of Figures}

Figure 1: Experiment Setup 9

Figure 2: Hydraulic Loading Machine: Loading Table (Left) and Control (Right) 11

Figure 3: Shear Bar Assembly $\quad 12$

Figure 4: 0.25 inch gap between shear bar and ram block 14

Figure 5: Mounting Plate and Block $\quad 15$

Figure 6: Support Bars $\quad 15$

Figure 7: Side View of Force Determination Experiment 16

Figure 8: Data Collection Instrumentation $\quad 17$

Figure 9: Data Collection Wiring 19

Figure 10: Front Panel Window for Data Collection VI 21

Figure 11: Diagram Window of Data Collection VI 22

Figure 12: Cardboard Bundle 23

Figure 13: Cardboard Test after Shear Bar Traveled 4 inches $\quad 25$

Figure 14: Newspaper Test after Shear Bar Traveled 4 inches 25

Figure 15: Magazine Test after Shear Bar Traveled 4 inches 26

Figure 16: Cardboard Test when Shear Bar Travel Ended 27

Figure 17: Newspaper Test when Shear Bar Travel Ended 27

Figure 18: Magazine Test when Shear Bar Travel Ended 28

Figure 19: Results of Cardboard Testing with Sharpest Shear Bar 29

Figure 20: Results of Newspaper Testing with Sharpest Shear Bar 30

Figure 21: Results of Magazine Testing with Sharpest Shear Bar 30

Figure 22: Results for Cardboard Using Shear Bar with 1/64" Radius on Edge 31

Figure 23: Results for Magazines Using Shear Bar with 1/64" Radius on Edge 32

Figure 24: Results for Newspaper Using Shear Bar with 1/64' Radius on Edge 32

Figure 25: Results for Cardboard using Shear Bar with 1/32" Radius on Edge 33

Figure 26: Results for Newspaper using Shear Bar with 1/32" Radius on Edge 33

Figure 27: Results for Magazines using Shear Bar with 1/32" Radius on Edge 34

Figure 28: Forces Created by Cardboard for each Shear Bar 35

Figure 29: Forces Created by Magazines for each Shear Bar 36 
Figure 30: Forces Created by Newspaper for each Shear Bar 36

Figure 31: Shear Bar in Recycling Baler 39

Figure 32: Shear Bar Drawing Imported into ANSYS 40

Figure 33: Meshed Model 41

Figure 34: Shear Bar Model with Structural Displacement Loads 42

Figure 35: Load Applied to Shear Bar Model 43

Figure 36: ANSYS Solution for Maximum force of 24,887 lb. 44

Figure 37: Strain Distribution from Cardboard on Sharp Shear Bar 45

Figure 38: Strain Distribution from Magazines on Sharp Shear Bar 46

Figure 39: Strain Distribution from Newspaper on Sharp Shear Bar 46

Figure 40: Strain Distribution from Cardboard on Shear Bar with 1/64" Edge Radius 47

Figure 41: Strain Distribution from Magazines on Shear Bar with 1/64" edge radius 47

Figure 42: Strain Distribution of Newspaper on Shear Bar with 1/64" Edge Radius 48

Figure 43: Strain Distribution of Cardboard on Shear Bar with 1/32" Edge Radius 48

Figure 44: Strain Distribution from Magazines on Shear Bar with 1/32" Edge Radius 49

Figure 45: Strain Distribution from Newspaper on Shear Bar with 1/32" Edge Radius 49

Figure 46: Strain Gage Location on Shear Bar 51

Figure 47: Industry Recycling Baler used for Validation Tests 52

Figure 48: Strain Plot for Cardboard 54

Figure 49: Strain Plots for Magazines 55

Figure 50: Strain Plots for Newspaper 55

Figure 51: Shear Bar Drawing $\quad 64$

Figure 52: Load Cell to Machine Connector Drawing 65

Figure 53: Threaded Rod Drawing 66

Figure 54: Shear Bar to Load Cell Connector Drawing 67

Figure 55: Welded Bar Drawing $\quad 68$

Figure 56: Wedge Drawing $\quad 69$

Figure 57: Bursting Strength of Cardboard versus Multiple Sheets of Cardboard 72 


\section{Chapter 1 - Overview}

\subsection{Introduction}

Among workplace injuries, amputations are one of the most severe. On an average there are approximately 18,000 workers that suffer amputations and 800 deaths from workers using machinery in a year (Taylor, 2002). A portion of these amputations come from workers that use and maintain recycling balers. From 1986 until 2002, there were 43 fatalities involving recycling balers. Of these fatalities, 29 involved horizontal balers that were baling paper (Taylor, 2002). Recycling balers are used at sites where recyclable materials are collected before being shipped to recycling plants. The recycling baler is used to compress and bind together the material into manageable blocks. Material is loaded into the machine through a hopper on top of the baler. From the hopper, the material falls into the baler chamber. A cylinder then provides power to the ram which moves across the length of the baler and forces the material to be compressed into a block in the compacting bin. The excess material is cut off by a shear bar. This bar is welded in the baler so that the ram travels right below it as it moves towards the compacting bin. Once the ram is not capable of compacting any more material into the compacting bin, the bale is tied with wire and pushed out of the chamber. Often the baler becomes jammed while the baling process is occurring, and the only way to remove the jam is manually. Not only does this reduce productivity by stopping the entire baling process, but it also creates a hazard for the baler operator. This jam requires an employee to place a limb of their body in the jammed area and remove the material that is causing the jam. Although the machine is stopped by the jam, this doesn't mean that the machine is safe. If the machine is still energized there exists the possibility that the baling process 
will continue once the jam is removed. It is when this happens and the employee does not have a chance to remove their limb from the baling area that amputation occurs. While it has been realized that these workplace hazards can be reduced by improving workplace practices, giving adequate training, and through administrative controls, it has been discovered that the most effective way to prevent injuries is through safeguarding the machines.

\subsection{Literature Review}

There are already programs that are in effect that are aimed at preventing injury from clearing jammed balers. Employers are beginning to take a more active role in educating their employees and making them aware of the hazards of their job. In order to ensure that employees follow certain safety procedures, the Occupational Safety and Health Administration (OSHA) has developed regulations regarding the control of hazardous energy sources and guarding machines. OSHA was created by congress in 1971 under the Occupational Safety and Health Act. The mission of this agency is to reduce the number of illnesses, injuries, and deaths that workers experience because of their occupations. Since OSHA was created, occupational deaths have decreased by $62 \%$ and occupational injuries have been reduced by $42 \%$ (OSHA, 1996).

There are no current OSHA regulations that are specific to balers, but general regulations can be applied to situations encountered when using a baler. One important standard addresses the control of hazardous energy (29 CFR 1910.147). When servicing or maintenance of machinery is required, there can be an unexpected release of stored energy that could cause injury to employees. It has been found that one-third of all 
hazardous energy release casualties occur during the cleaning and unjamming of equipment (Grund, 1995). Since this activity may not have been foreseen as part of the operation of the machinery, balers used may not have guidelines developed to instruct the employee, and freestyle approaches are used. These unexpected energy releases often occur when power is not turned off before servicing a machine or power is unexpectedly turned on during the servicing process. This OSHA standard requires that procedures be developed to place appropriate lockout or tagout devices on energy isolating mechanisms to prevent unexpected energization or unexpected releases of energy. This procedure is to be part of an entire energy control program that is supposed to be established by the employer. This lockout/tagout standard assigns the responsibility to the employers to protect the employees from hazardous energy sources. This program is to consist of energy control procedures, employee training, and periodic inspections. These inspections are to make certain that all employees make the machine inoperative by isolating the energy source before any maintenance or servicing is done on the machine.

Lockout/tagout methods have become more widely used in order to protect employees as part of the recent safety movement. Because of the lockout/tagout standard developed by OSHA, approximately 120 fatalities and 50,000 injuries have been prevented each year (OSHA, 2001). The use of lockout is required at any time when it is necessary that an employee place a part of their body within a zone on a machine where work is executed on material. Lockout is defined as the placement of a lockout device on an energy isolating device, in accordance with an established procedure, ensuring that the energy isolating device and the equipment being controlled cannot be operated until the lockout device is removed (OSHA, 1996). This usually consists of a lock being placed 
on the main power switch when it is in the off position to ensure that the power is not turned on while a jam is being cleared or maintenance is being done. Tagout is used to prevent unwanted energy releases as well by placing a tagout device on an energy isolating mechanism. This tagout device is usually a tag that acts as a warning to indicate that the energy isolating device should not be operated until the tag is removed. While lockout is safer than tagout, using tagout still serves as a precaution to prevent energy release incidents when lockout is not able to be used. During these instances, the employer must provide systematic rationale as to why a lock cannot be used.

Other OSHA regulations that could apply to balers are the regulations on machine guarding (29 CFR Part 1910.212) and the confined spaces standard (29 CFR 1910.146). Both of these standards provide additional requirements for protecting employees while operating machinery. The machine guarding regulation states that any point of operation that exposes an employee to injury shall be guarded. This guard is to be designed in such a way that it prevents the employee from having any part of his body within the danger zone. Guards must be strong and secure physical barriers that enclose the hazardous machine parts. The guards must also be made so that the employee cannot remove them or easily able to bypass them. Other stipulations for machine guarding are that they must not interfere with the normal operation of the machinery and they must not create any additional hazards (OSHA, 1996).

Besides OSHA, the American National Standards Institute (ANSI) has developed safety requirements specifically for baling equipment. This private, non-profit organization has an objective of improving the competitiveness of the businesses within the United States as well as the quality of life of the employees by organizing and 
promoting voluntary standards and consistent assessment systems. Founded in 1918, this organization is comprised of 1000 companies, organizations and government institutions. Their safety standards address a variety of equipment, but the regulation that specifically addresses baling equipment is ANSI Z245.5-2002. This regulation states that the employer is responsible for providing the employee with all of the information and training necessary so that they can successfully work safely with the baler. Once the employer informs the employee of all of the safety equipment on the baler, it is the responsibility of the employee to use these devices appropriately. The employer is then responsible for inspecting the safety devices to ensure that they work properly and are not being bypassed. It is then the responsibility of the employer to not allow a baler to be operated unless all of the safety devices are completely operational (OSHA, 1996).

While great effort has been used in order to make employers and employees more aware of the dangers that may occur while using a baler, and what precautions they can take during the baling process to prevent injury, there are still more safety developments that can be made. Lockout and tagout procedures reduce the risk of hazardous energy being released, but they can still be easily bypassed, ignored, or forgotten. The most recent efforts to reduce machine related injury and death involve the development of control systems for the machines that automatically detect hazardous operating conditions and respond accordingly. One of these control systems is being developed at the National Institute for Occupational Safety and Health (NIOSH). This system, JamAlert, automatically terminates the power to the machine whenever a jam is detected. Once the power is shut off, a trapped-key method is used to ensure that the employee can remove the jam safely without the threat of an unexpected energy release. The trapped key 
method involves a series of keys that must be turned in order to resume power to the machine and in order to start the machine. Once a jam is detected the only way to restore the power is by using the appropriate key. This will require the employee to take the key to the power source which is a distance away from the baler. This allows the employee to be a safe distance away from the operating zone before power is returned. The trapped key method ensures that the keys are only used at the appropriate time and in the appropriate order. A sequence will be set that will only allow certain keys to be removed when others are locked in position. This will ensure that the proper jam clearing procedure is used and that power is returned only when the operator is a safe distance from the machine. This system detects a jam by observing the strain that is experienced by the shear bar of the baler and the pressure at which the ram is operating. If both of these measurements exceed a value that is associated with jamming, operation of the machine is stopped by eliminating the power. The power can not be returned until the proper procedures have been followed (Phillips, 1996). Determination of the strain that is experienced by the baler shear bar when a jam is initiated is proposed to be calculated in this study through finite element modeling.

The JamAlert system is not the only control system that detects hazards with a strain gage. Strain gages are commonly found within the control systems of other industrial equipment. An example would be the strain gage that is found in the control system of a metal press. This strain gage is used to monitor the counterbalance of the press. Through analysis of the strain, modifications can be automatically made to ensure that all the parts of the machinery are lined up properly. 
Numerous studies have been completed on the properties of cardboard and its strength when used in shipping containers. The strength of a cardboard box to resist crushing through compression, bursting, and puncture have all been published previously. In Malenfort's Corrugated Shipping Containers: An Engineering Approach, it was determined that a corrugated cardboard box made with a regular kraft liner grade has a compression strength of 46 pounds per inch and a burst strength of $65 \mathrm{psi}$ (Malenfort,1996). All of the tests done to determine these properties were done on single sheets of cardboard or boxes made from corrugated cardboard. Some of the data collected from these tests can be found in Appendix B. No testing has been published on the shear strength or compressive strength of cardboard, newspaper, or magazines that have been layered together.

\subsection{Objectives}

The objective of this study is to research elements that will make operating industrial recycling balers safer. This is primarily done by determining the strain that is experienced by the shear bar when the recycling baler jams. This value is necessary for tuning the JamAlert system to respond to a jam. Besides determining theoretical values of strain during jamming, this study will also determine how the material being baled and the sharpness of the shear bar affect jams. Knowing this will also assist in adjusting the JamAlert system and will ultimately help to prevent jams in recycling balers and injuries from removing these jams. 


\section{Chapter 2 - Force Determination Experiment}

\subsection{Experiment Overview}

It was necessary to perform this experiment in order to determine the force that the shear bar experiences during jamming. When a jam occurs within the baler, the ram is not able to move forward. It is assumed that when this happens the material is applying a maximum force to the shear bar. For the force determination experiment a baling situation was simulated through the use of a Baldwin-Southwark loading machine in the laboratory at West Virginia University. The loading machine was used to apply a maximum force to a model of the shear bar which was attached to the machine. As load was applied by the machine, the shear bar was lowered onto a bundle of material. This bundle of material was extended over the edge of a fixed block that was attached to the base of the machine. This block acted as the ram of the baler. As the shear bar was lowered into the material, the block of material was free to rotate as the shear bar moved down along the block. This simulated the action of the ram moving the material into the shear bar. A load cell placed above the shear bar transmitted the force that was applied to the shear bar to a digital indicator and the values were stored in a spreadsheet.

The objective of this experiment was to determine the maximum force that is exerted on the shear bar by the material during baling. This experiment was done using three different materials as well as with three different shear bars. Each shear bar had a different sharpness. All three materials were commonly baled materials: cardboard, newspaper, and magazines. The experiment was first done with the shear bar at a maximum sharpness as though it was brand new. After force measurements were recorded for each of the three materials with the sharp shear bar, the bar was rounded to a 
medium dullness with an edge radius of 1/64 inch, and finally a greater dullness with an edge radius of $1 / 32$ inch. The bar was used with each of the three degrees of sharpness on all three materials, and the forces from each trial were compared. These forces were used in the finite element modeling to estimate the strain that the shear bar experiences when the baler jams. By realizing the forces that were created by the three different materials and the three different shear bars, a characterization of how these variables affect baler jamming was developed as well. The setup of the force determination experiment can be seen in Figure 1.

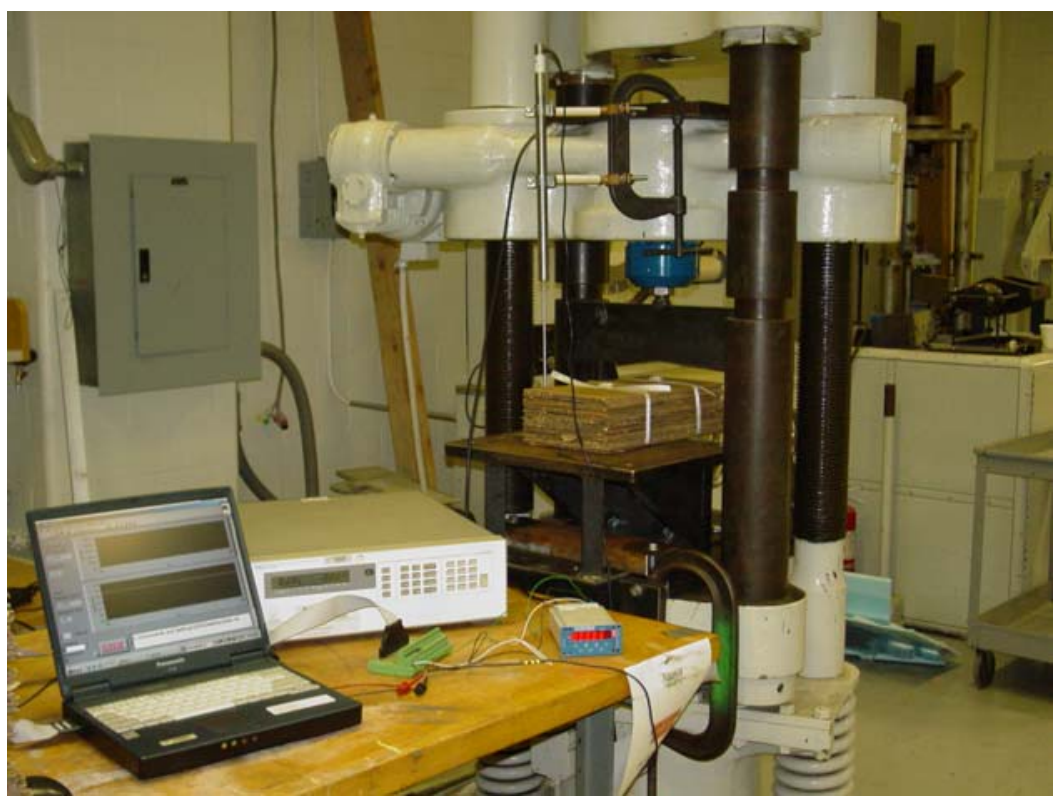

Figure 1: Experiment Setup 


\subsection{Equipment Setup and Description}

\subsubsection{Loading Machine}

The load application mechanism was a static hydraulic testing machine. The machine was produced by the Baldwin-Southwark Corporation. This company has been producing testing machinery since the 1930's and has since been renamed SATEC. Currently SATEC manufactures Instron hydraulically powered universal testing machines in Grove City, Pennsylvania. This testing machine applies and measures testing loads by using hydraulic fluid. The model 200 BTE testing machine that was used for the force determination test has the ability to apply loads from 0 pounds to 200,000 pounds. For the purpose of our experiment, the load machine was run at a maximum force. This load was determined by the use of the load cell placed above the shear bar.

The load machine consists of two parts, the loading platform and the control station. The loading platform is the table where the testing material is placed. The shear bar assembly is attached to the head of the machine above the table. Both the loading table and the head are capable of moving upward or downward. The control station consists of the control buttons, valve knobs, and the dial indicator. There are four control buttons. There is a button to start the machine, a button to stop the machine, a button to lower the head and a button to raise the head. The valves control the direction the loading table moves. When the right knob is turned the valve is opened so that the table moves upward. Turning the left knob causes the table to move downward. The dial indicator shows what load is being applied by the machine in pounds. The load machine can be seen in Figure 2. 

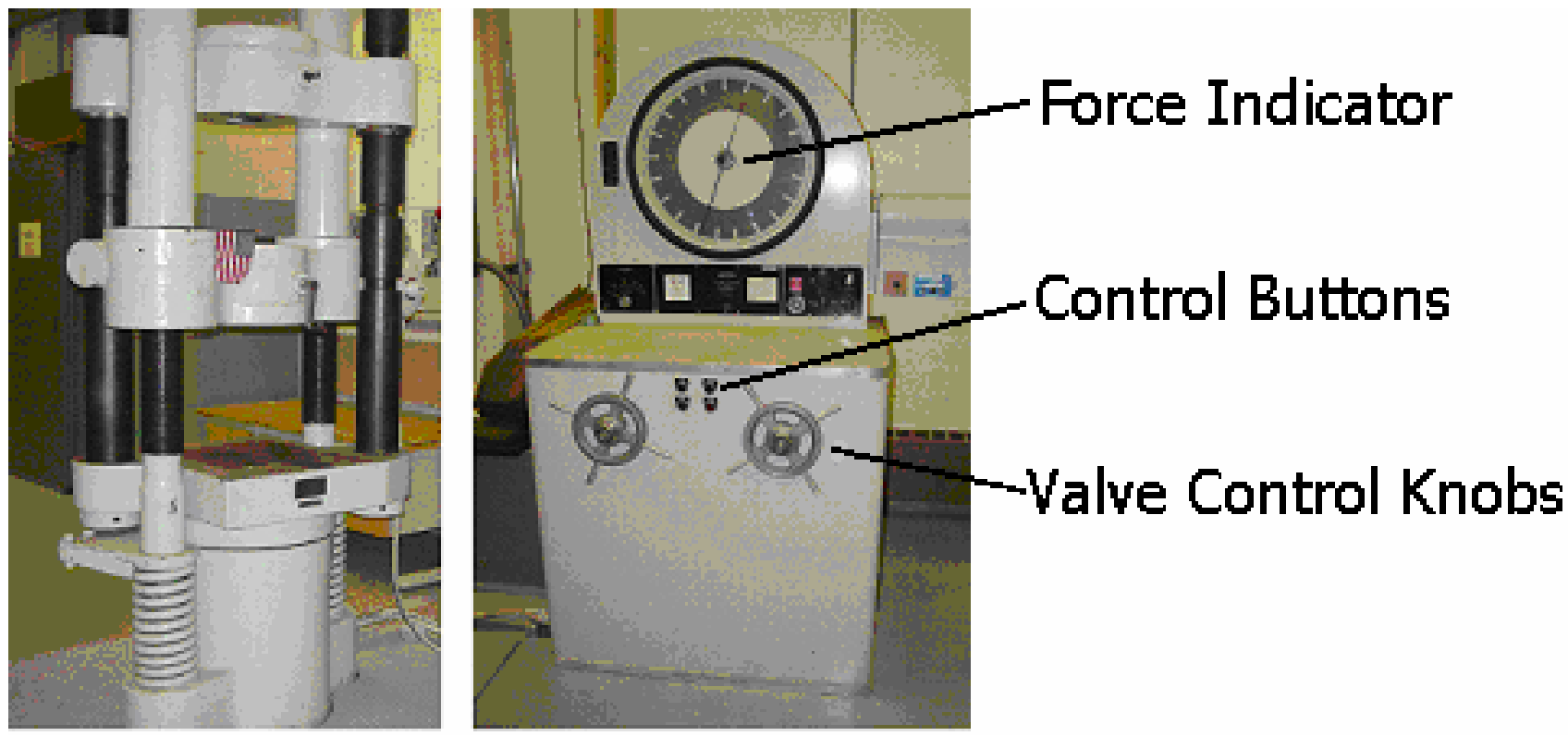

Figure 2: Hydraulic Loading Machine: Loading Table (Left) and Control (Right)

\subsubsection{Shear bar setup}

For this experiment, the shear bar and load cell act as an attachment to the loading machine. The shear bar was welded to a threaded rod. A jam nut was then put on the threaded rod followed by the load cell. On top of the load cell another threaded rod was inserted. This threaded rod was welded to a round plate that had a rectangular block welded to the top of it. This block was how the shear bar and load cell were secured within the loading machine. The rectangular block was held in the machine with wedges that were placed on either side of the block. As load was applied by the machine and transferred through the shear bar, the wedges were squeezed between the block and the inside of the head of the load machine. Coming from the top of the block was another threaded rod. This rod extended through a plate on top of the head of the machine. A bolt was then screwed on the rod to hold the entire assembly in place when load was not being applied. The entire assembly can be seen in the figure below. 


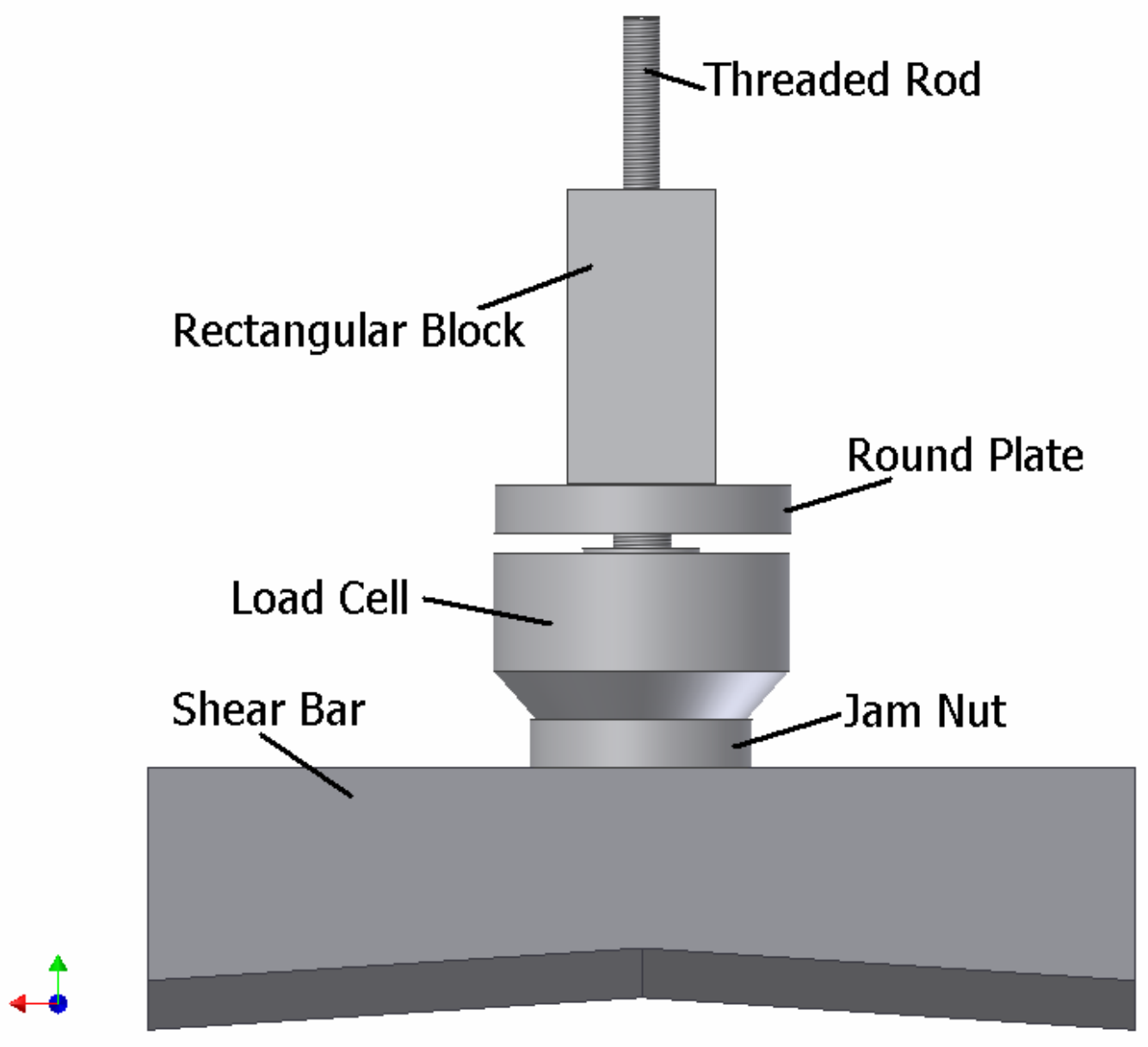

Figure 3: Shear Bar Assembly

\section{Load cell Description}

The load cell used for this experiment was the model 1200 Precision Series made by Interface. This model has a 25,000 pound capacity and can measure forces both in tension and compression. The load cell is accurate to 0.04 percent, and it has a high output of $4 \mathrm{mV} / \mathrm{V}$. This compact load cell has a diameter of 6.06 inches. It also came equipped with a mountable base that was attached to the cell. The connector holes on 
either side of the load cell are threaded and have diameters of 1.25 inches with 28 threads per inch.

\section{Shear bar and connectors description}

All of the components of the shear bar assembly except for the load cell and the jam nut were built in the machine shop at NIOSH. Drawings with dimensions of the shear bar, block, wedges, and threaded rod can be seen in the Appendix A

The jam nut was needed in order to provide a secure fit between the shear bar and the load cell. When the shear bar was screwed tightly into the load cell at first, the edge of the shear bar was not parallel with the edge on the ram block. If the head were to be lowered, the shear bar would hit the ram block instead of traveling in line with it. The shear bar was unscrewed, and the jam nut was screwed onto the threaded rod that was welded to the shear bar. The shear bar was once again threaded into the load cell. Because of the alignment the shear bar could not be screwed into the load cell tightly. It was screwed in all of the way and then unscrewed until it was in line with the ram block. The jam nut was then tightened up to the bottom of the load cell. This allowed for the shear bar to remain in the correct position but also ensured that the shear bar was tightly in place. This guaranteed that the shear bar would not rotate once the load was applied. The jam nut used had a hole with diameter 1.25 inches, had 28 threads per inch, and was 1 inch tall.

\subsubsection{Mounting Plate and Block Setup}

A mounting plate was placed on the platform of the loading machine. The block that simulates the baler ram was bolted to this mounting plate to ensure that the block did not move once force was applied to the material. The bundles of material were placed on 
this block so that an inch of the bundle extended past the block. The shear bar was then lowered to just above the material to prepare for the load to be applied. Two supporting plates were mounted on the opposite side of the shear bar as the ram block. These plates were attached to the mounting plate and were designed so that the shear bar would slide on these two plates as it moved along the end of the ram block. Since the shear bar in the recycling baler is welded into the baler, the compressive force from baling is distributed throughout the machine. The purpose of these support plates were to provide support for the shear bar as it cuts through the material. The support plates kept the blade from deforming by transferring the compressive forces to the mounting plate. In the recycling baler there is a 0.25 inch gap between the bottom of the shear bar and the top of the ram. In the experiment this dimension was maintained because the ram block was bolted to the mounting plate with slotted holes. This allowed the gap to be adjusted to the appropriate dimensions by sliding the block forward or backward. Once the ram block was in the right position, the bolts were then tightened to ensure that the block did not move during testing. Throughout the testing the space was checked frequently to ensure that the 0.25 inch was maintained.

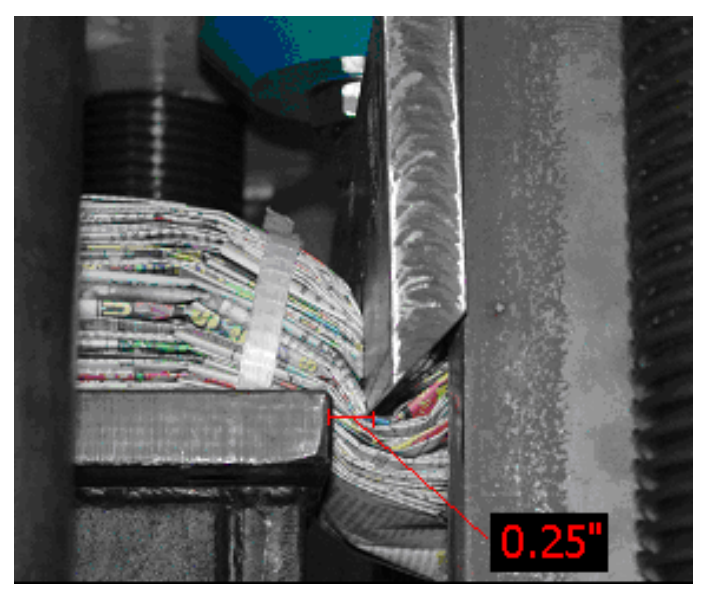

Figure 4: 0.25 inch gap between shear bar and ram block 


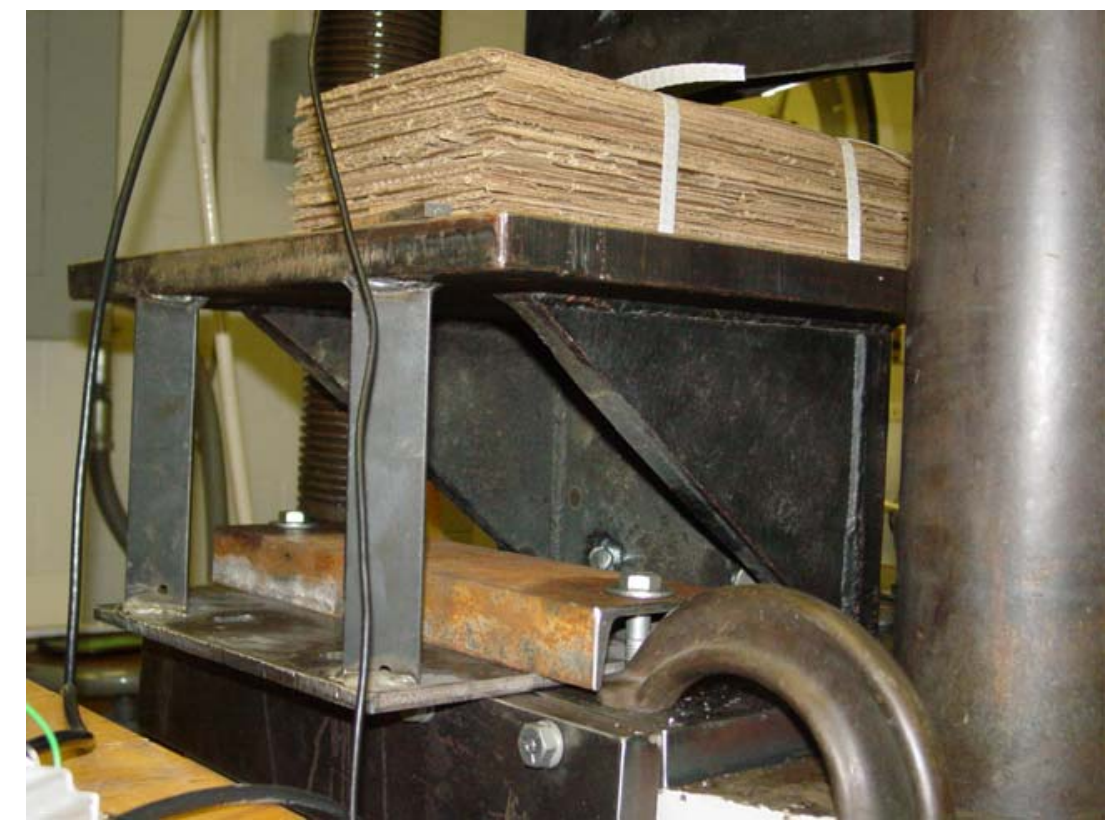

Figure 5: Mounting Plate and Block

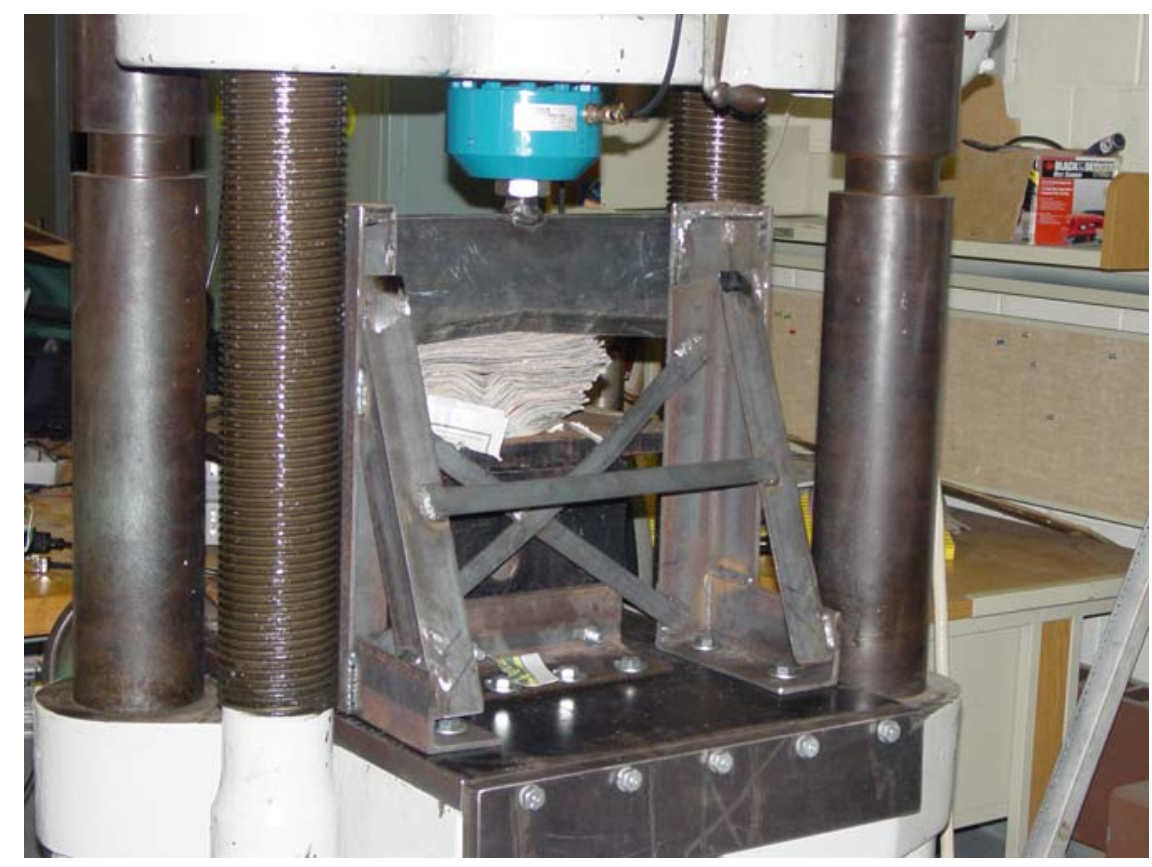

Figure 6: Support Bars 


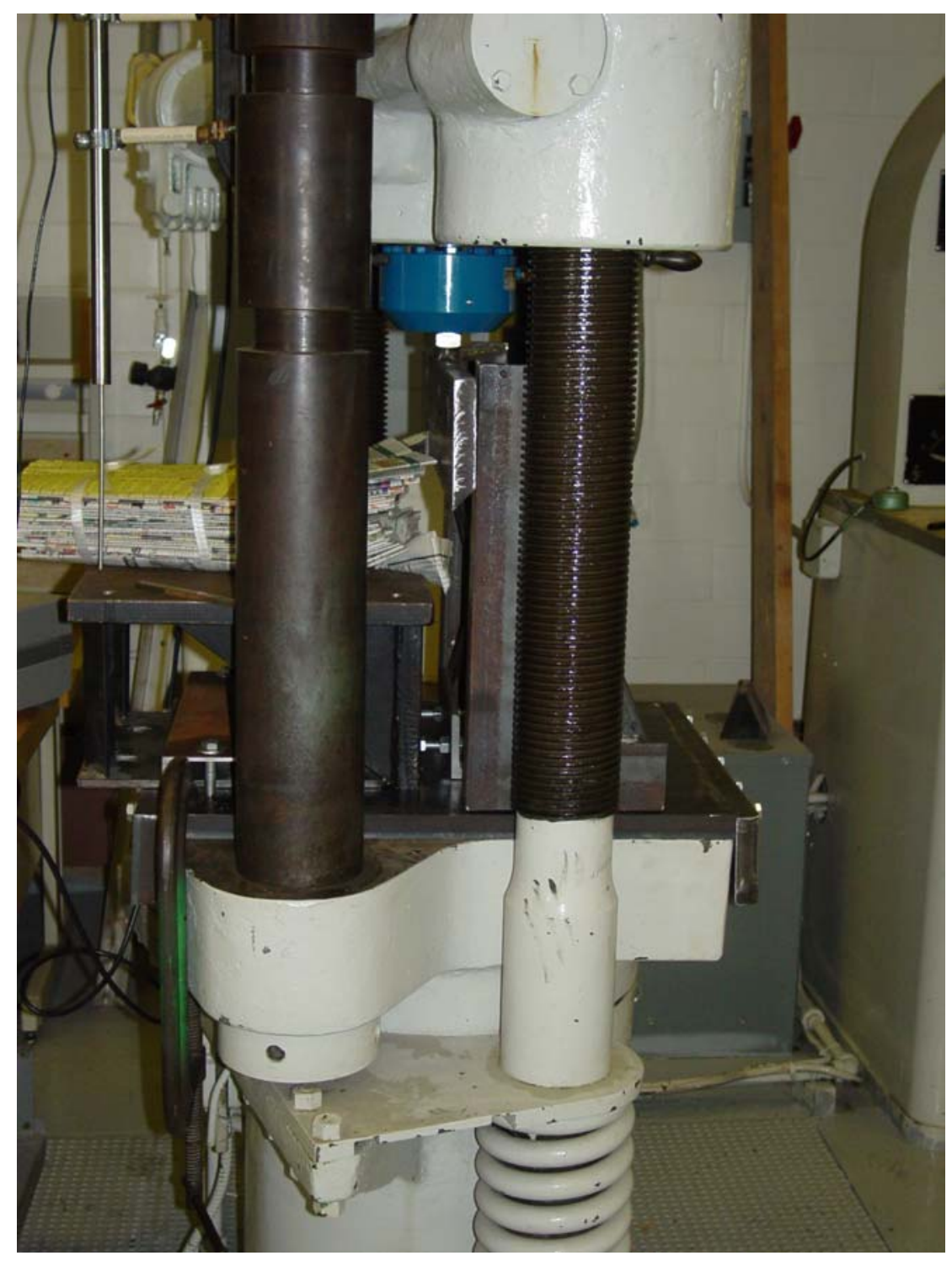

Figure 7: Side View of Force Determination Experiment

\subsubsection{Data Collection Device Setup}

In this experiment data was produced by two different devices. A load cell was used to indicate the force that the shear bar experienced as it sheared through the material. A linear variable differential transformer (LVDT) was used in order to indicate the distance that the shear bar traveled. In order to record the data from both the load cell 
and the LVDT simultaneously during testing, a LabVIEW Virtual Instrument (VI) was created. This program took the voltage input from two separate channels, derived the appropriate values, and stored the values in two separate columns within a spread sheet file. The input for these channels came from the digital indicator of the load cell and the LVDT. The digital indicator and the LVDT were connected to the laptop through a connector block that lead to a data acquisition card within the laptop.

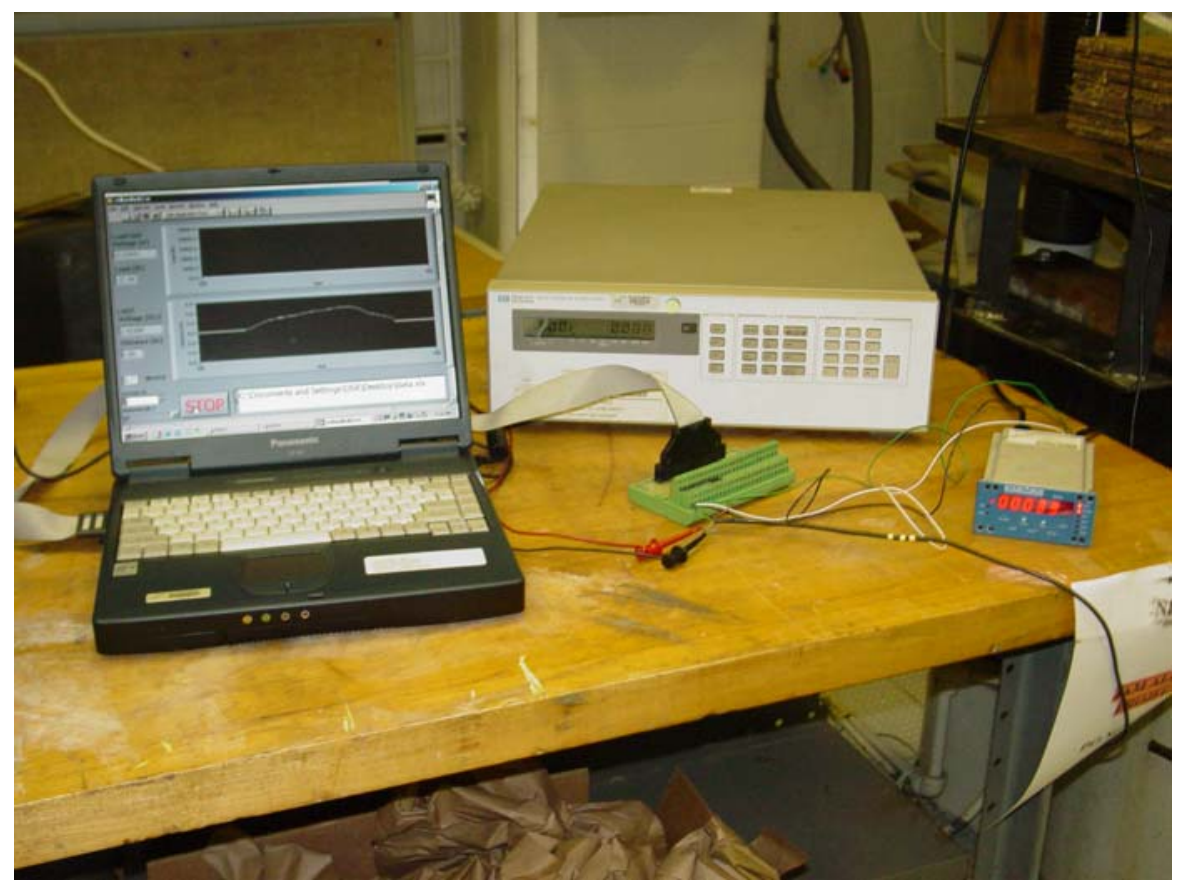

Figure 8: Data Collection Instrumentation

\section{LVDT Description}

The LVDT that was used during testing was made by Sensotec. This device has a range of $+/-3$ inches and required an excitation voltage of 6 VDC. The excitation voltage came from a 6623A Hewlett Packard power supply. This power supply was set 
to supply 5 volts and 2 amps. The calibration factor for the LVDT used during testing was 0.769 volts per inch. This calibration factor was incorporated into the LabVIEW VI so that the signal from the LVDT would be automatically converted to distance and stored.

\section{Digital Indicator Description}

The purpose of the digital indicator was to supply power for the load cell, digitally display the force measured by the load cell, and to transmit this force to the laptop. It is a microprocessor-based digital indicator that is composed of a fullydifferential amplifier and a 16-bit analog to digital converter. This model 9830 indicator is also manufactured by Interface. It has a sample rate of 100 readings per second.

\section{Connection Description}

In order to relay the measurement data from the devices to the DAQ card where the data was input into the laptop, numerous connections needed to be made. A Phoenix Contact UMK-SE terminal block was used to connect the output wires of the measurement devices to the DAQ card. Only 3 connector pins were needed for all of the appropriate connections. Connector pin 1 was the analog ground, connector pin 3 was analog channel 0 , and connector pin 5 was analog channel 1.

The LVDT had four colored wires. The blue and the yellow wires both were connected to the power supply. The blue wire was connected to $\mathrm{V}+$ and the yellow wire was connected to V-. The black and green wires went to the terminal block. The black wire was ground and was connected with pin 1. The green wire was the output and was connected with pin 3. 
For the purposes of this test it was required to create an output connector for the digital indicator. In order to transfer the output signal from the indicator to the connector board only two pins on the I/O connector of the indicator needed to be used. These pins were pin 5, which was the ground, and pin 6 , which was the analog output. Pin 5 in the indicator was connected to pin 1 in the connector board and Pin 6 in the indicator was connected to pin 5 in the connector board. It was also necessary to ground the chassis of the indicator. This was done by connecting a third wire to the ground, pin 1, of the connector block. This wire was then wedged into the case of the indicator to ensure a definite connection with the metal.

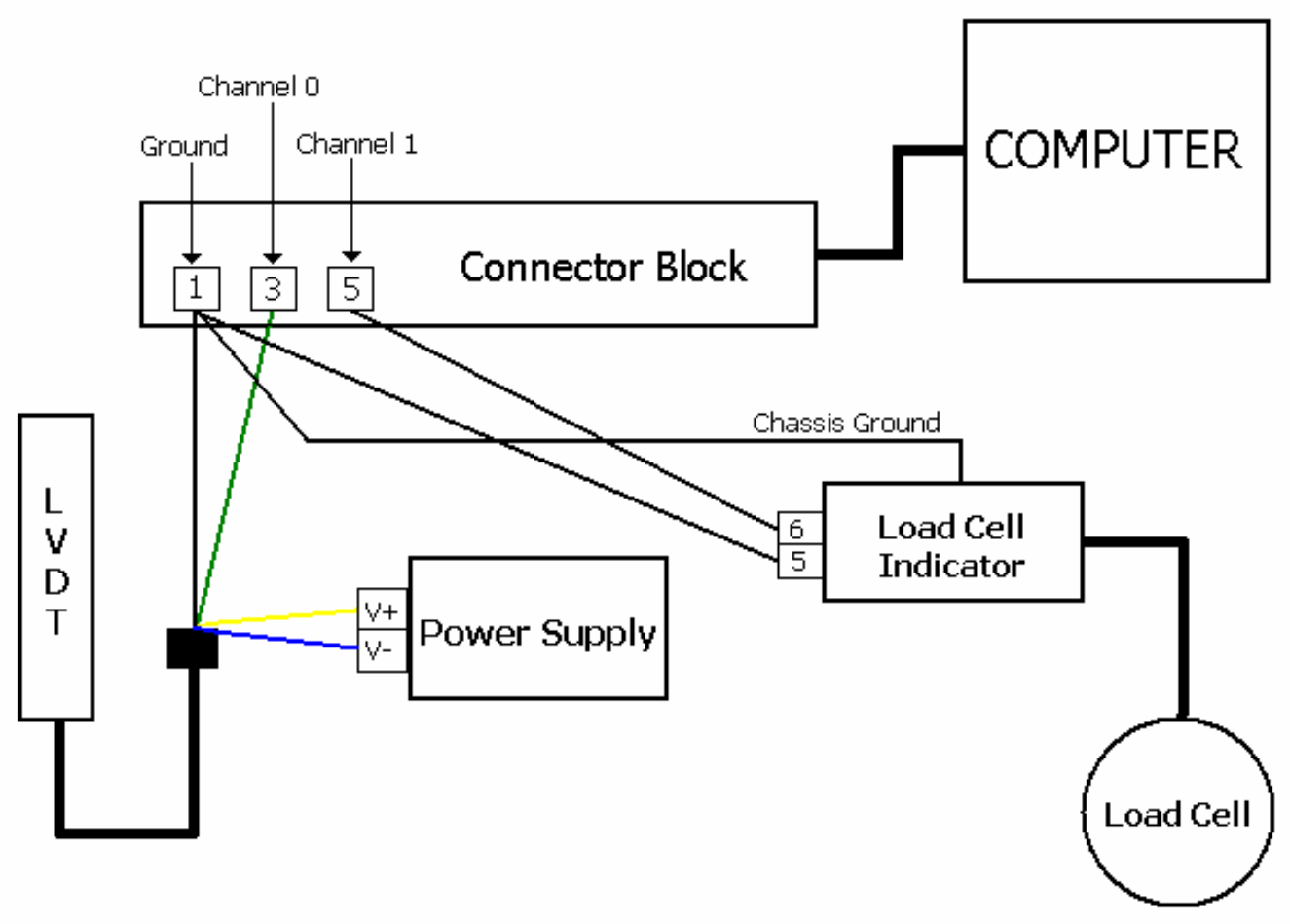

Figure 9: Data Collection Wiring 


\section{Laptop, DAQ Card}

The DAQCard-700 served as an analog input, digital, and timing I/O card for the computer. This DAQCard has a 50 pin I/O connector that enabled all of the measurement channels to be connected directly to the card. The card contained sixteen single-ended or eight differential analog inputs, eight lines of TTL-compatible digital input, and eight lines of digital output. The card also contained a 12-bit, successive-approximation ADC. This card fit into the Type II PCMCIA slot in the laptop. The laptop that was used was a CF-48 Panasonic running Windows 2000.

\section{LabVIEW VI Description}

LabVIEW was used to convert the voltage signals from the LVDT and the load cell into the equivalent units of measurement. Once the conversion was made, the load and the distance the shear bar traveled were stored simultaneously in a Microsoft Excel spreadsheet. This virtual instrument (VI) was created using LabVIEW 6i. The VI consists of two windows. The Panel window is where all of the recorded data is displayed. The data is displayed in boxes that correspond to the appropriate channels that are found in the diagram window. The boxes that display the data are all arranged in a vertical line on the left hand side of the panel window. The top box displays the voltage that is transmitted by the load cell. Below the voltage is the corresponding force that is calculated using the calibration factor for the load cell and the recorded voltage. The next box contains the voltage recorded by the LVDT. This box is followed by a box that contains the distance that the LVDT travels. This measurement is also found by using a calibration factor for the LVDT along with the voltage that is recorded by the LVDT. The panel window also displays a continuous graph of the force experienced by the load 
cell and the distance that the LVDT travels. Other items that can be found on the panel window of the VI are the boxes to specify what channels are being used and what device is being used. For this experiment the device is 1 , and channel 0 is used by the LVDT while channel 1 is used by the load cell. The panel window for this VI can be seen in Figure 10.

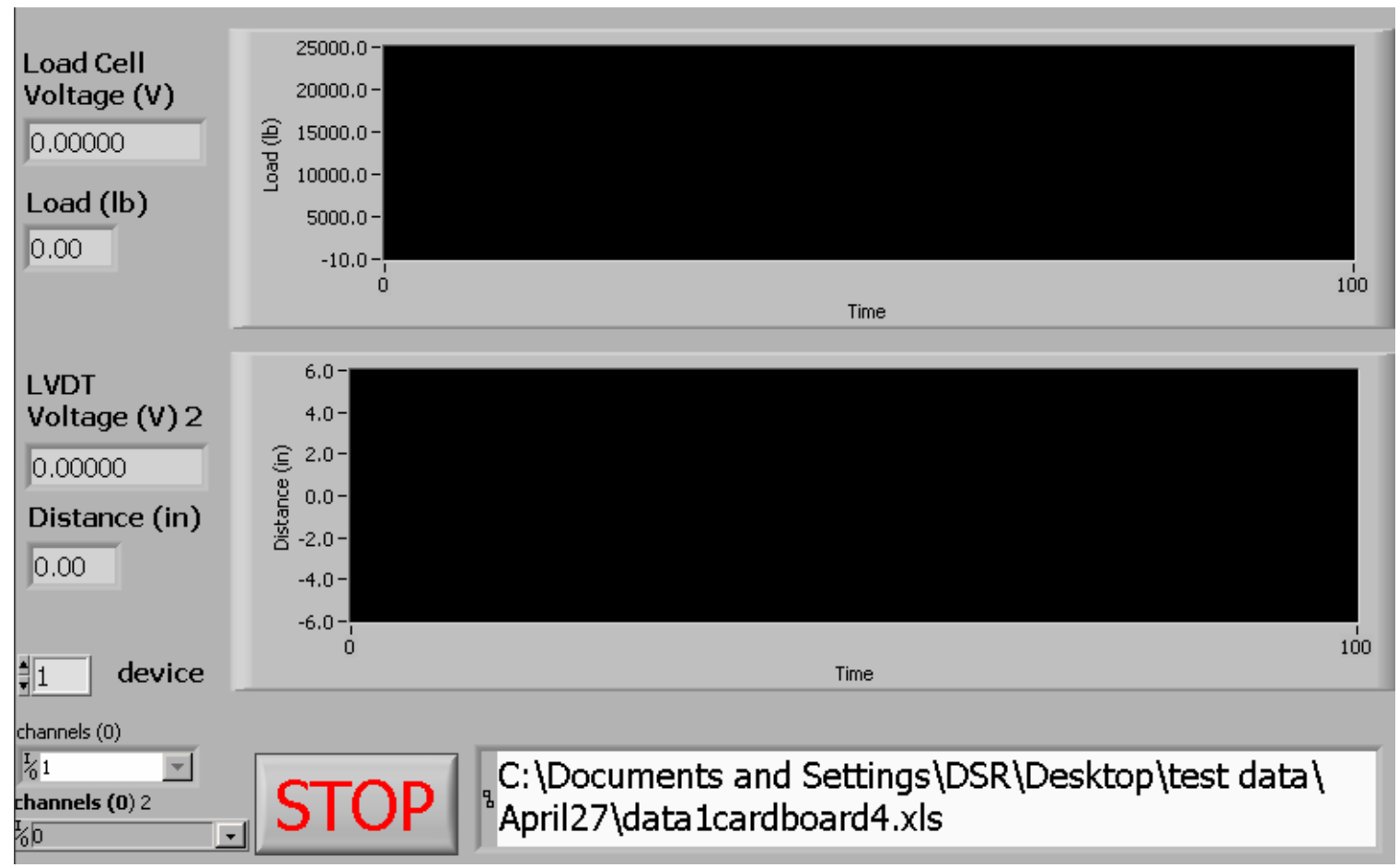

Figure 10: Front Panel Window for Data Collection VI

The diagram window of the VI is where all of the calculations are completed. The signal from both the load cell and the LVDT are brought in through separate channels. The sampling rate was 100 samples per second. Each voltage signal was converted to the equivalent force and distance using the calibration factor associated with each. These values are then displayed on the front panel as well as stored simultaneously in a spreadsheet. The diagram window for this VI can be seen in the following figure. 


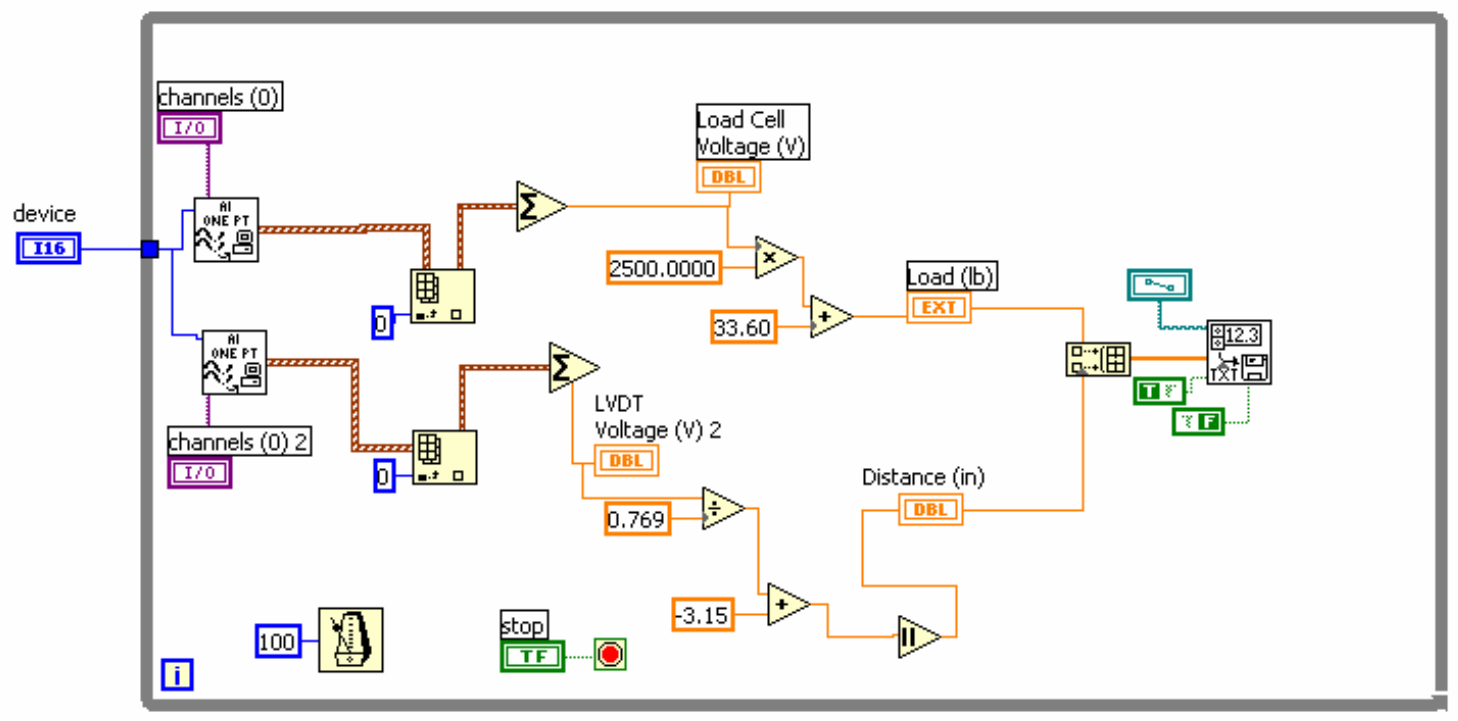

Figure 11: Diagram Window of Data Collection VI

\subsubsection{Test Material}

The material bundles that were used for the experiment were all 16 inches long, 8 inches wide and 4 inches tall. Each material was cut to the appropriate dimensions and held together with plastic straps. Bundles of each of three materials were made, with enough bundles of each material to do four trials with each of the three shear bars. Twelve bundles of each material were used, with thirty six bundles being used altogether. All of the material that was used for testing was collected from NIOSH or from neighbors that had been saving magazines and newspapers for recycling. After the experiment was completed, the material was taken to the local recycling center. The properties of each bundle can be seen in the table below. 
Table 1: Properties of Test Material Bundles

\begin{tabular}{|c|c|c|c|c|}
\hline & $\begin{array}{c}\text { volume } \\
\left(\mathrm{lb}^{3}\right)\end{array}$ & weight $(\mathrm{lb})$ & $\begin{array}{c}\text { density } \\
\left({\left.\mathrm{lb} . / \mathrm{ft}^{3}\right)}\right.\end{array}$ & $\begin{array}{c}\text { number of } \\
\text { layers }\end{array}$ \\
\hline cardboard & 0.296 & 4 & 13.514 & 26 \\
\hline magazines & 0.296 & 13 & 43.919 & 22 \\
\hline newspaper & 0.296 & 9 & 30.405 & 360 \\
\hline
\end{tabular}

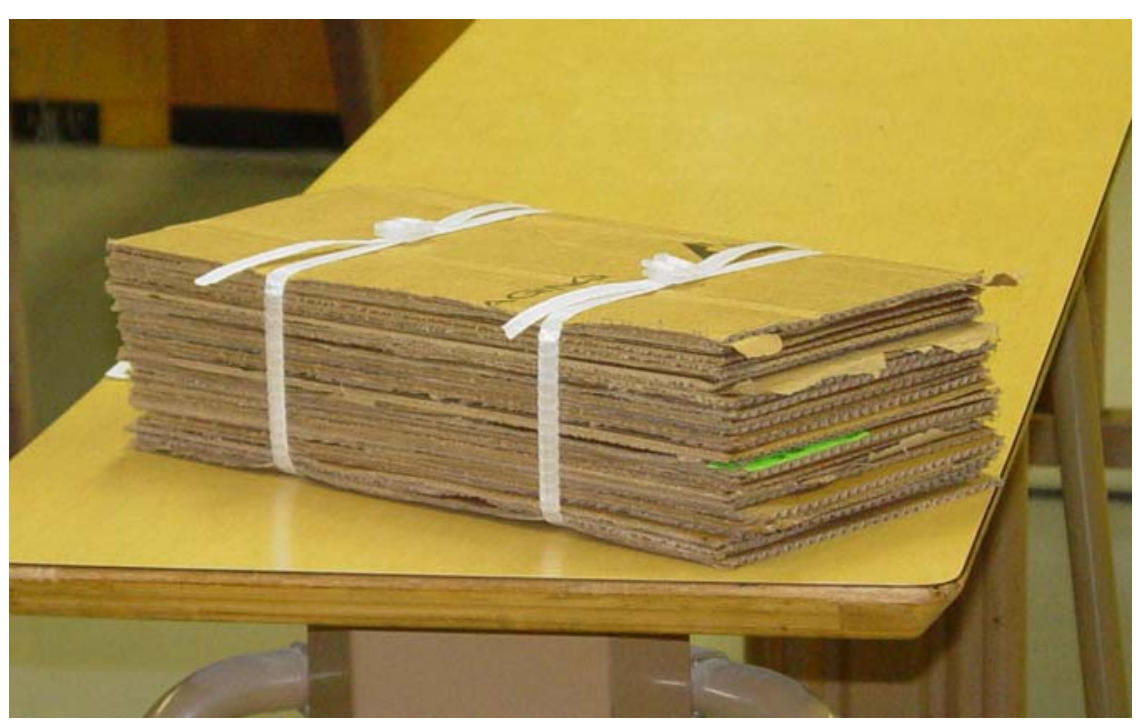

Figure 12: Cardboard Bundle

\subsection{Experimental Procedure}

Once the force determination experiment was assembled and trial testing had been completed, data was collected for three different cases. These three cases were for the three different degrees of sharpness of the shear bar. For the first case, tests were run with the sharpest shear bar. For each test a material block was placed directly under the shear bar on the block. Once in position the head of the testing machine was lowered until the shear bar was just resting above the material. This was the starting position for the data collection. The LVDT was clamped to the testing machine so that the end of the device was touching the table of the machine, but the LVDT was still fully extended. At 
this initial position the LVDT records 0 inches. Once the LVDT was secured, the valve on the testing machine was open and the flow control knob was turned 1.5 times. This caused the table to lift up at a constant rate of 0.057 inches per second. As the table began to rise, the material block was forced against the shear bar. As the shear bar cut through the material, the force that was exerted was recorded by the load cell. Simultaneously the distance that the table moved relative to the shear bar was recorded by the LVDT. The machine table continued to move upwards the total distance possible which was six inches.

During the first four inches of travel the test material was both compressed and sheared. Each of the three materials behaved differently during this part of the testing. Cardboard was mostly compressed, newspaper was compressed and sheared, and magazines were mostly sheared. The figures below show each material during the first 4 inches of travel. 


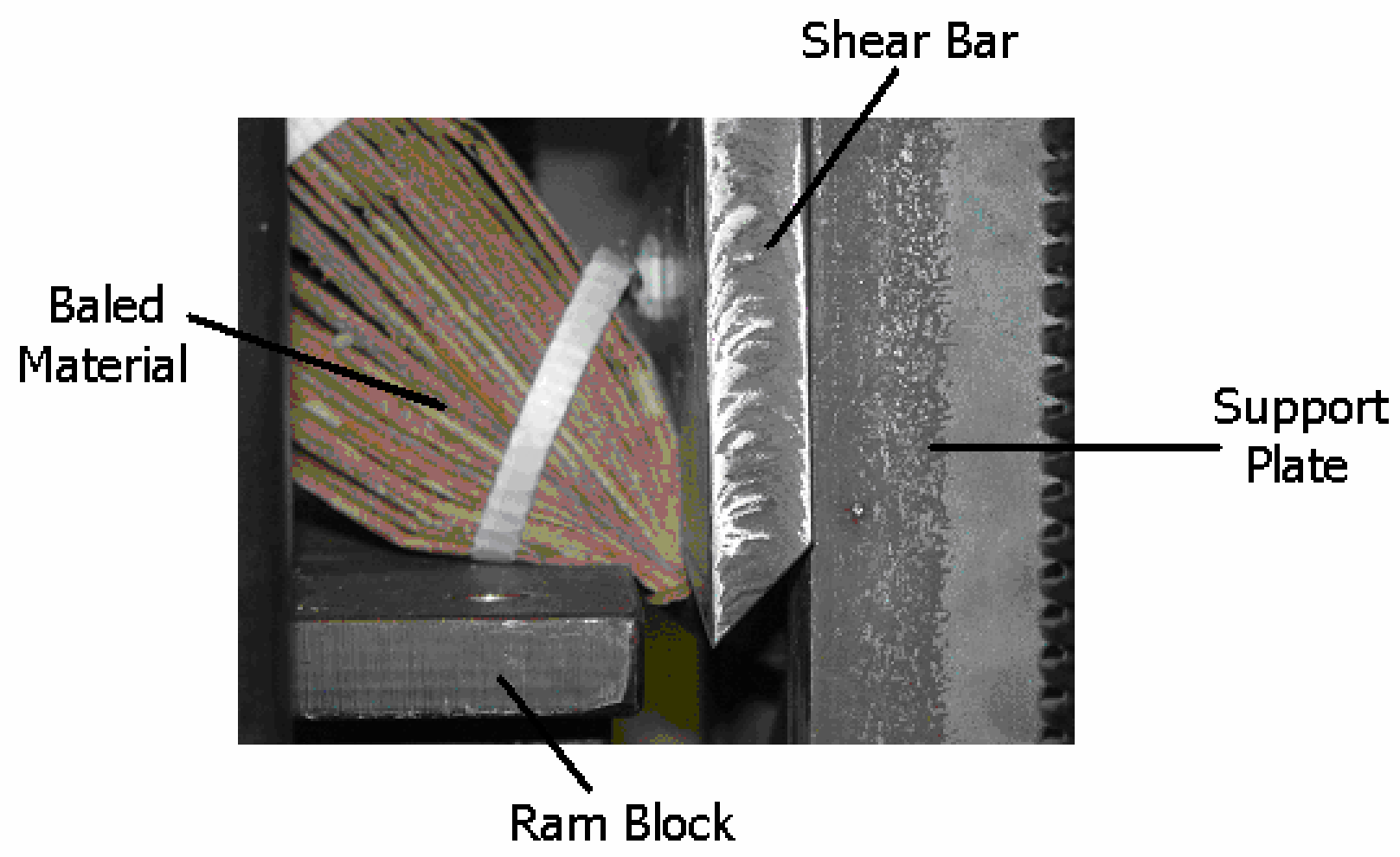

Figure 13: Cardboard Test after Shear Bar Traveled 4 inches

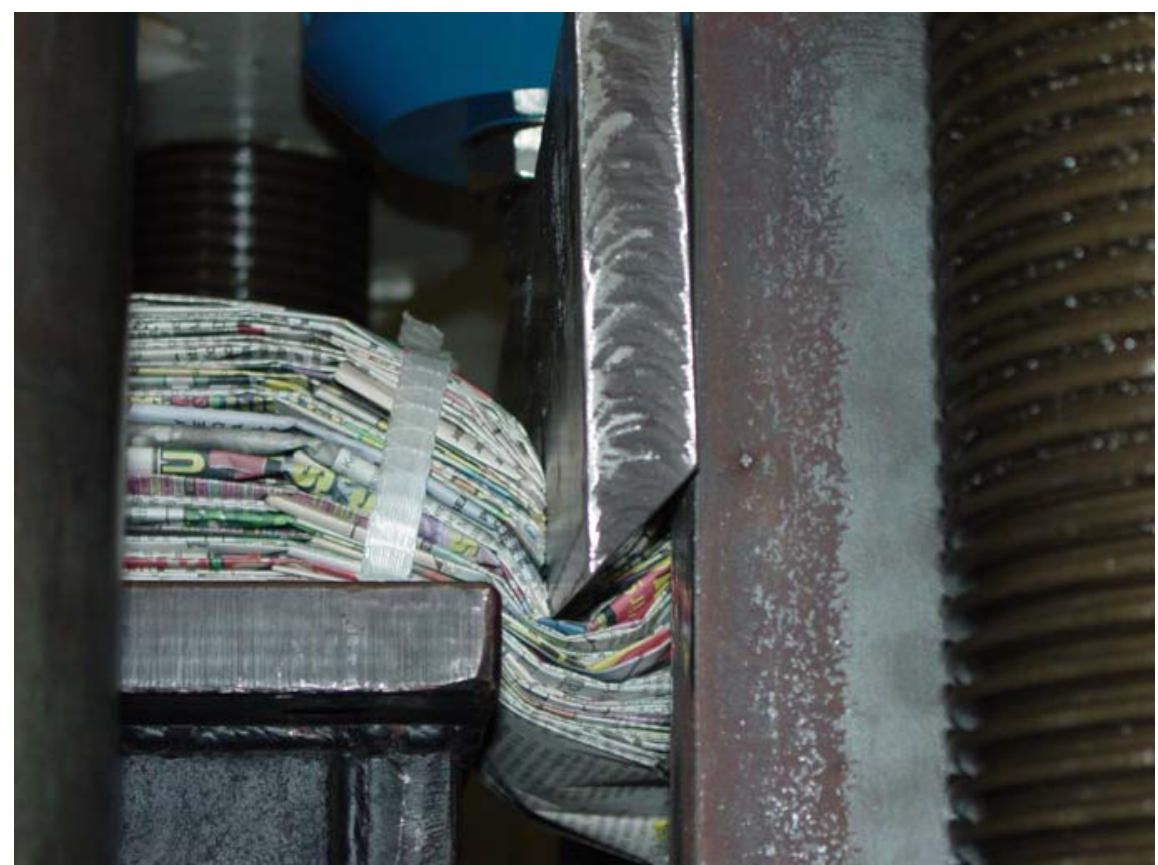

Figure 14: Newspaper Test after Shear Bar Traveled 4 inches 


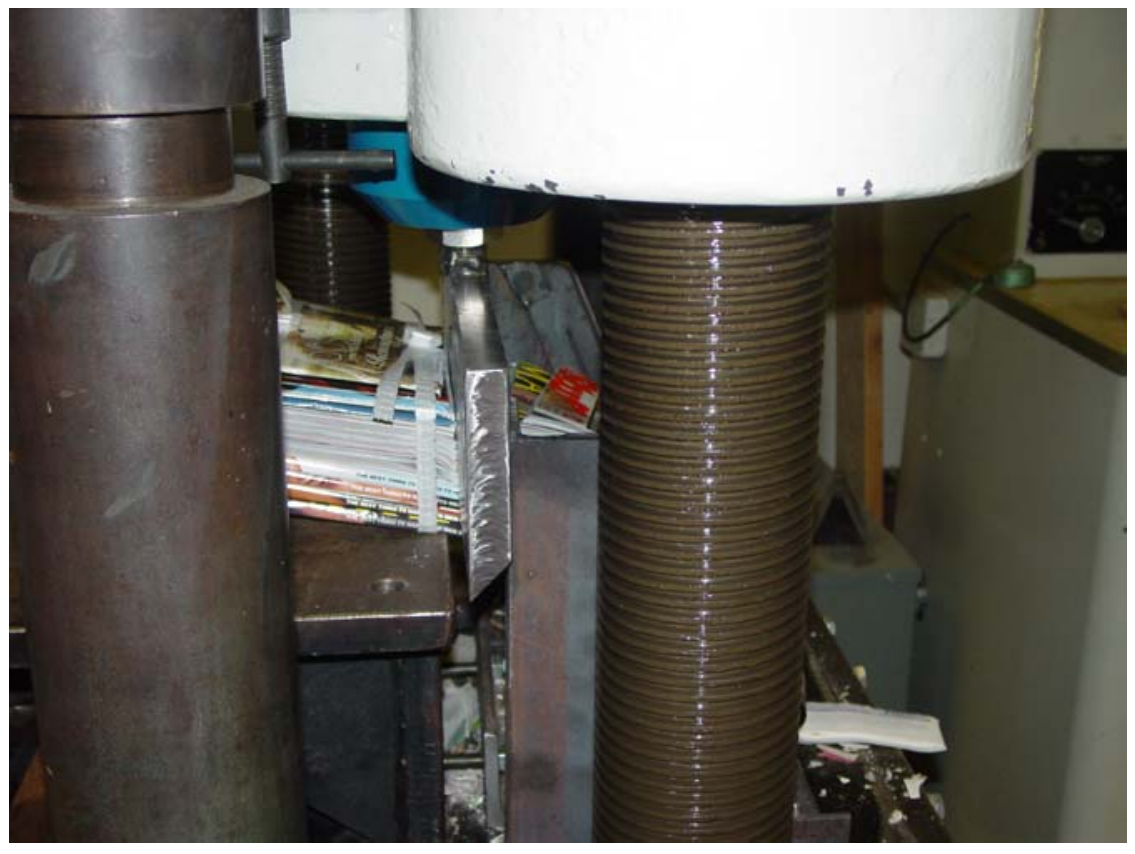

Figure 15: Magazine Test after Shear Bar Traveled 4 inches

Once the shear bar traveled past the edge of the block the material was no longer sheared. The material that was not sheared already was compressed in the 0.25 inch gap between the shear bar and the edge of the block. The following figures show the test material at the end of each run. 


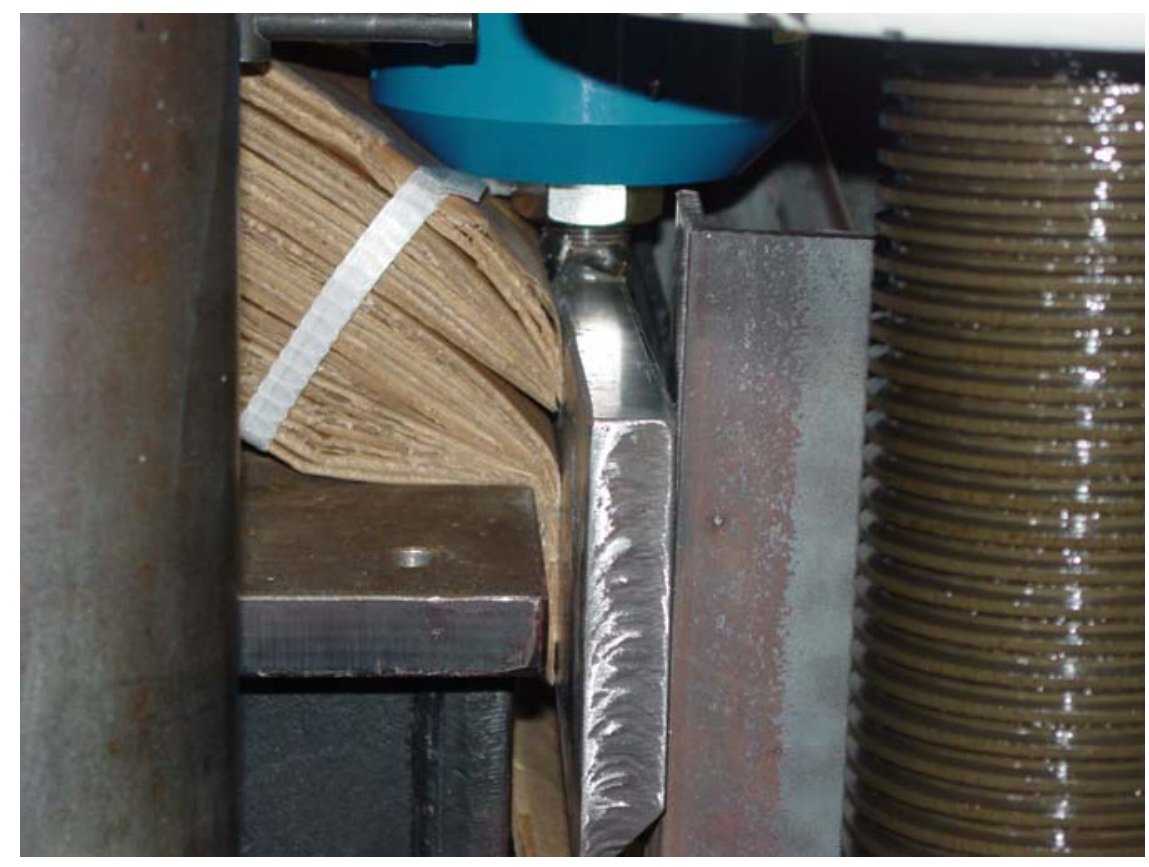

Figure 16: Cardboard Test when Shear Bar Travel Ended

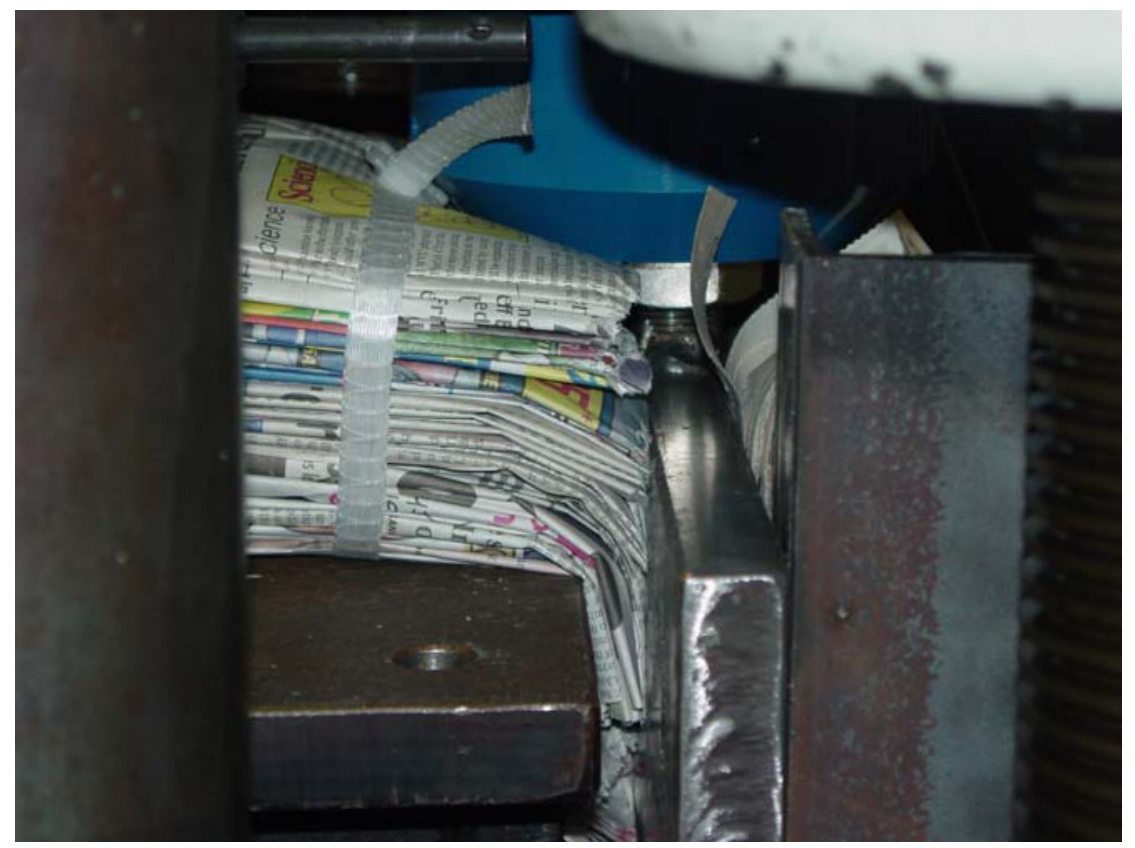

Figure 17: Newspaper Test when Shear Bar Travel Ended 


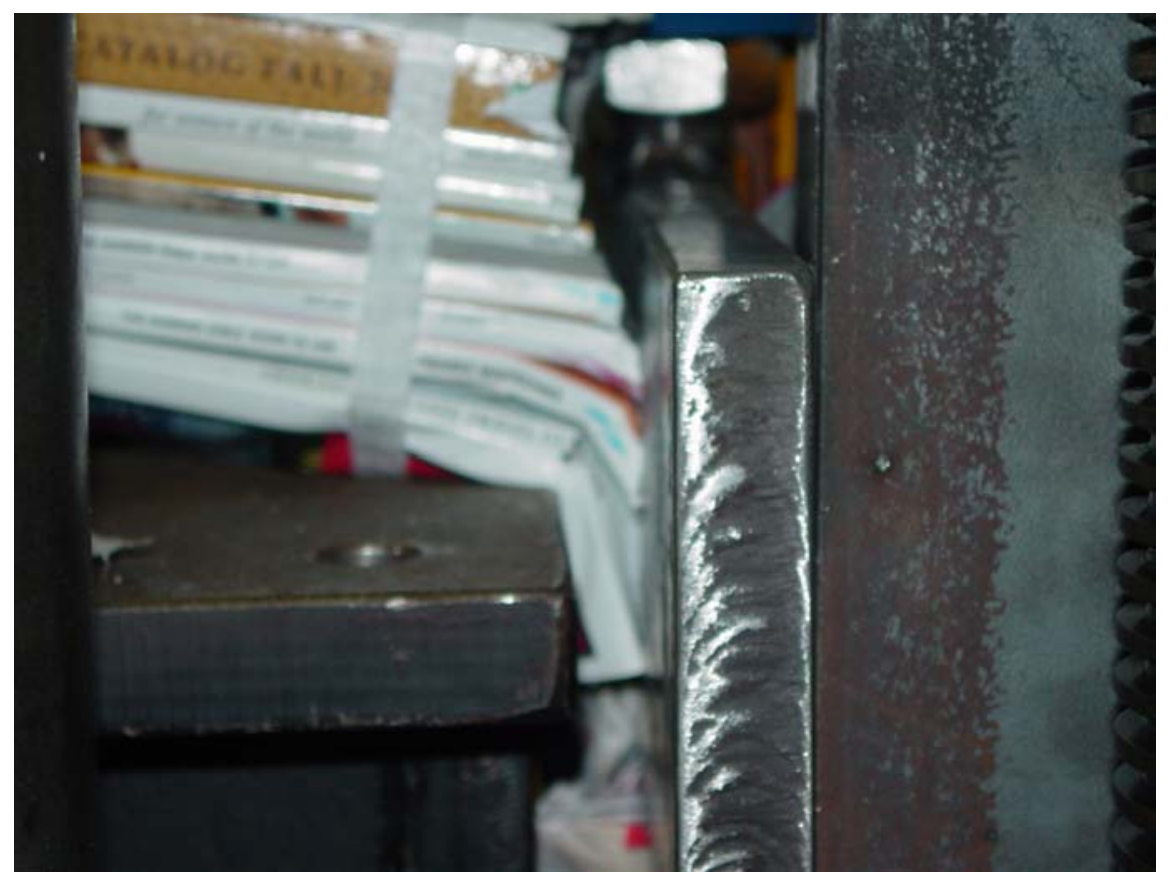

Figure 18: Magazine Test when Shear Bar Travel Ended

At the end of this travel, the table stopped moving but continued to hold the same force until the table was lowered. This procedure was repeated four times for each of the three materials that were tested. Once all of the data was collected using the sharp shear bar, the bar was dulled. The dulling process involved removing the shear bar from the machine and using a flat file to round the edge. A radius gauge was used to make sure that the dulling was made constant throughout the length of the bar. The second shear bar tests were done with the edge of the shear bar having a radius of 1/64 inch. Once the first dulling was complete four runs were done again with each of the three materials. After all of the data was collected for the bar at this medium sharpness, the shear bar was dulled once more. This time the shear bar was dulled to have a radius of $1 / 32$ inch. After 
this last dulling, the testing procedure was completed once more for the four runs of each of the three materials.

\subsection{Experimental Results}

Figures 19, 20, and 21 show the forces recorded from the testing done with the sharp shear bar.

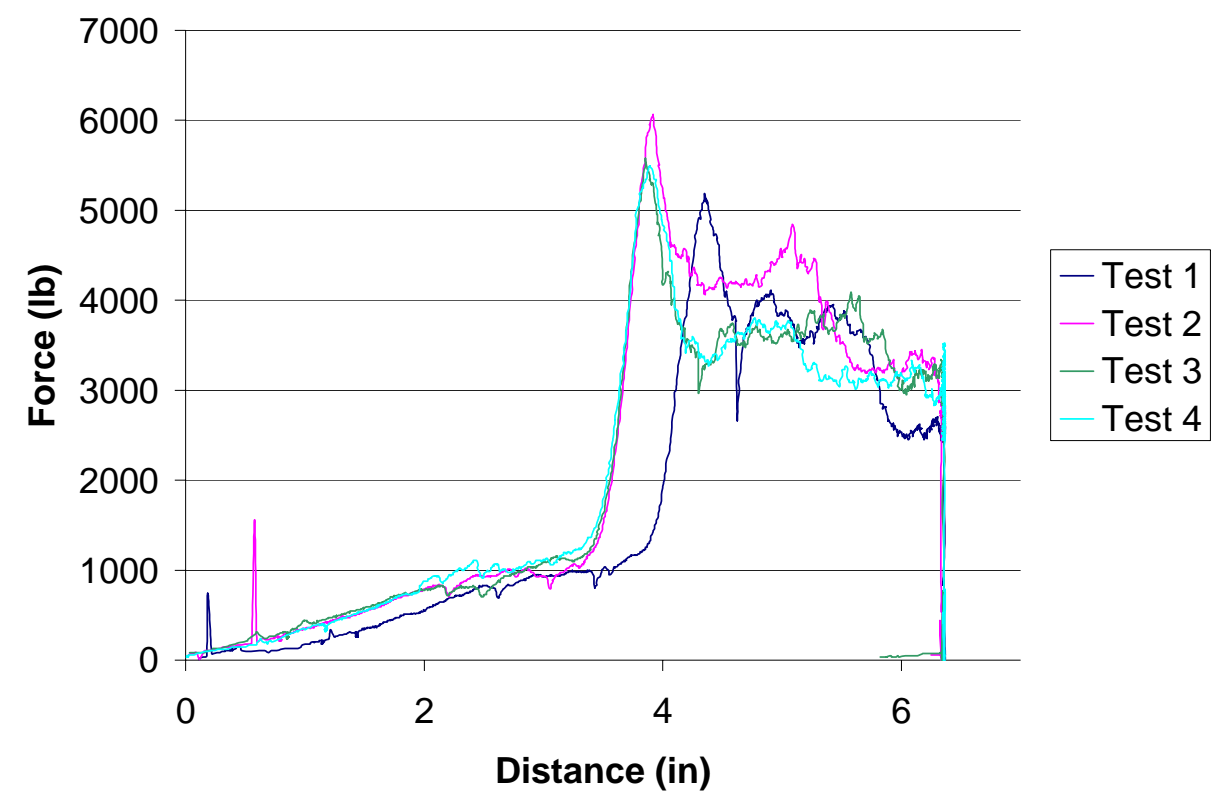

Figure 19: Results of Cardboard Testing with Sharpest Shear Bar 


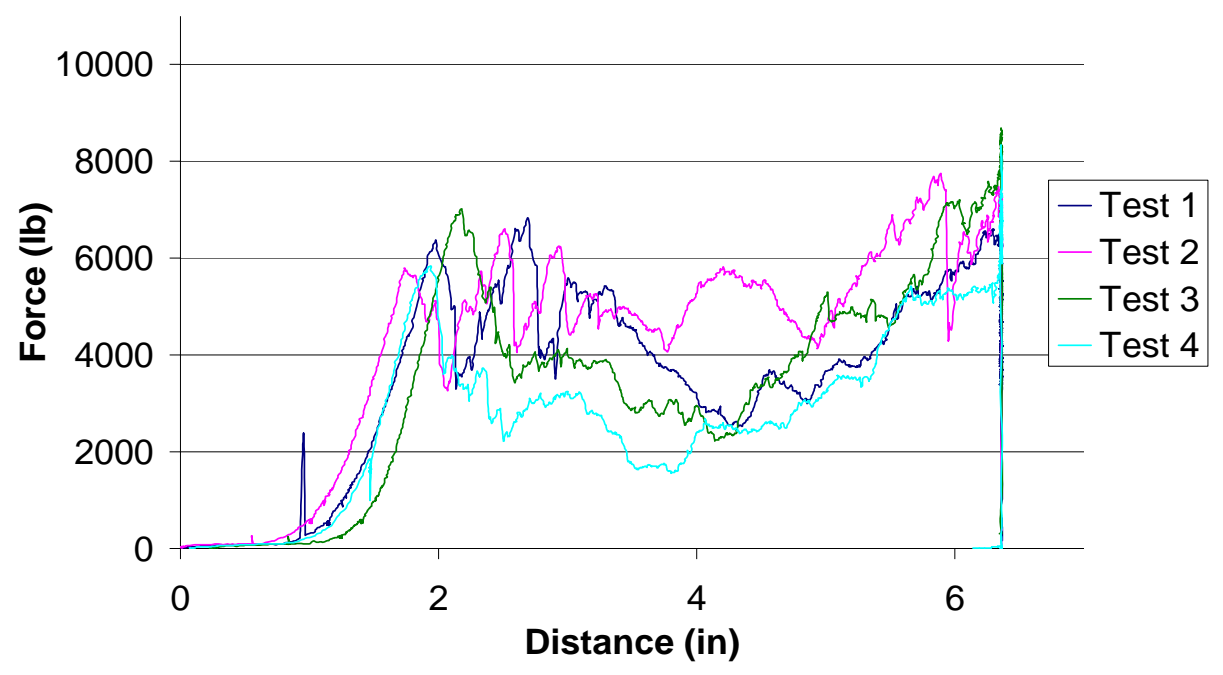

Figure 20: Results of Newspaper Testing with Sharpest Shear Bar

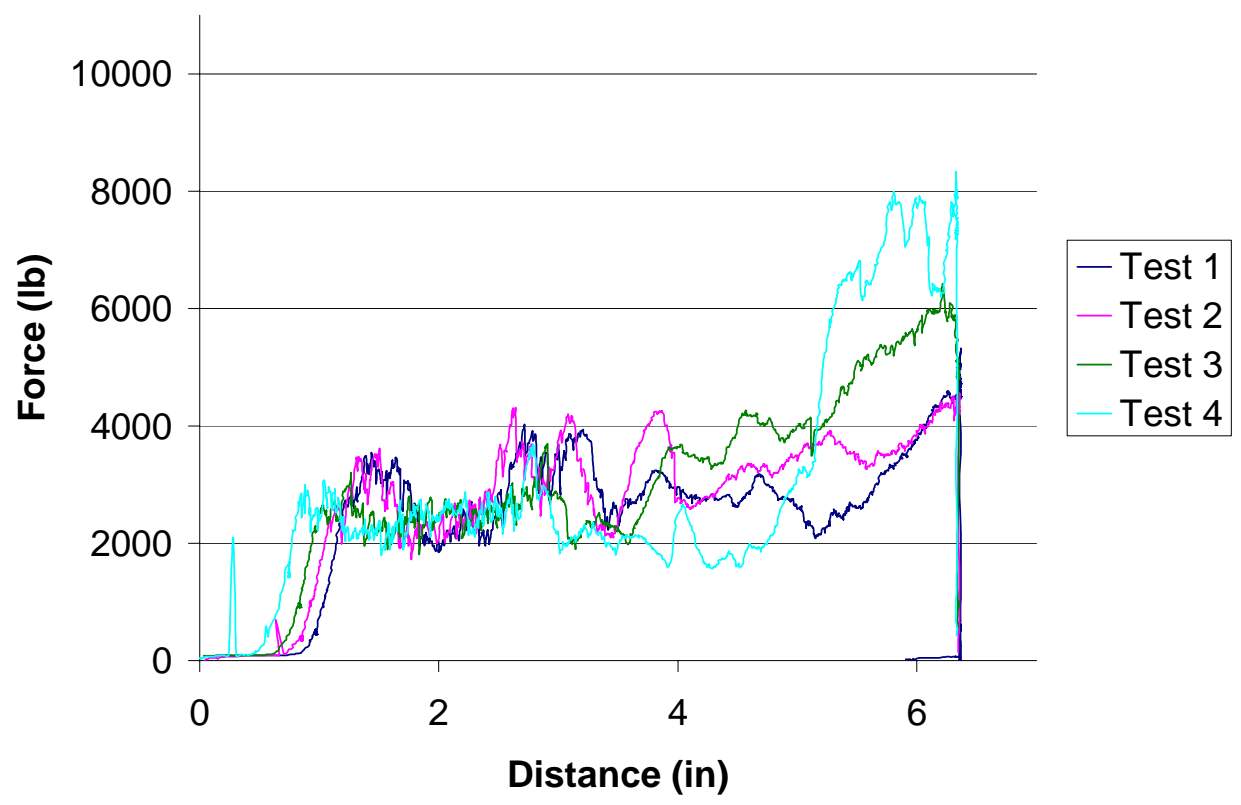

Figure 21: Results of Magazine Testing with Sharpest Shear Bar 
The next group of tests were run with a 1/64 inch radius on the edge of the shear bar. The forces recorded for each of the three materials with this shear bar can be seen below in Figures 22, 23, and 24.

\section{Cardboard Results for Shear Bar with 1/64" Radius}

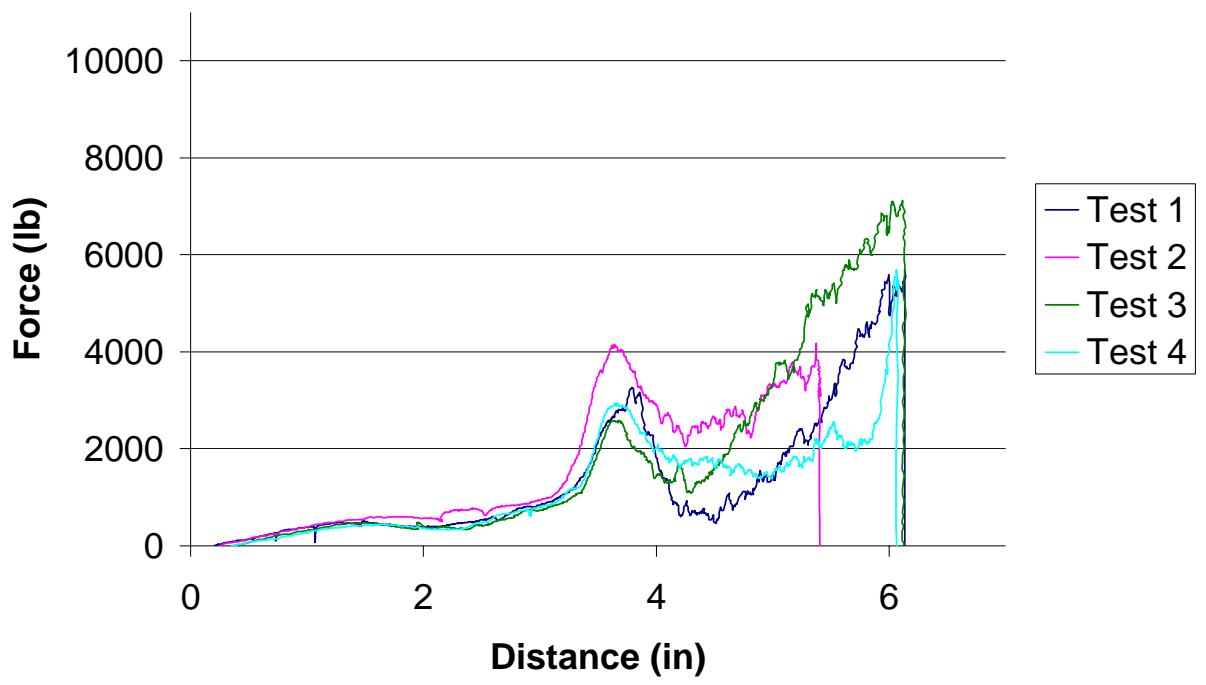

Figure 22: Results for Cardboard Using Shear Bar with 1/64" Radius on Edge 


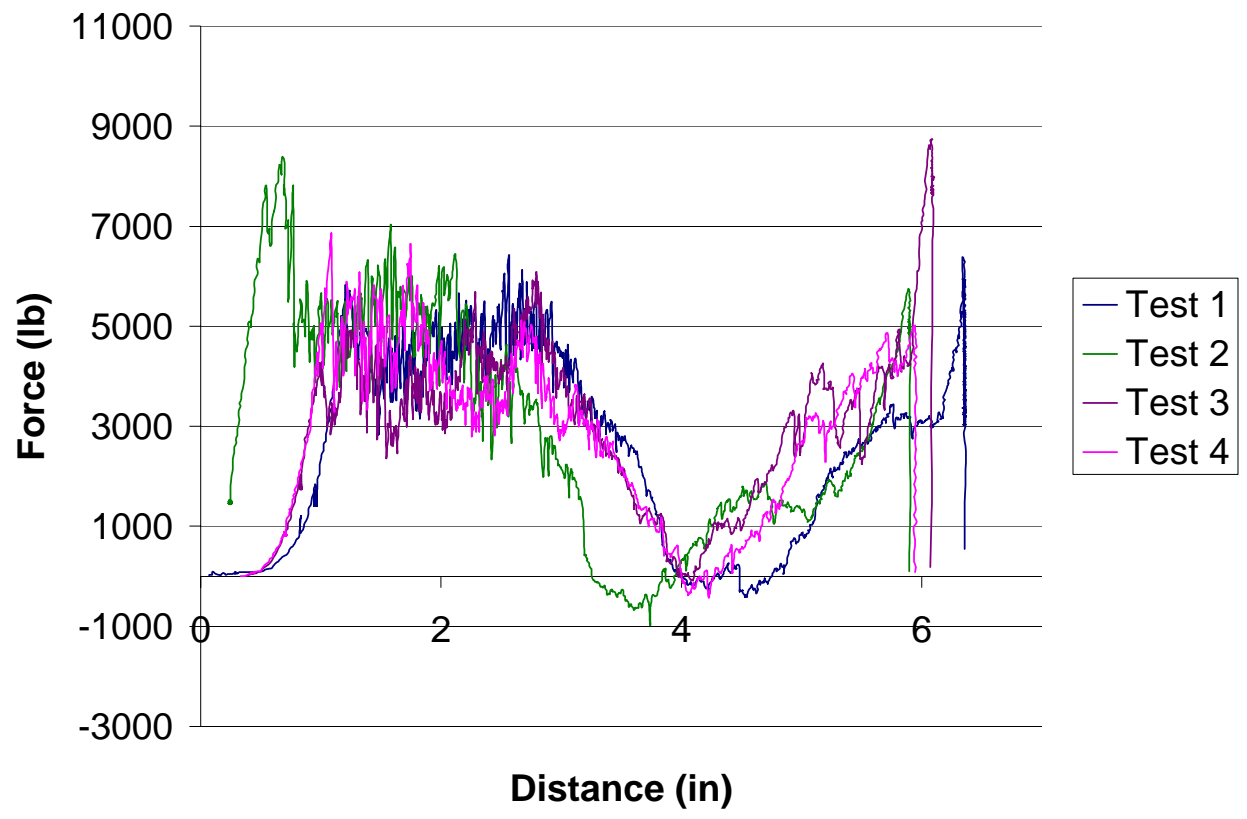

Figure 23: Results for Magazines Using Shear Bar with 1/64" Radius on Edge

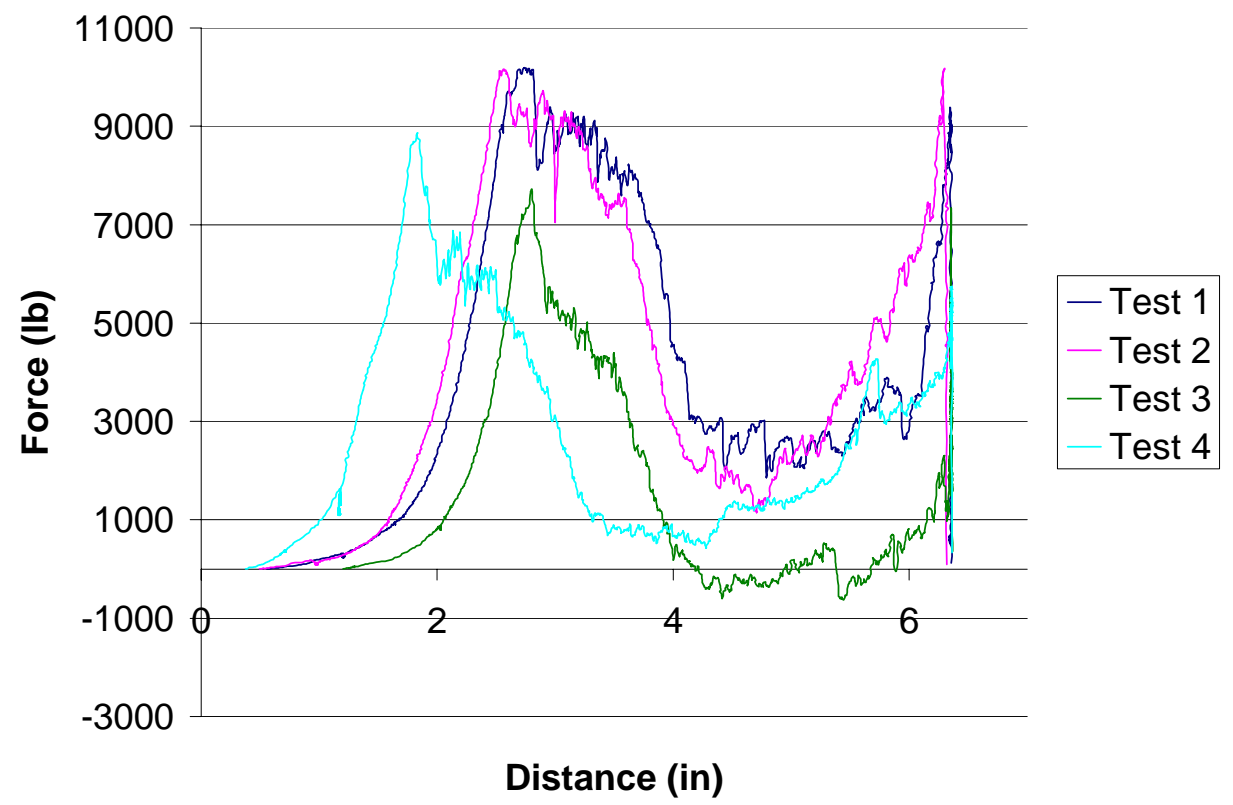

Figure 24: Results for Newspaper Using Shear Bar with 1/64' Radius on Edge 
The final group of tests was run with a 1/32 inch radius on the edge of the shear bar. The results for each of the three materials with this shear bar can be seen in Figures 25,26 , and 27 .

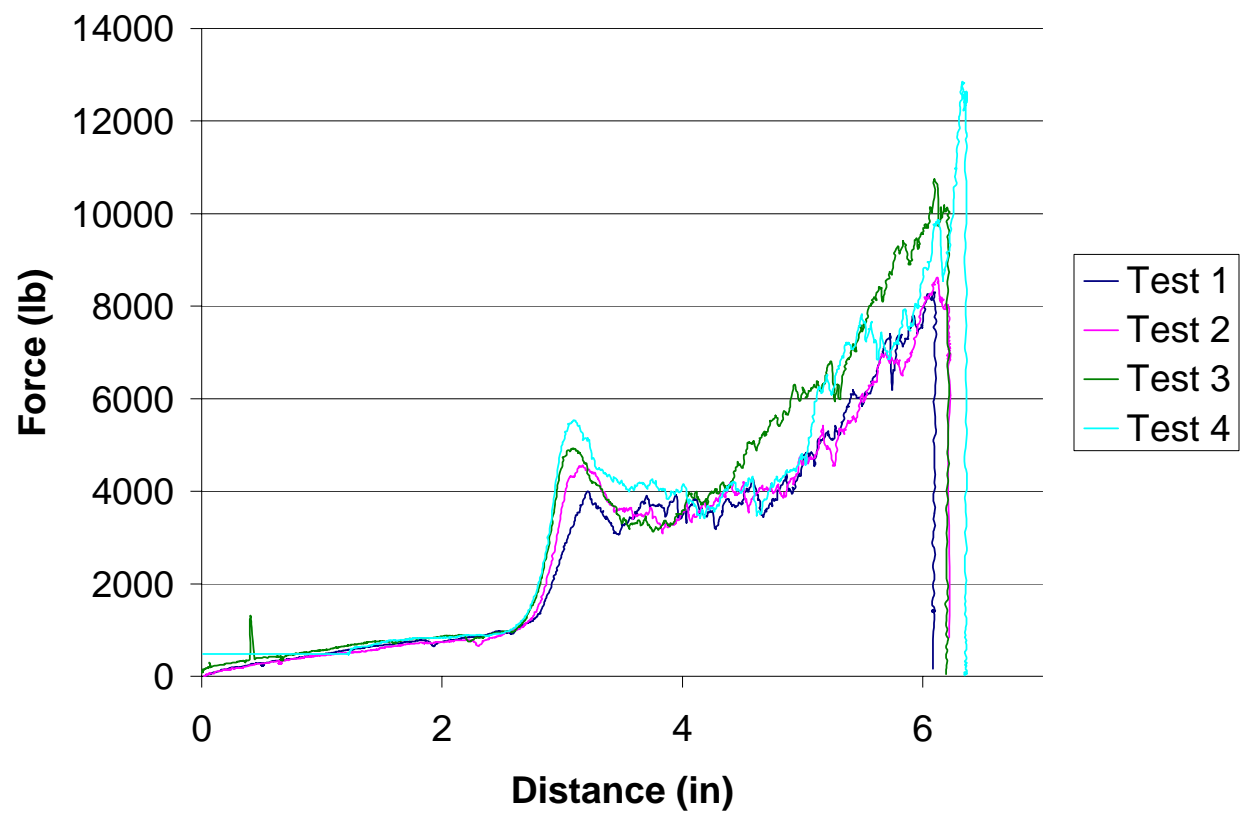

Figure 25: Results for Cardboard using Shear Bar with 1/32" Radius on Edge

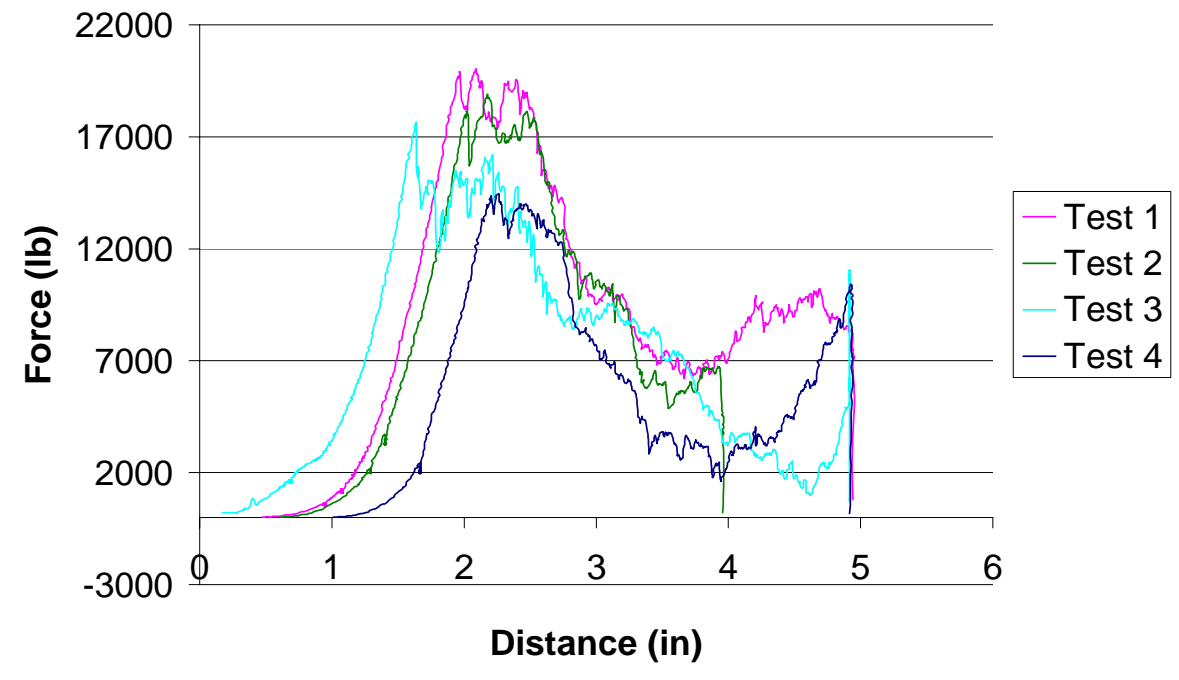

Figure 26: Results for Newspaper using Shear Bar with 1/32" Radius on Edge 


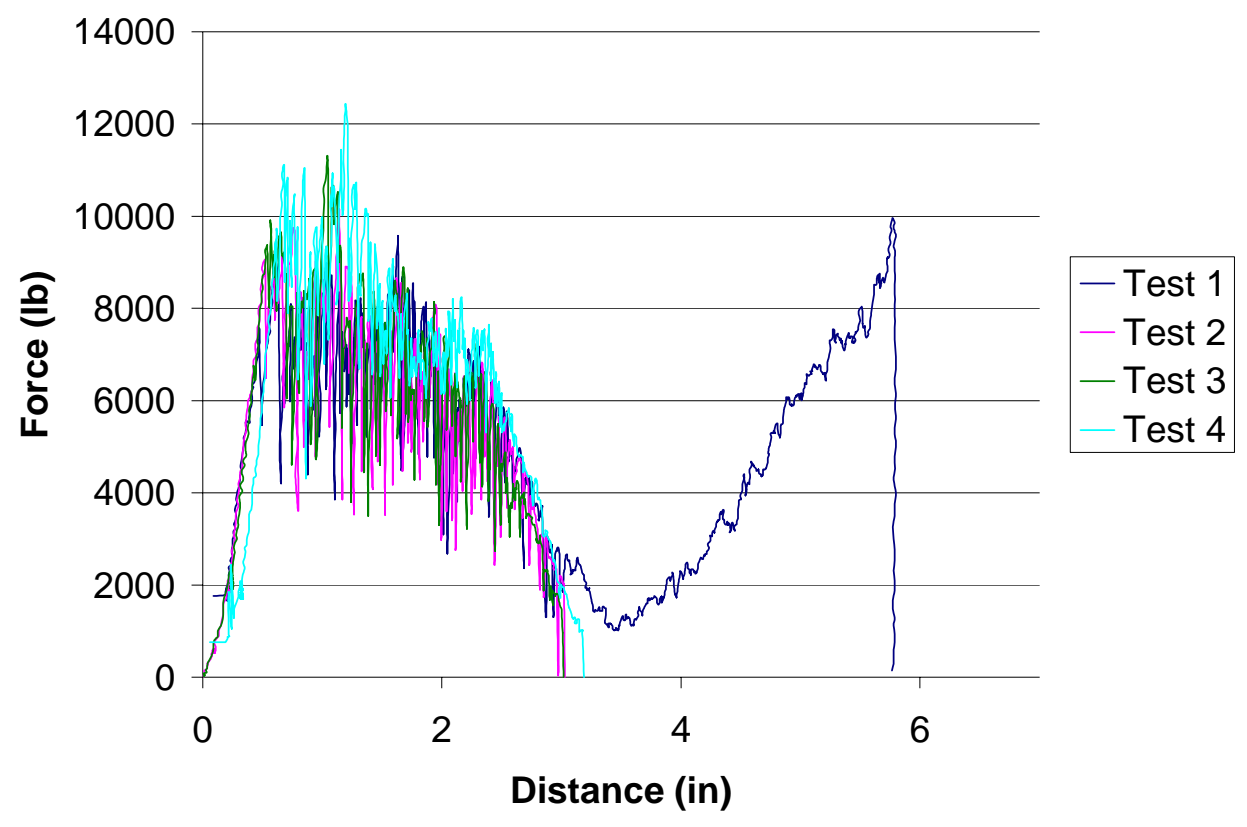

Figure 27: Results for Magazines using Shear Bar with 1/32" Radius on Edge

\subsection{Experiment Results Discussion}

It can be seen from the data collected during the force determination experiment that the material being baled and the sharpness of the shear bar both affect the force that the shear bar experiences. As the shear bar is dulled, the forces created by all three materials are increased. For cardboard the sharp shear bar produces maximum forces ranging between 5000 to 6000 pounds. These maximum forces are increased slightly with the 1/64 inch radius shear bar that produced maximum forces between 5500 and 6500 pounds. Once the bar was dulled again to have a $1 / 32$ inch radius, the maximum forces caused by cardboard were between 8000 and 12,000 pounds. This trend was also evident with the magazine tests. The sharp shear bar produced maximum forces that ranged between 5000 and 8000 pounds. The range of the maximum forces were increased 
to be between 6000 to 9000 pounds with the 1/64 inch radius bar. The shear bar with the $1 / 32$ inch radius created the largest maximum forces for the magazines. These forces ranged from 8000 to 12,000 pounds. The forces experienced with newspaper had the most significant increase. The sharp shear bar produced maximum forces between 7000 and 8500 pounds. The $1 / 64$ inch radius shear bar increased the maximum forces to between 8000 and 10,000 pounds. These forces increased even more with the $1 / 32$ inch radius shear bar that produced maximum forces between 14,000 to 20,000 pounds. The affect of the shear bar radius on the force created for each material can be seen in the following three figures. These graphs show that the shear bar with $1 / 32$ inch edge radius consistently created larger forces with each of the three materials.

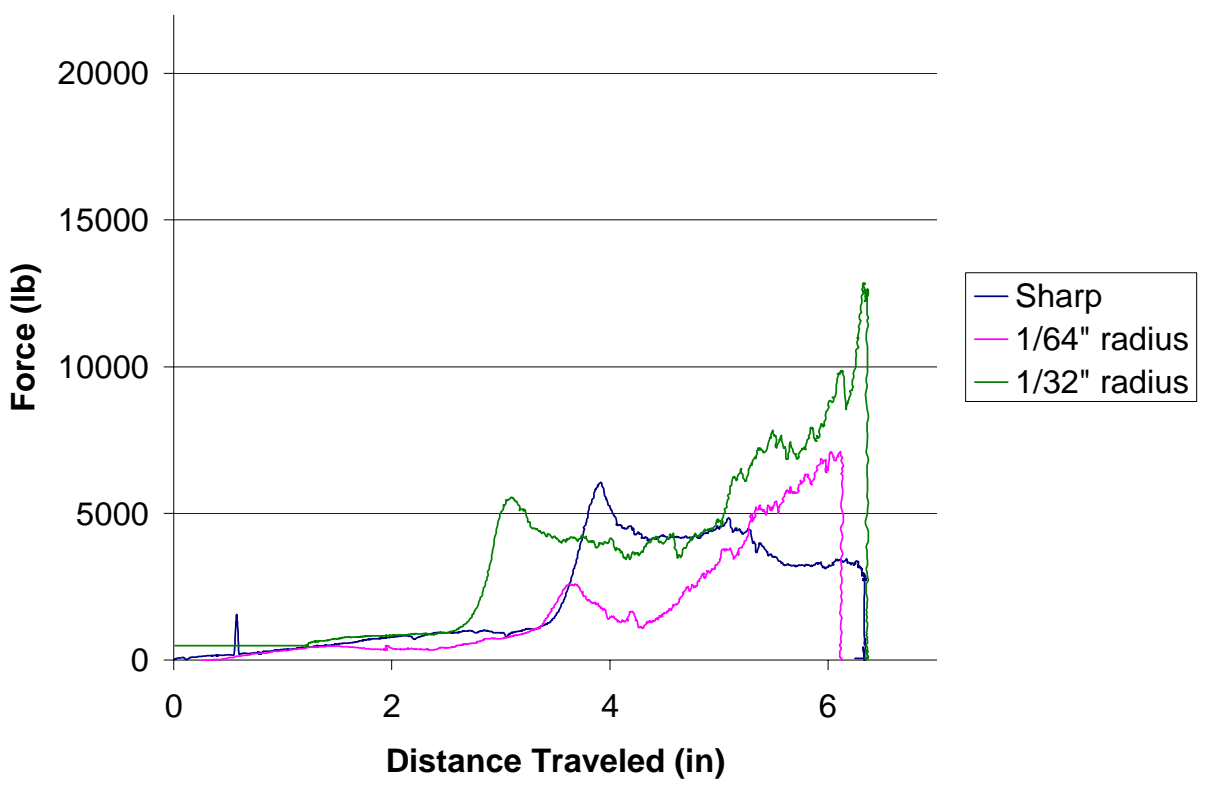

Figure 28: Forces Created by Cardboard for each Shear Bar 


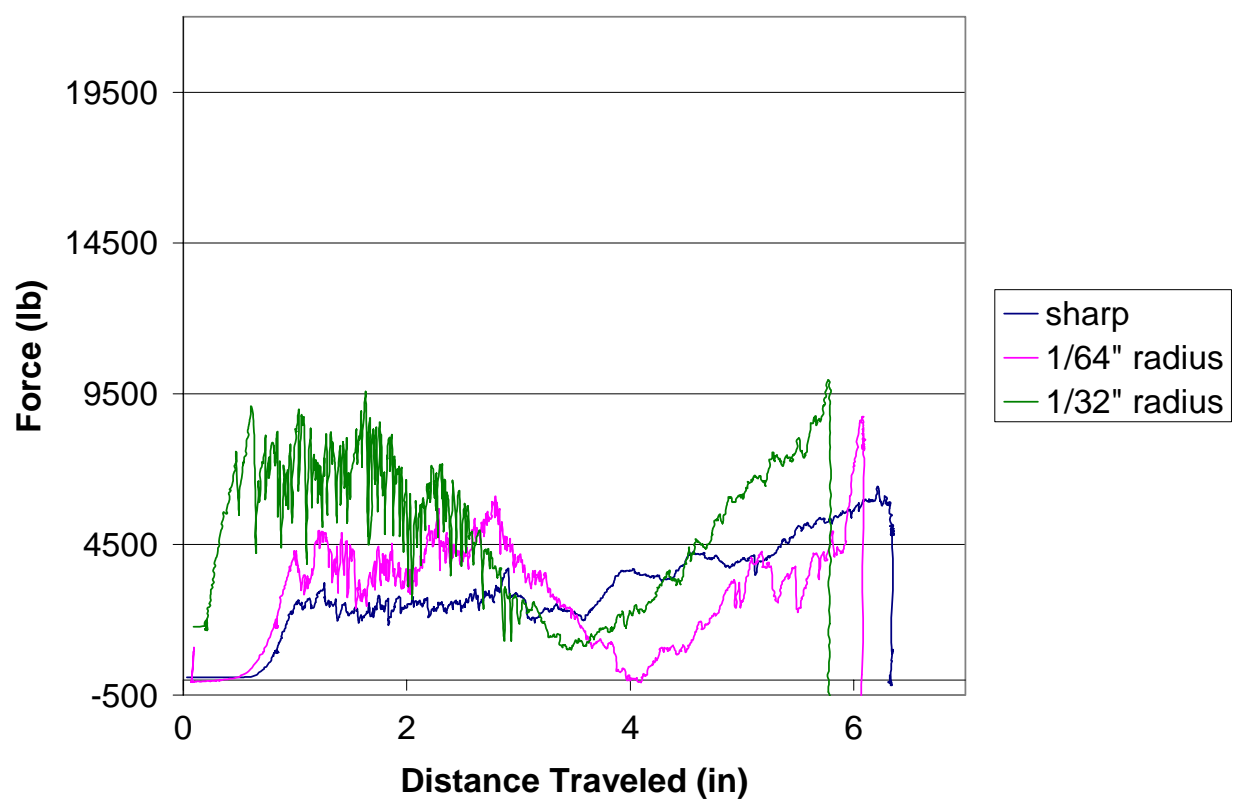

Figure 29: Forces Created by Magazines for each Shear Bar

\section{Newspaper Testing Results}

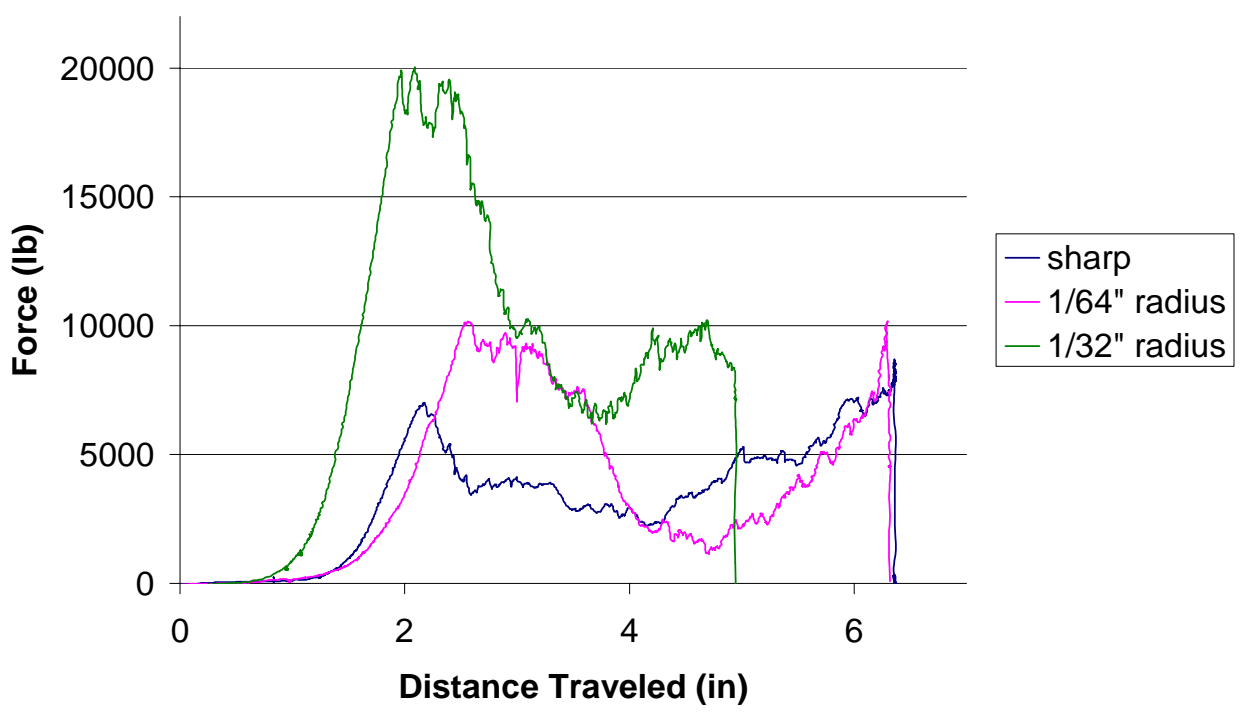

Figure 30: Forces Created by Newspaper for each Shear Bar

It was also consistently seen that the greatest average forces were created by newspaper. Magazines created the next greatest forces with cardboard creating the 
smallest forces out of the three. With the sharp shear bar, the average maximum force for newspapers was 7900 pounds while the average maximum force for magazines was 6200 pounds and cardboard was only 5600 pounds. With the 1/64 inch radius shear bar, the average maximum force for newspaper was found to be 9200 pounds while the average maximum force for magazines was 7600 pounds and cardboard was 5700 pounds. Also for the 1/32 inch radius shear bar the average maximum force was almost 18,000 pounds while the average maximum force for magazines was 10,900 pounds and for cardboard was 10,100 pounds.

During the experiment the force experienced by the shear bar peaked at two separate points. The first peak occurred within the first four inches of the experiment once the material has been compressed by the bar. This first peak is the force that is required to initially shear through the material. The second peak occurred at the end of the experiment when the material was being compressed between the shear bar and the ram block. This force was found to usually be as much or more than the force it took to shear through the material. The maximum force that was found when the material was being compressed between the ram and the shear bar is of the greatest interest since this is the situation where the baler most often jams.

Since the measurement devices were only capable of taking measurements with a certain amount of accuracy, there was obviously experimental uncertainty within the data collected. This uncertainty was determined by realizing the lowest increment of measurement that was possible for the load cell. The load cell was capable of measuring up 0.001 pounds. This is the uncertainty of the load cell also known as $\Delta \mathrm{x}_{1}$. It was also known that load was a function of voltage. The following equation shows this function. 
$\mathrm{L}$ is the load measured by the load cell in pounds, $\mathrm{k}$ is the calibration constant which was 2500 , and $\mathrm{V}$ is the voltage.

$$
L=k^{*} V
$$

The uncertainty can be calculated by the following equation.

$$
\Delta u_{1}=\sqrt{\left(\frac{\partial L}{\partial V}\right)^{2} * \Delta x_{1}^{2}}
$$

The uncertainty, $\Delta \mathrm{u}_{1}$, of the data collected from the load cell was found to be 2.5 pounds. This means that the force recorded by the load cell is accurate to \pm 2.5 pounds. 


\section{Chapter 3 - Finite Element Modeling}

\subsection{ANSYS Overview}

The Finite Element Analysis Code ANSYS was used in order to theoretically determine the strain that was experienced by the shear bar during baling. With this program, models of structures or systems can be created and then boundary conditions, loads, and other design criteria can be applied. ANSYS then computes how the structure or system will respond.

\subsection{Model Description}

In order to begin the modeling process a drawing of the shear bar was imported into ANSYS from AutoDesk Inventor. The actual shear bar can be seen in the figure below.

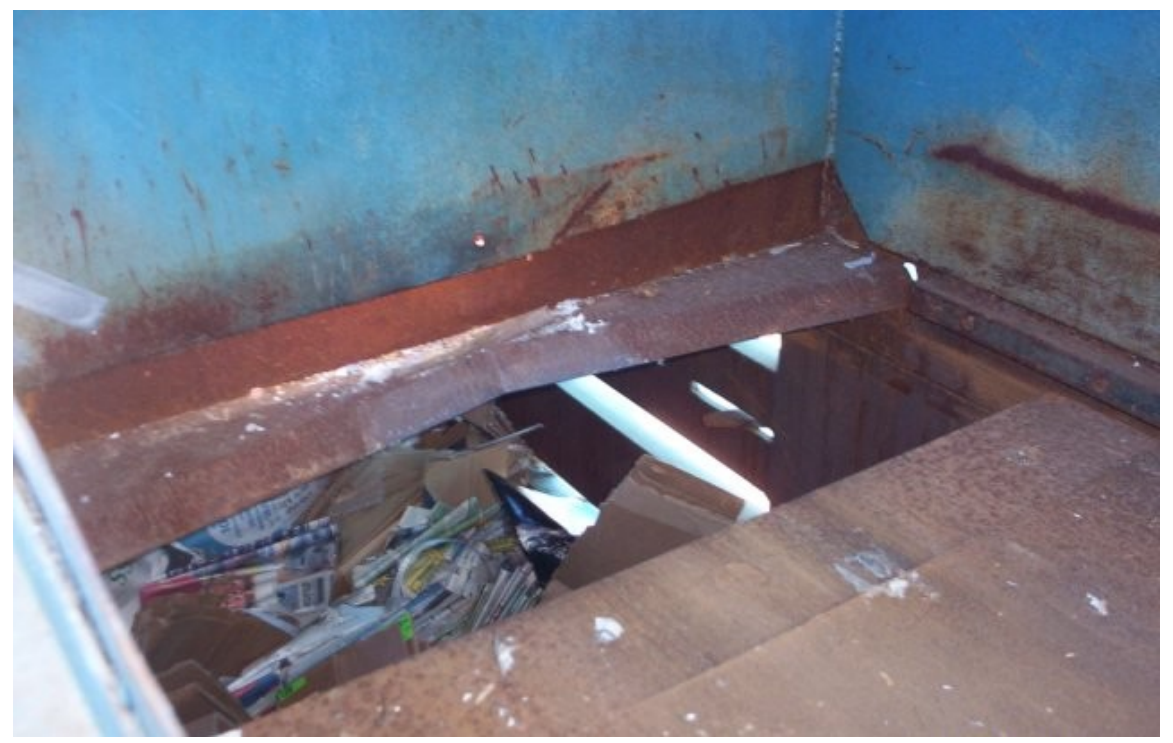

Figure 31: Shear Bar in Recycling Baler 
The drawing is a scaled representation of the shear bar and the block that attached the shear bar to the recycling baler. This imported image can be seen below.

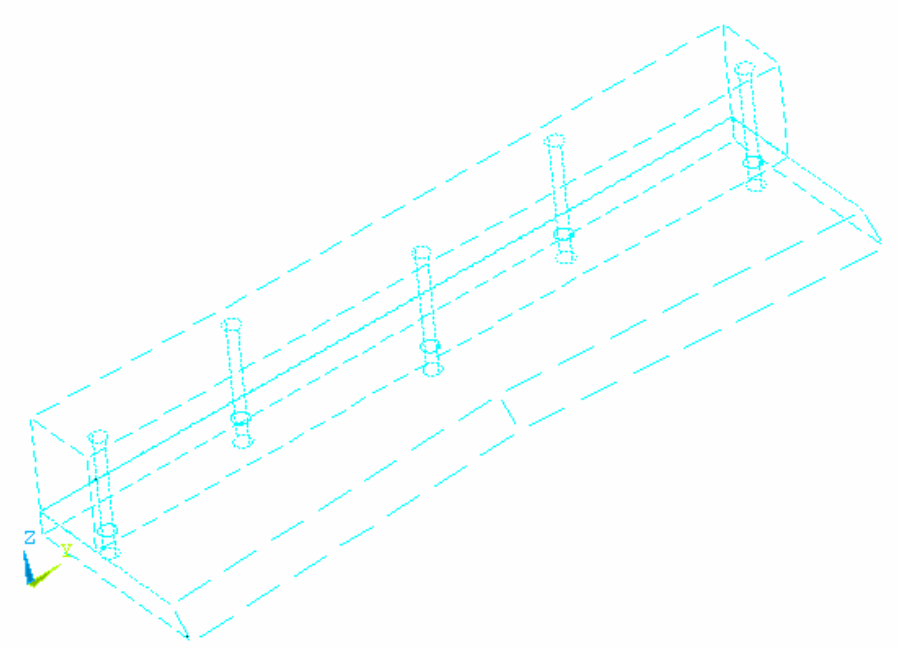

Figure 32: Shear Bar Drawing Imported into ANSYS

Once the drawing was imported the element type was selected. The element type determines how the element will behave and whether it is in two dimensional or three dimensional space. The element type selected for this model was SOLID45. This element type is used for modeling solids in a three dimensional space. Eight nodes define this element and each node has three degrees of freedom. This element is also capable of large strains and deflections, plasticity, and creep.

Next the material model behavior was determined by setting the material properties. The material model was chosen to be structural, linear, elastic, and isotropic. The Modulus of Elasticity was set to be $3 \times 10^{7}$ psi and Poisson's ratio was set to be 0.3 since the shear bar is made mild of steel. 
After the element type was chosen and the material properties were set, the model was meshed using the mesh tool. For meshing, the smart size was used at size 6 . The meshed model can be seen in the figure below.

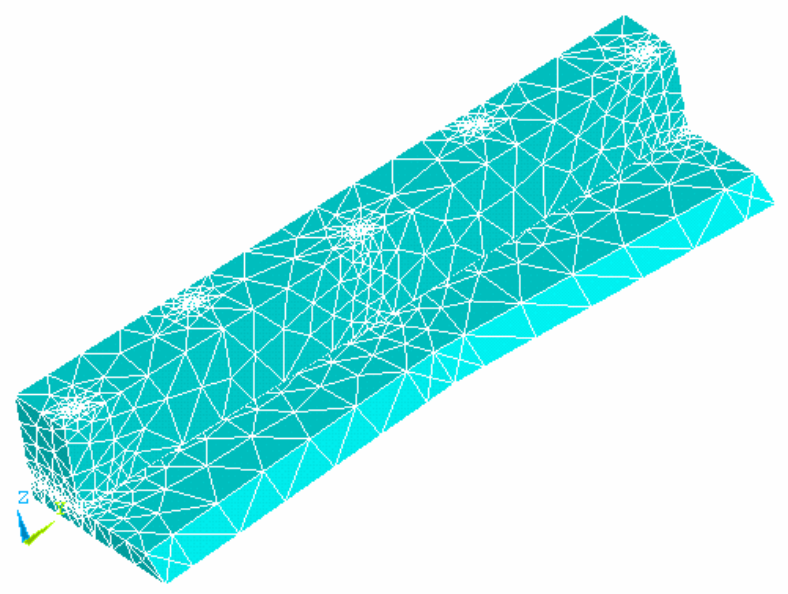

\section{Figure 33: Meshed Model}

After the model was meshed, the displacement loads were established. The model was constrained in all degrees of freedom on either end of the shear bar where it is welded to the baler. The bar was also constrained at the top of all five holes in the block since this is where the bar and blade are bolted into the baler. It was also necessary to set constraints within the holes where the shear bar and the block connect. When the drawing was imported into ANSYS the bar and block were two separate parts. This constraint in all degrees of freedom was necessary since the two parts are actually bolted together. The model with all of the displacement loads can be seen in the figure below. 


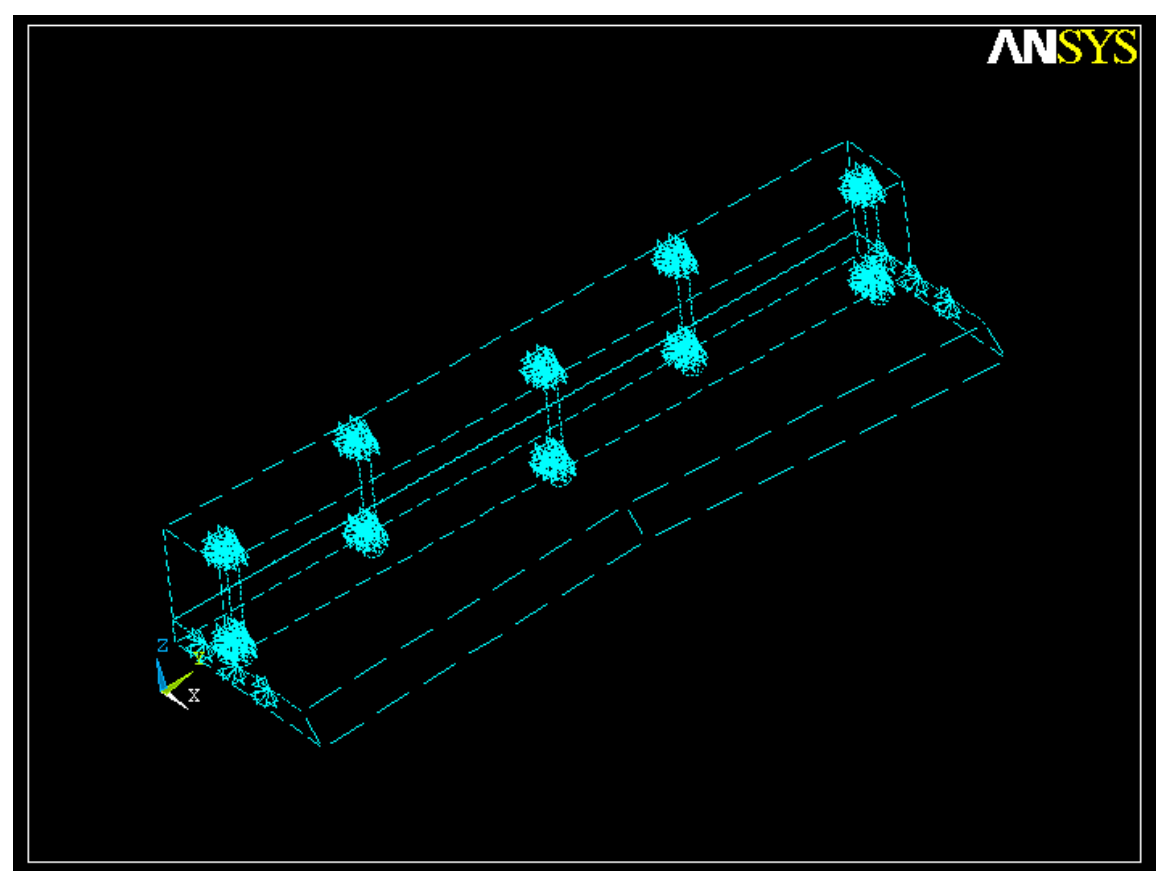

Figure 34: Shear Bar Model with Structural Displacement Loads

The last part that was added to the model before it was solved was the structural load. This was the force on the shear bar that was caused by cutting through the material or the compression of the material between the shear bar and the ram. While all of the other components of the model remained the same for each case, the force varied according to the situation. The force that was used was the average maximum force that was found for each material and shear bar. Since there were three materials and three shear bars, there were nine average maximum forces, and thus nine solutions for the model. The force applied to the model can be seen in the figure below. The direction of the force and the area that it was applied to remains the same for each situation. The magnitude of the force is all that changes. The force was applied over a length of 8 inches directly in the middle of the shear blade in the direction towards the shear bar. This location was chosen because this is where the material was always placed for the force determination experiment. 


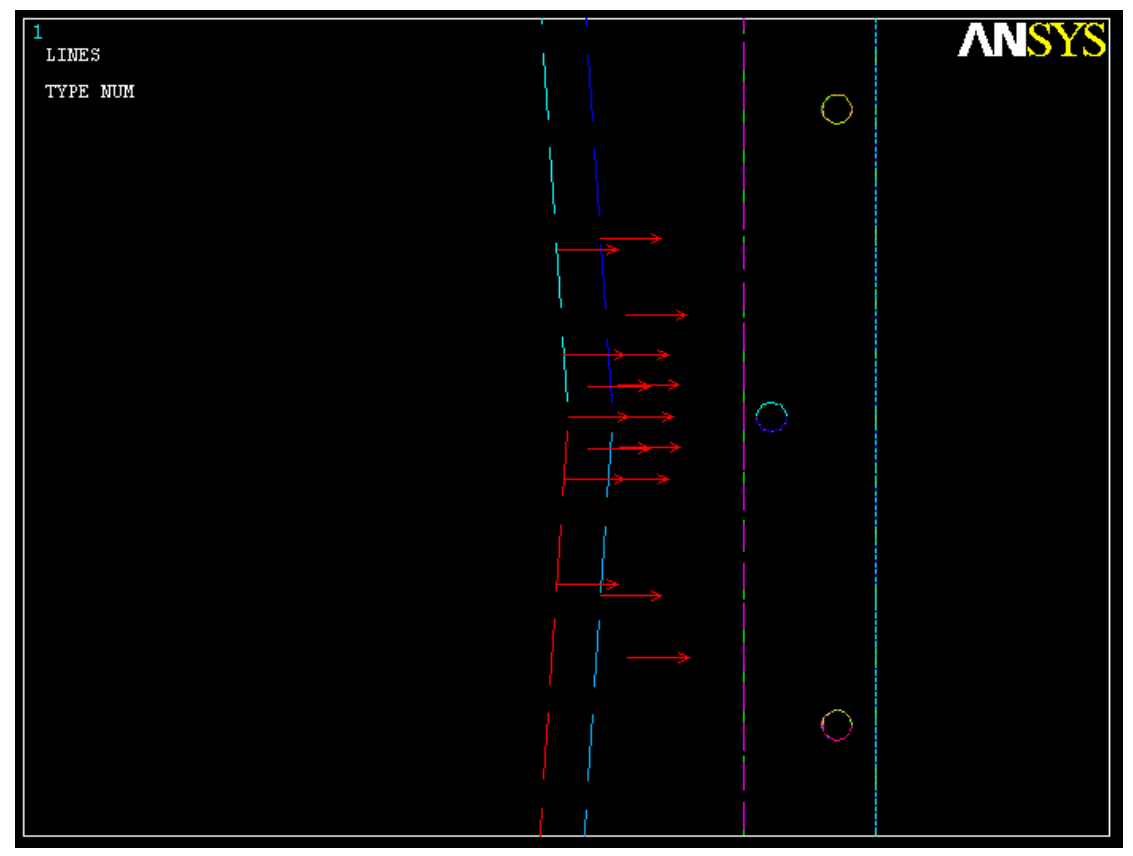

Figure 35: Load Applied to Shear Bar Model

\subsection{Finite Element Modeling Results}

The purpose of the finite element modeling was to determine the strain that was experienced by the shear bar when different loads were applied. From the Force Determination Experiment, the forces caused by different materials were determined. The maximum force that the ram is capable of supplying can also be determined since the maximum pressure the ram can operate is known to be 3000 psi and the diameter of the piston known to be 3.25 in. This maximum force can be found by first solving for the area of the piston as seen in Equation 1. This area is then used in Equation 2 to solve for the maximum force.

$$
\begin{aligned}
& A=\pi *\left(\frac{d^{2}}{4}\right) \\
& F=P^{*} A
\end{aligned}
$$


From these two equations the area was found to be $8.3 \mathrm{in}^{2}$ and the force was found to $24,887 \mathrm{lb}$. When the model was solved with this maximum force, the solution created by ANSYS gave a maximum strain of 0.059 . This solution can be seen in the figure below.

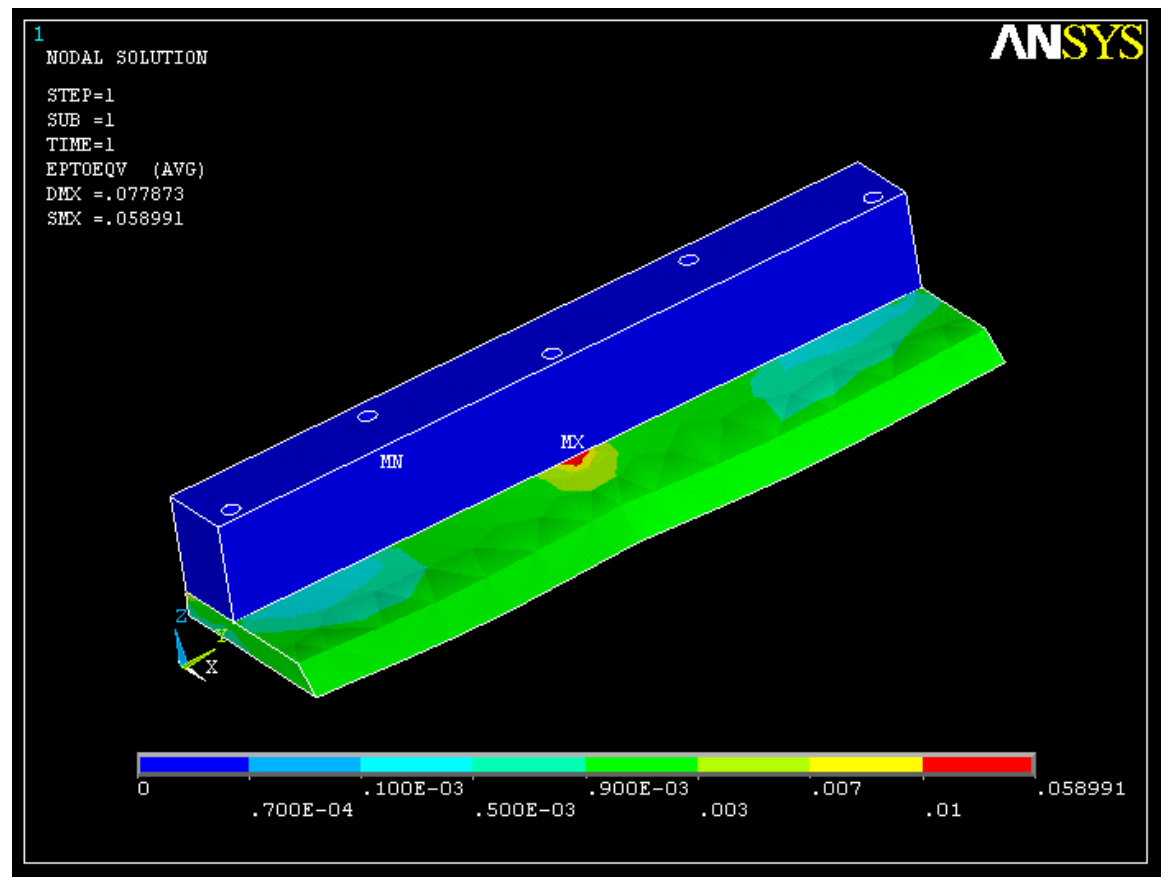

Figure 36: ANSYS Solution for Maximum force of 24,887 lb.

This maximum force is what the ram is capable of without any restrictions on the pressure. A pressure switch was placed on the recycling baler to limit the pressure that is allowed to operate the piston. This was done as a safety precaution and is present in all commercial recycling balers. Although the strain on the shear bar will never reach this value because of the pressure switch, this provides an upper limit for the strain.

The forces found during the Force Determination Experiment are used to determine a range for the strain when a jam occurs. For each of the nine cases, an average maximum force was determined. This force was used in the ANSYS model to 
calculate the strain experienced by the shear bar at this maximum load. Since this is a maximum load, it is assumed that the ram cannot apply any greater load and thus the baler must be jammed. The average maximum forces for each case can be seen in the table below.

Table 2: Average Experimental Maximum Force (lbs.) for Three Shear Bar Radii and Three Materials

\begin{tabular}{|l|c|c|c|}
\hline & sharp & $\begin{array}{c}1 / 64 " \\
\text { radius }\end{array}$ & $\begin{array}{c}1 / 32 " \\
\text { radius }\end{array}$ \\
\hline cardboard & 5578 & 5664 & 10132 \\
\hline newspaper & 7901 & 9241 & 17761 \\
\hline magazines & 6161 & 7596 & 10855 \\
\hline
\end{tabular}

Each of these forces was applied to the ANSYS model, and the strain distribution on the shear bar was determined. These solutions can be seen in the following figures.

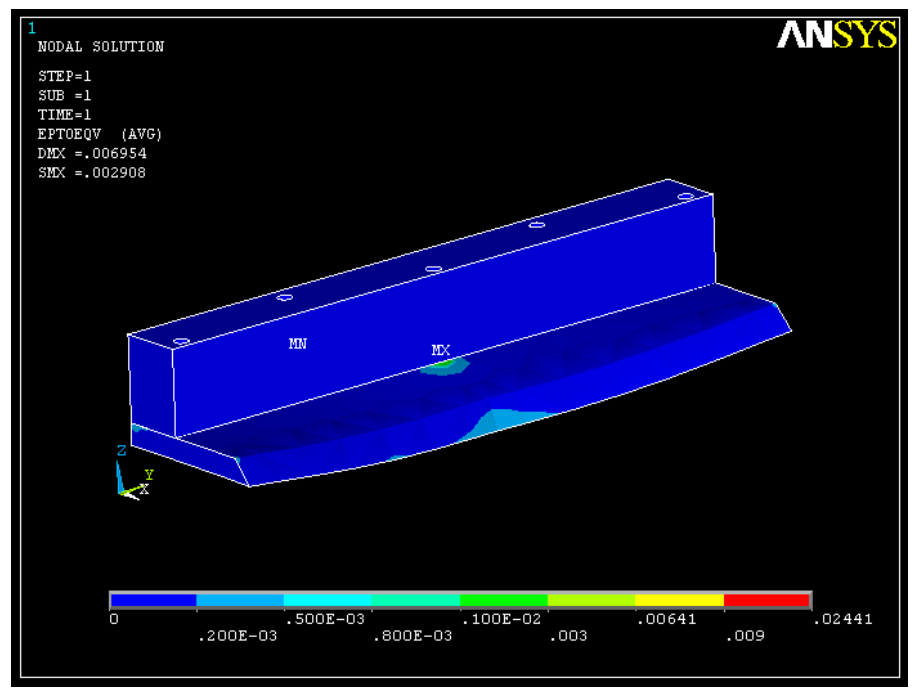

Figure 37: Strain Distribution from Cardboard on Sharp Shear Bar 


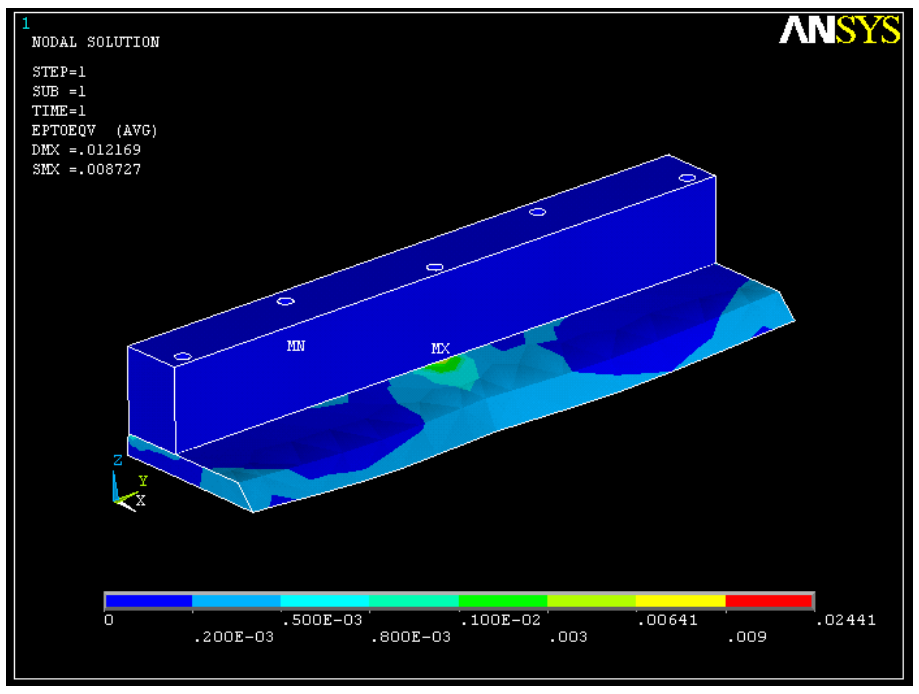

Figure 38: Strain Distribution from Magazines on Sharp Shear Bar

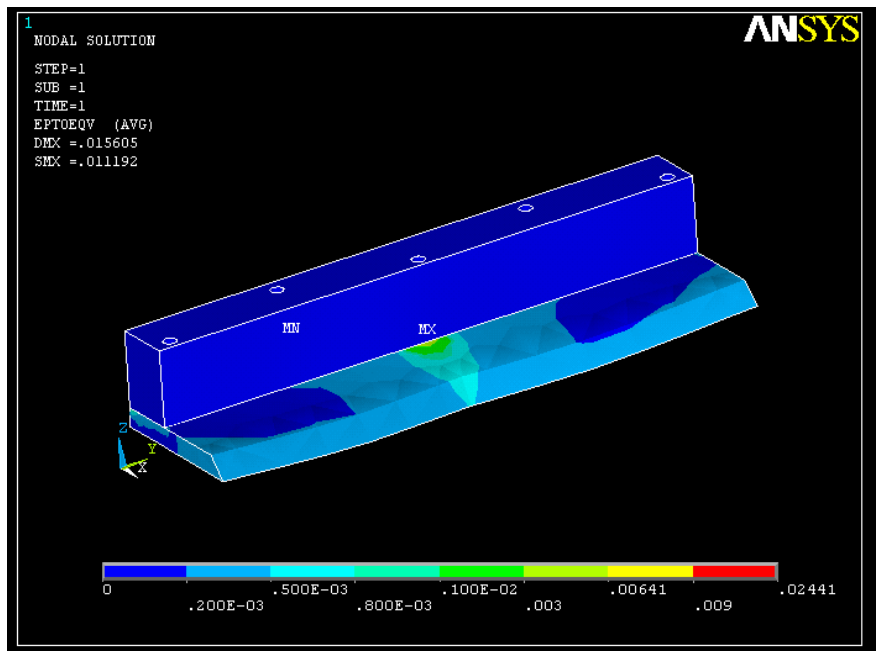

Figure 39: Strain Distribution from Newspaper on Sharp Shear Bar 


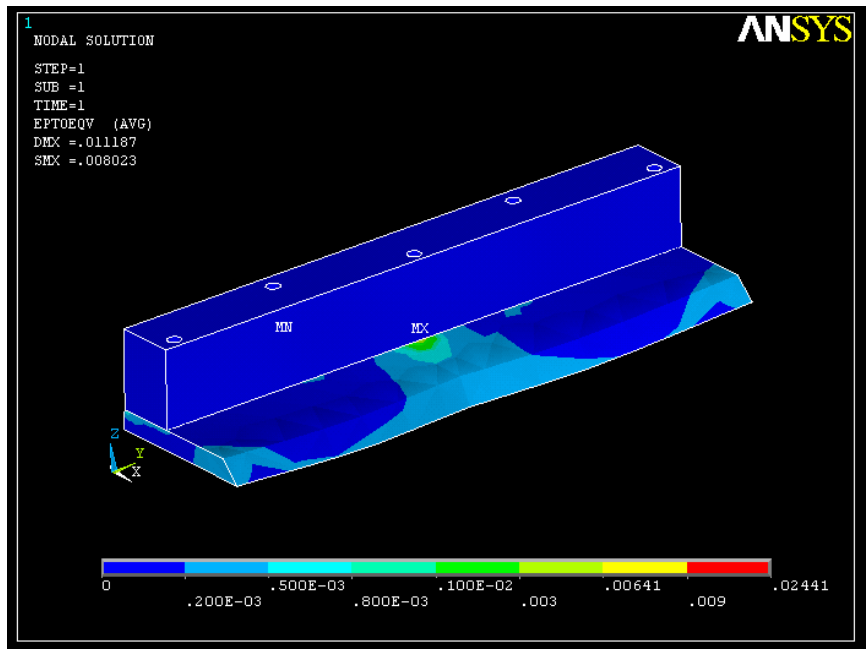

Figure 40: Strain Distribution from Cardboard on Shear Bar with 1/64" Edge Radius

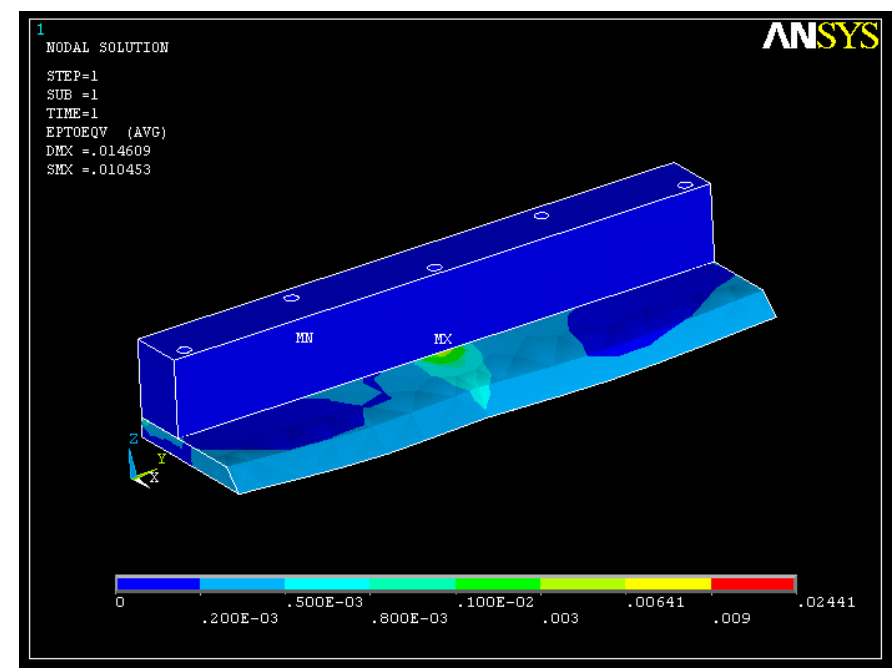

Figure 41: Strain Distribution from Magazines on Shear Bar with 1/64" edge radius 


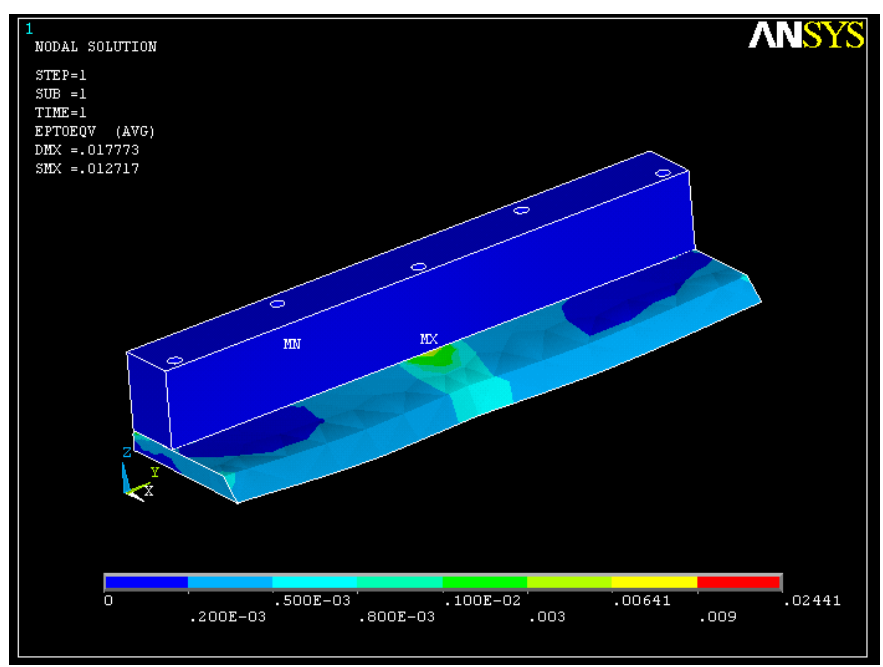

Figure 42: Strain Distribution of Newspaper on Shear Bar with 1/64" Edge Radius

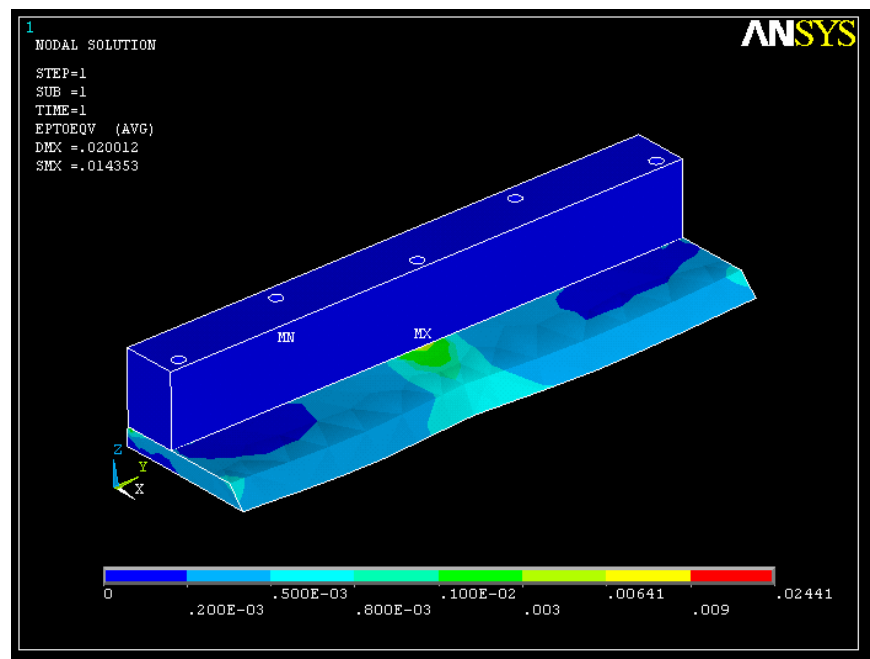

Figure 43: Strain Distribution of Cardboard on Shear Bar with 1/32" Edge Radius 


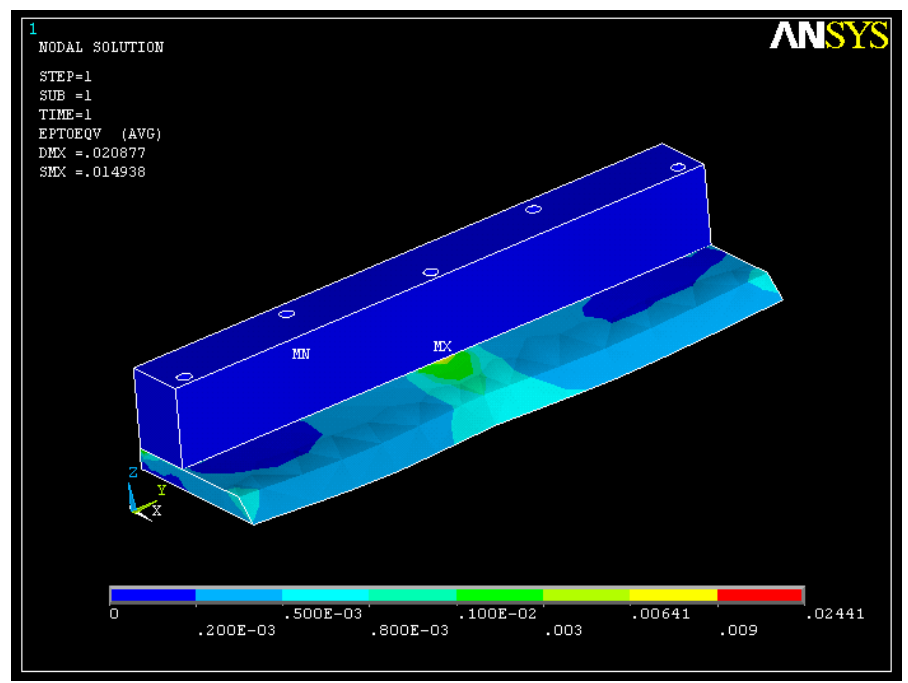

Figure 44: Strain Distribution from Magazines on Shear Bar with 1/32" Edge Radius

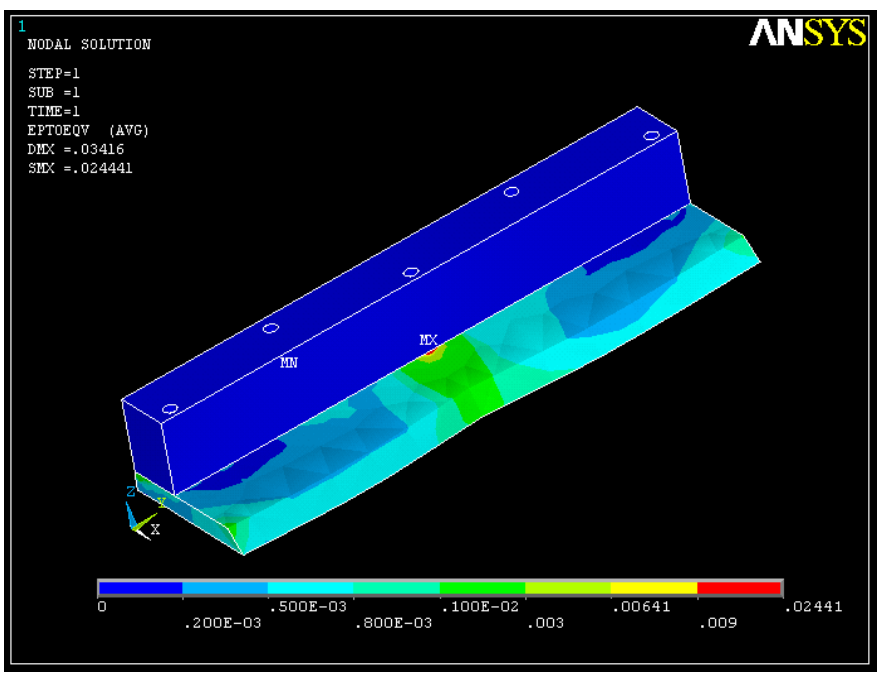

Figure 45: Strain Distribution from Newspaper on Shear Bar with 1/32" Edge Radius

From these solutions the maximum strain for each case could be determined. The strain that is of interest is the strain in the y-direction. When the baler jams, the material between the shear bar and the ram apply a force to the bottom of the shear bar. This force causes the bar to deform and creates tension in the top of the bar. Because of the deformation, the top of the shear bar elongates creating strain. This is the strain that is 
measured by the strain gage and used to anticipate when a jam will occur. The following table lists the maximum strains in the y-direction determined by the model solutions.

Table 3: Maximum Strain (in/in) in y-direction for different shear bar edge radii and materials

\begin{tabular}{|c|c|c|c|}
\hline & sharp & $1 / 64 "$ radius & $1 / 32$ " radius \\
\hline cardboard & 0.002908 & 0.008023 & 0.014353 \\
\hline magazines & 0.008727 & 0.010453 & 0.014938 \\
\hline newspaper & 0.011192 & 0.012717 & 0.024441 \\
\hline
\end{tabular}

\subsection{Discussion of Finite Element Model Results}

From the modeling it can be seen that the strain increases as the shear bar becomes duller. For cardboard the maximum strain was 0.0029 in/in with the sharp shear bar. The maximum strain increased to $0.008 \mathrm{in} / \mathrm{in}$ for the $1 / 64 \mathrm{inch}$ radius shear bar and to 0.014 in/in for the $1 / 32$ inch radius shear bar. For magazines the maximum strain was $0.0087 \mathrm{in} /$ in for the sharp shear bar. As the shear bar was dulled to a $1 / 64$ inch radius the maximum strain increased to $0.01 \mathrm{in} / \mathrm{in}$ and increased again to $0.015 \mathrm{in} / \mathrm{in}$ for the $1 / 32$ inch radius. The maximum strain found using newspaper followed the same trend. For the sharp shear bar the maximum strain was $0.011 \mathrm{in} / \mathrm{in}$. For the 1/64 inch radius shear bar the maximum strain increased to $0.013 \mathrm{in} / \mathrm{in}$ and increased again to $0.024 \mathrm{in} / \mathrm{in}$ for the $1 / 32$ inch radius shear bar.

The maximum strain is also consistently greater when newspaper is used rather than magazines or cardboard. For the sharp shear bar the maximum strain found with newspaper was $0.011 \mathrm{in} / \mathrm{in}$ while it was only $0.0087 \mathrm{in} / \mathrm{in}$ for magazines and $0.003 \mathrm{in} / \mathrm{in}$ for newspapers. When the 1/64 inch radius shear bar was considered, the maximum strain found for newspaper was $0.013 \mathrm{in} / \mathrm{in}$ while it was only $0.01 \mathrm{in} / \mathrm{in}$ for magazines and 
$0.008 \mathrm{in} / \mathrm{in}$ for cardboard. The same follows for the $1 / 32$ inch radius shear bar. For newspapers the maximum strain was found to be $0.024 \mathrm{in} /$ in while the maximum strain was only $0.015 \mathrm{in} / \mathrm{in}$ for magazines and $0.014 \mathrm{in} / \mathrm{in}$ for cardboard.

This seems reasonable because both of these circumstances created larger forces which lead to greater values of strain. The model also shows the location of the maximum strain. These maximum values consistently occur in the middle of the upper side of the shear bar. This is where the strain gage is placed in order to observe the strain for the JamAlert system. The figure below shows the location of the strain gage on the shear bar. The red rectangle represents the gage.

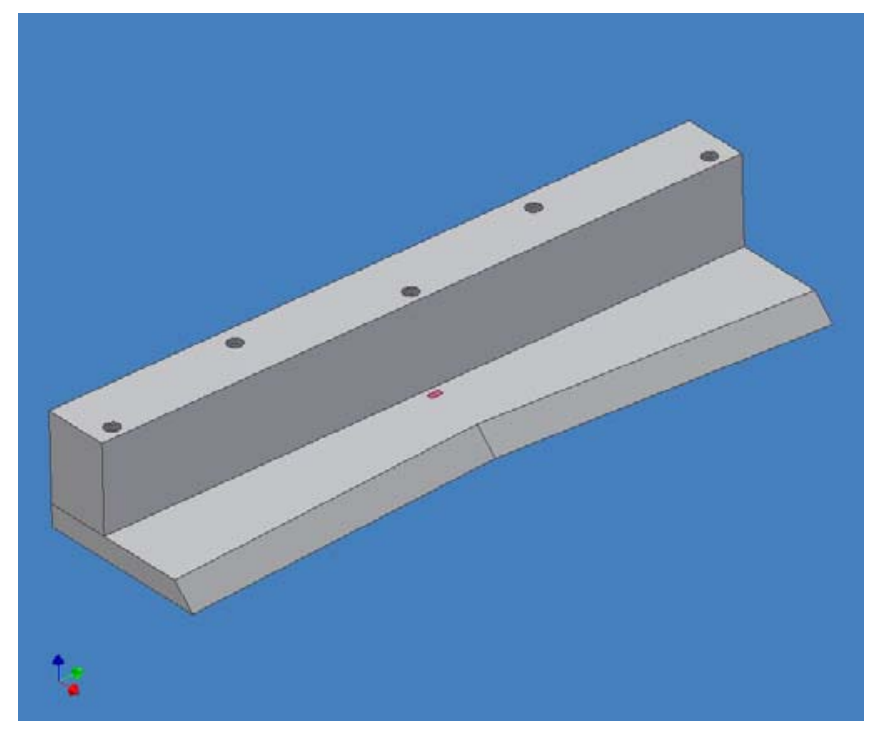

Figure 46: Strain Gage Location on Shear Bar 


\section{Chapter 4 - Validation of Finite Element Model}

\subsection{Description of Recycling Baler}

The recycling baler that was used for the validation of the finite element modeling was manufactured by International Baler Corporation. This model NA-1272 horizontal baler is commonly used in the baling industry. It has hydraulic and electrical systems which control the baling process together. The hydraulic system extends and retracts the ram. The electrical system is used for the controls and the switches on the machine. The hydraulic system also has a pressure switch which limits the maximum pressure the ram can operate. The baler can be operated in two modes. The automatic mode is controlled by an electric eye which starts the machine whenever material is sensed in the hopper and stops the machine when the area is clear. The baler can also be operated manually. The baler has a 30 horse power motor and a hydraulic pump that is capable of 3000 psi. The main cylinder has a 7 inch bore and a 63 inch stroke. There is also a 4-way valve with 35 GPM nominal flow. This valve is used to control the flow to the main cylinder. The NA1272 baler can be seen in the figure below.

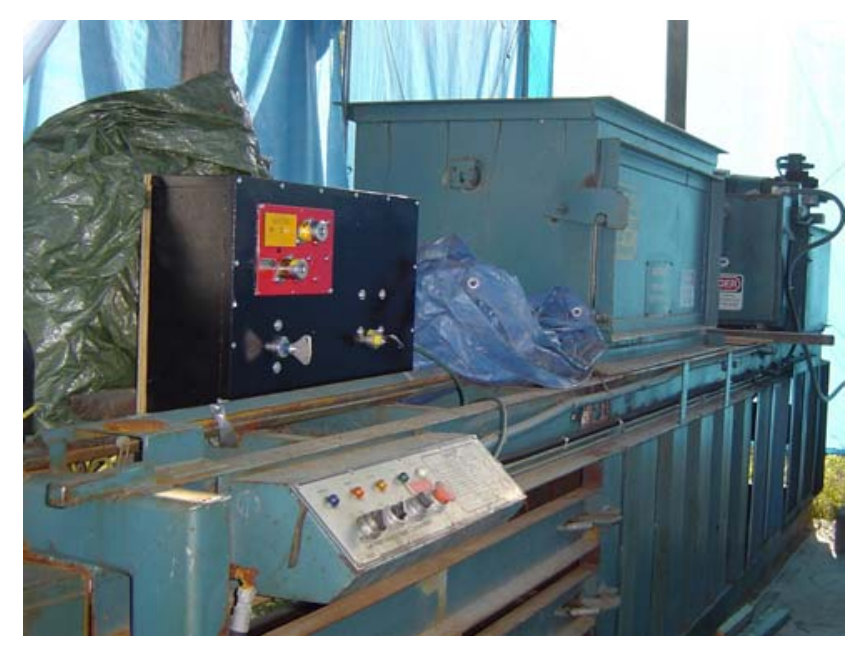

Figure 47: Industry Recycling Baler used for Validation Tests 


\subsection{Validation Overview}

The purpose of the validation done with the actual recycling baler is to compare the values of strain that were computed through modeling with values of strain that were collected experimentally. For this validation three different runs were completed for each of the three test materials. Each block of material was placed between the shear bar and the ram. The ram was then slowly moved towards the shear bar until the material was wedged between the shear bar and the ram. Once the material was held in place, the baling motion was initiated, and the ram began to travel towards the shear bar. As the ram moved beneath the shear bar, the material was compressed between the ram and the bottom of the shear bar. The excess material was sheared. During the entire motion of the ram, a single axis strain gage that was adhered on top of the shear bar transmitted the strain that the shear bar was experiencing to a nearby laptop. As material was sheared by the shear bar and began to be compressed between the shear bar and the ram, the shear bar began to deflect. The strain on the shear bar was a measure of this deflection. There comes a point when the material will cease to deflect the bar, and will instead impede the motion of the ram. It is when this happens that the ram stops its motion and the baler becomes jammed. This maximum strain that occurs right before the baler jams is the necessary value that the JamAlert system will use to indicate an incipient jam. Once this occurs the baler shutdown will be initiated.

The strain gage that was used on the recycling baler was a CEA series strain gage that was made by Vishay Measurements Group. This widely used gage has a length of 0.5 inches and has a resistance of 120 ohms. The backing material of the gage is 
polyimide which is tough and flexible. The foil alloy is constantan which is good for fatigue life.

\subsection{Results of Validation}

Three trials were completed with each of the three materials. Since the voltage transmitted by the strain gage had been compiled, it was necessary to convert these measurements to values of strain. The gage factor of the strain gage GF was 2.05 and the excitation voltage $\mathrm{V}_{\text {ex }}$ was $15 \mathrm{~V}$. These values along with the output voltage Vo that was recorded were used in the following equation to compute the strain.

$$
\varepsilon=\frac{4^{*} V_{o}}{G F^{*} V_{E X}}
$$

Once all of the voltages were converted, the strain was plotted versus time for each trial. The strain plots for each material can be seen in the following three figures.

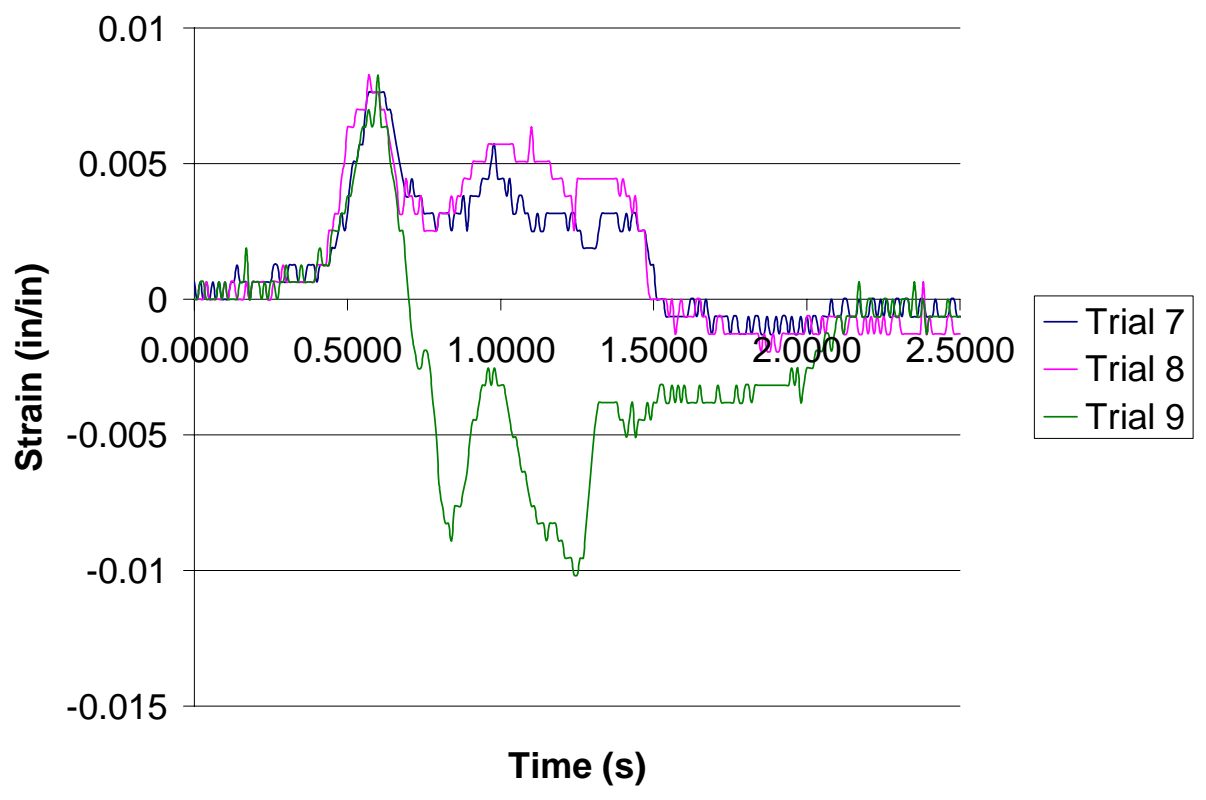

Figure 48: Strain Plot for Cardboard 


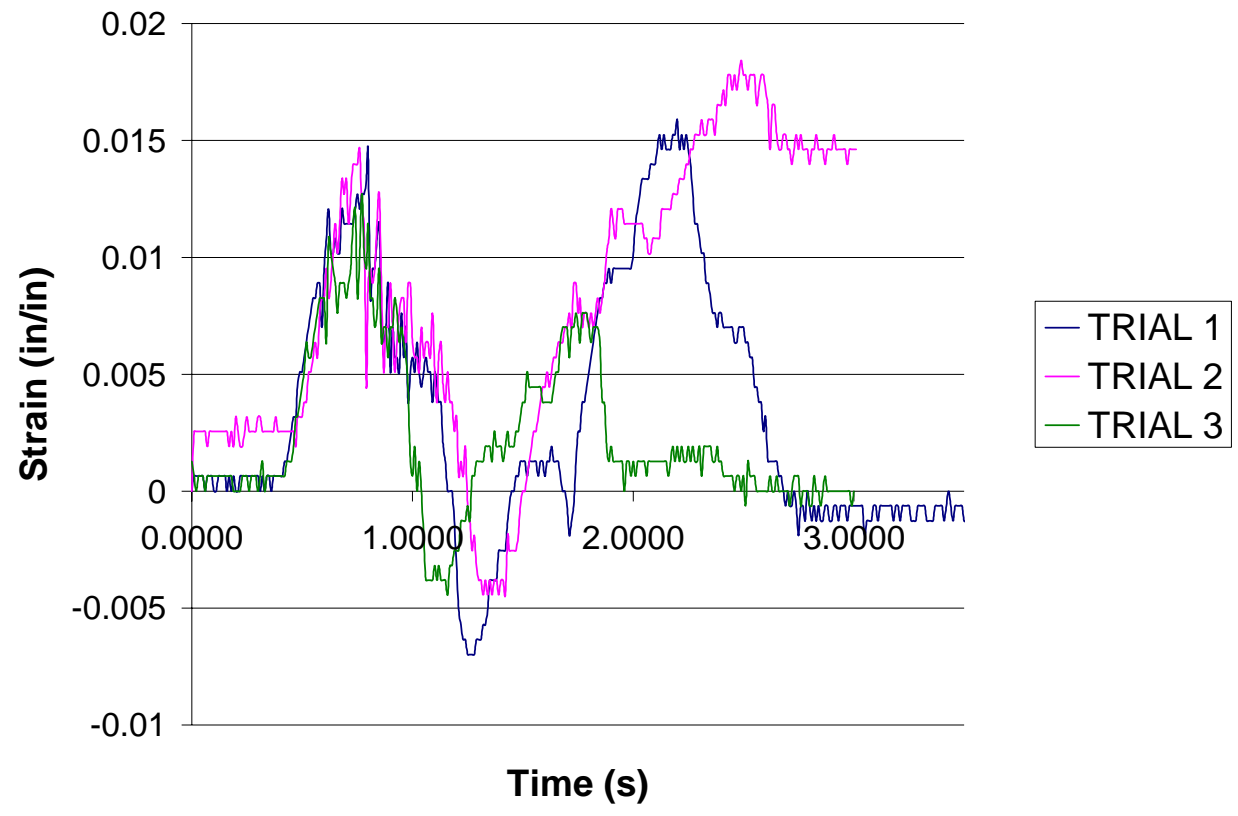

Figure 49: Strain Plots for Magazines

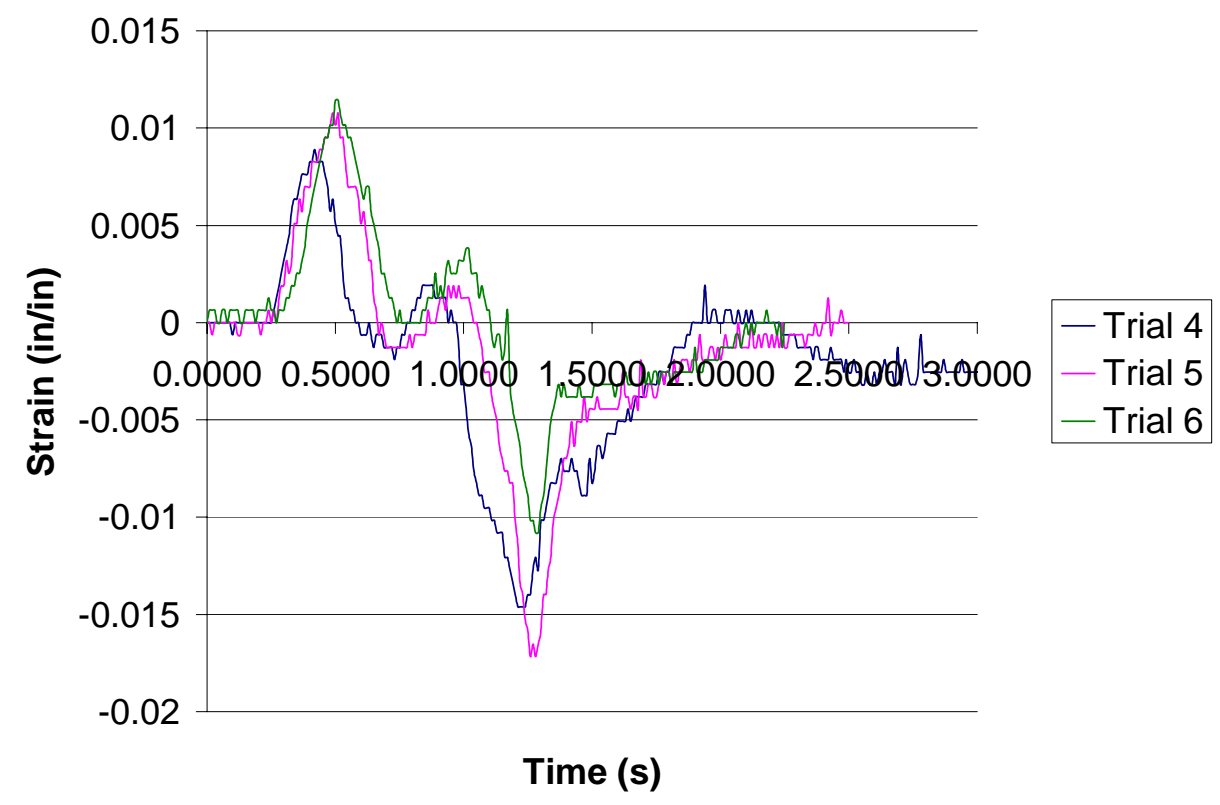

Figure 50: Strain Plots for Newspaper 
From these graphs the maximum strain for each trial was determined. The average maximum values of strain for each material along with the maximum pressure applied by the ram are in the table below.

Table 4: Average Maximum Strain and Pressure Caused by Cardboard, Magazines, and Newspaper

\begin{tabular}{|c|c|c|}
\hline & $\begin{array}{c}\text { Average Maximum } \\
\text { Strain (in/in) }\end{array}$ & $\begin{array}{c}\text { Maximum pressure } \\
(\mathrm{psi})\end{array}$ \\
\hline cardboard & 0.00805 & 1650 \\
\hline magazines & 0.01567 & 2200 \\
\hline newspaper & 0.01038 & 2200 \\
\hline
\end{tabular}

\subsection{Discussion of Validation Results}

The radius of the edge of the shear bar in the recycling baler was found to be $1 / 64$ of an inch. When the strains found in the validation experiment were compared with the theoretical strain values determined from the Finite Element Modeling for this edge radius, it was noticed that the theoretical strain was $23 \%$ greater than the experimental strains for newspaper. But not for magazines the experimental strain was $33 \%$ larger than the experimental strain. The strain results for cardboard were the closest. The experimental strain found with cardboard was only $0.31 \%$ larger than cardboard's theoretical strain. Also from the modeling it was concluded that newspaper would cause a larger strain than magazines with cardboard causing the smallest. From the validation experiment it was seen that cardboard still caused the smallest strain, but magazines caused an average maximum strain that was greater than newspaper. A reason for this discrepancy could be due to the set up of the force determination experiment. In the actual baler, the sides of the shear bar were fixed by welds on each side. In the Force 
Determination Experiment, the sides of the shear bar were free. Since the magazines didn't compress as much as the newspapers, the magazines caused the shear bar of the baler to deform more since the sides of the bar were fixed. This greater deflection obviously would cause a larger strain.

The uncertainty of the data collected by the strain gage can be determined in the same way the uncertainty was determined for the load cell. It is known that the strain gage can measure up to $0.0001 \mathrm{in} / \mathrm{in}$ which is $\Delta \mathrm{x}_{2}$. Also the strain is a function of voltage, $\mathrm{V}$, as was seen in Equation 5. Using Equation 6, the uncertainty of the strain gage, $\Delta \mathrm{u}_{2}$, can be calculated.

$$
\Delta u=\sqrt{\left(\frac{\delta \varepsilon}{\partial V}\right)^{2 * \Delta x_{2}^{2}}}
$$

The uncertainty of the strain was found to be $0.000013 \mathrm{in} / \mathrm{in}$. 


\section{Chapter 5 - Conclusions and Recommendations}

\subsection{Conclusions}

From the finite element modeling and the validation experiment, two sets of strain values were obtained. The finite element modeling computed strains experienced by three different shear bars with three different materials. The validation experiment made it possible to realize the strain caused by three different materials on only one shear bar. Since the shear bar edge radius on the recycling baler had already been dulled to $1 / 64$ of an inch, it is only possible to compare the strains for this radius. The strains found through the finite element modeling and the validation experiment can be seen in the following table. The percent error represents the experimental error. It was found by subtracting the theoretical strain value from the experimental strain value and dividing. This result was then divided by the theoretical value.

Table 5: Experimental and Theoretical Average Maximum Strains

\begin{tabular}{|c|c|c|c|}
\hline & $\begin{array}{c}\text { Experimental Maximum } \\
\text { Strain }\end{array}$ & $\begin{array}{c}\text { Theoretical } \\
\text { Maximum Strain }\end{array}$ & Error (\%) \\
\hline cardboard & 0.00805 & 0.00802 & 0.31 \\
\hline magazines & 0.01567 & 0.01045 & 33.30 \\
\hline newspaper & 0.01038 & 0.01272 & 22.56 \\
\hline
\end{tabular}

From these values of strain that were collected, it can be seen that the strain varies according to the material that is being baled. For the JamAlert system to be successful, it will be necessary for the system to be tuned according to the material that is being baled by the machine. A range of strains that could serve as the limit strain for the JamAlert 
system can be seen in the table below. The maximum theoretical strains were taken and then strains that were $2 \%, 5 \%$ and $10 \%$ below this maximum value were determined. The voltage that corresponds with each of these strains is also displayed in the Table 5 . The voltage was calculated using Equation 3 from earlier. The value of the voltage is what is actually programmed into the JamAlert system since the voltage is what is transmitted by the strain gage and observed by the system. If the voltage transmitted by the strain gage is higher than the limit voltage it will be assumed that there is a jam in the baler, and the power to the baler will be terminated.

Table 6: Ranges of Strains for Limit Value and Corresponding Voltages for JamAlert System

\begin{tabular}{|c||c|c|c||c|c|c|}
\hline \multicolumn{1}{|c||}{} & \multicolumn{3}{c||}{ Strains } & \multicolumn{3}{c|}{ Voltages } \\
$\%$ & cardboard & magazines & newspaper & cardboard & magazines & newspaper \\
\hline \hline 2 & 0.00786 & 0.01024 & 0.01246 & 0.06044 & 0.07875 & 0.09581 \\
\hline 5 & 0.00762 & 0.00993 & 0.01208 & 0.05859 & 0.07634 & 0.09287 \\
\hline 10 & 0.00722 & 0.00941 & 0.01145 & 0.05551 & 0.07232 & 0.08799 \\
\hline
\end{tabular}

The maximum pressure exerted by the ram piston during the validation experiment was found to be consistently near 2200 psi. This is another limit that can be added to the JamAlert system. If the piston exerts a pressure that is greater than $2200 \mathrm{psi}$, it should be assumed that there is a jam.

\subsection{Recommendations}

Currently there are many precautions that are being taken to improve the safety of the workers that operate industrial recycling balers. With the application of the JamAlert system, clearing jams will be much safer since the power to the machine will be 
eliminated before the jam becomes serious. The safety of the employees could be improved even more if the jams did not occur as often in the baler. From this study it was concluded that the sharpness of the shear bar affects the force that the ram in the baler is required to operate. Once this force exceeds the maximum force that the ram can supply, a jam is created. This force can be reduced, thus reducing the likelihood of a jam, by keeping the shear bar of the baler sharp.

Another element that could reduce the number of jams experienced by a recycling baler is the gap between the ram and the shear bar. This is the area where the material becomes trapped and compressed once the ram passes the end of the shear bar. The force on the shear bar dramatically increases as material continues to be compressed in this space. As this force increases it also prevents the ram from moving forward and causes the baler to jam. If this space were to be removed, material would not be allowed to apply such great forces on the shear bar. The only force that the shear bar would experience would be due to shearing through the material. This force was found during the force determination experiment to have a much smaller magnitude and would be less likely to create jams.

It is important to establish safer recycling baler jam controls in order to protect the health of the recycling baler operators. As more of the world's natural resources are depleted, recycling will continue to become more popular and necessary. Recycling used material to make new products reduces the consumption of natural resources but it also saves energy and reduces emissions of pollutants. As these benefits continue to be realized, recycling is going to be utilized much more. This is going to increase the need for recycling balers. As the numbers of balers in use are increased, the hazards caused by 
these balers will be increased as well. By acknowledging what the source of these hazards are and developing control systems to prevent them, the safety of the recycling baler operator will continue to be improved. 


\section{Bibliography}

ANSI. American national standard for equipment technology and operations for wastes and recyclable materials - baling equipment - safety requirements. New York: American National Standards Institute, Inc., ANSI Z245.5-2002, 2002.

ANSYS 8.1. Canonsburg, PA: ANSYS Inc., 2000.

Building Better Balers. Mark Phillips. 1996, Recycling Today, August 2004. http://www.recyclingtoday.com/articles.

Etherton, J.R., E.A. McKenzie, Jr. "The Machine Operator's Jammed-Feedstock-Clearing Task: A Safety Design Challenge." Proc. of ASME International Mechanical

Engineering Congress and Exposition., November 11-16, 2001, New York: 2001.

Grund E., Lockout/Tagout: The Process of Controlling Hazardous Energy. Itasca, IL: NSC Press 1995.

History of SATEC. 2003. Instron. Nov. 2004. http://www.instron.us/wa/library/.

LabView 6i. National Instruments Corporation, 2001.

Malenfort, George G., Corrugated Shipping Containers: An Engineering Approach.

Plainview, NY: Jelmar Publishing Co.,Inc., 1996.

NIOSH. "Preventing Deaths and Injuries While Compacting or Baling Refuse Material," Cincinnati, OH: DHHS (NIOSH) PUBLICATION No. 2003-124, 2003.

Occupational Safety and Health Administration, OSHA 29 CFR 1910.147, "The Control of Hazardous Energy (Lockout/Tagout)." Washington, DC: Government Printing Office, 1996.

OSHA, "Safeguarding Equipment and Protecting Workers from Amputations."

Washington, DC: U.S. Department of Labor, Occupational Safety and Health Administration, Publication 3170, 2001.

Paper Recycling Supplement - Clean and Healthy. Brian Taylor. 2002. Recycling Today, $18 \mathrm{Feb} 2005$. http://www.recyclingtoday.com/articles.

Special Emphasis Program. 2005. TOSHA. 28 Jan 2005. http://www.state.tn.us/laborwfd/tosha_amputations.html.

Understanding Press Counterbalance Conditions Using Strain Technology. William H. Hinterman. 1997. Metal Forming Magazine, 15 July 2005.

http://www.metalformingmagazine.com/1997/061697hint.htm/. 


\section{Appendix A - Shear Bar Assembly Drawings}




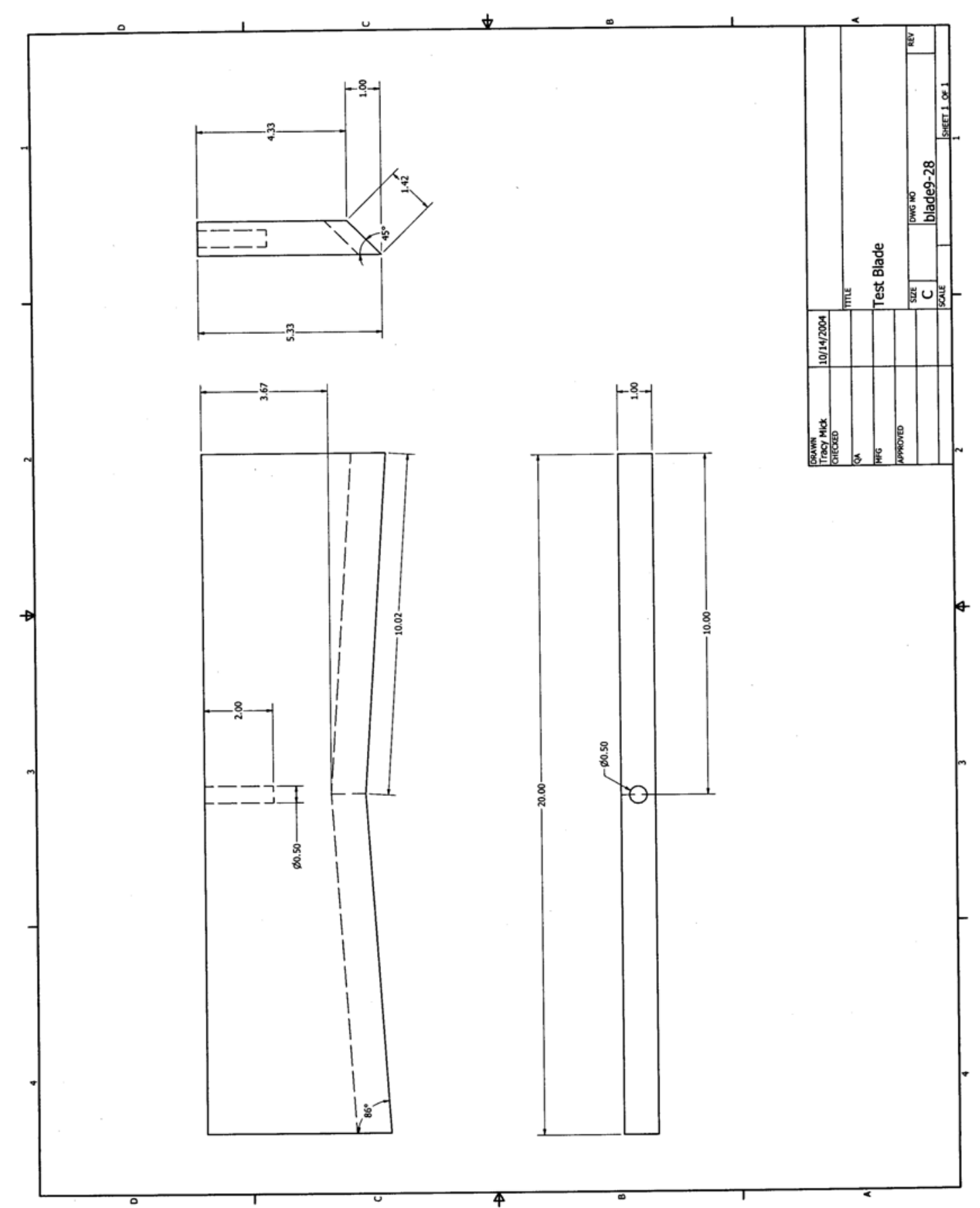

Figure 551: Shear Bar Drawing 


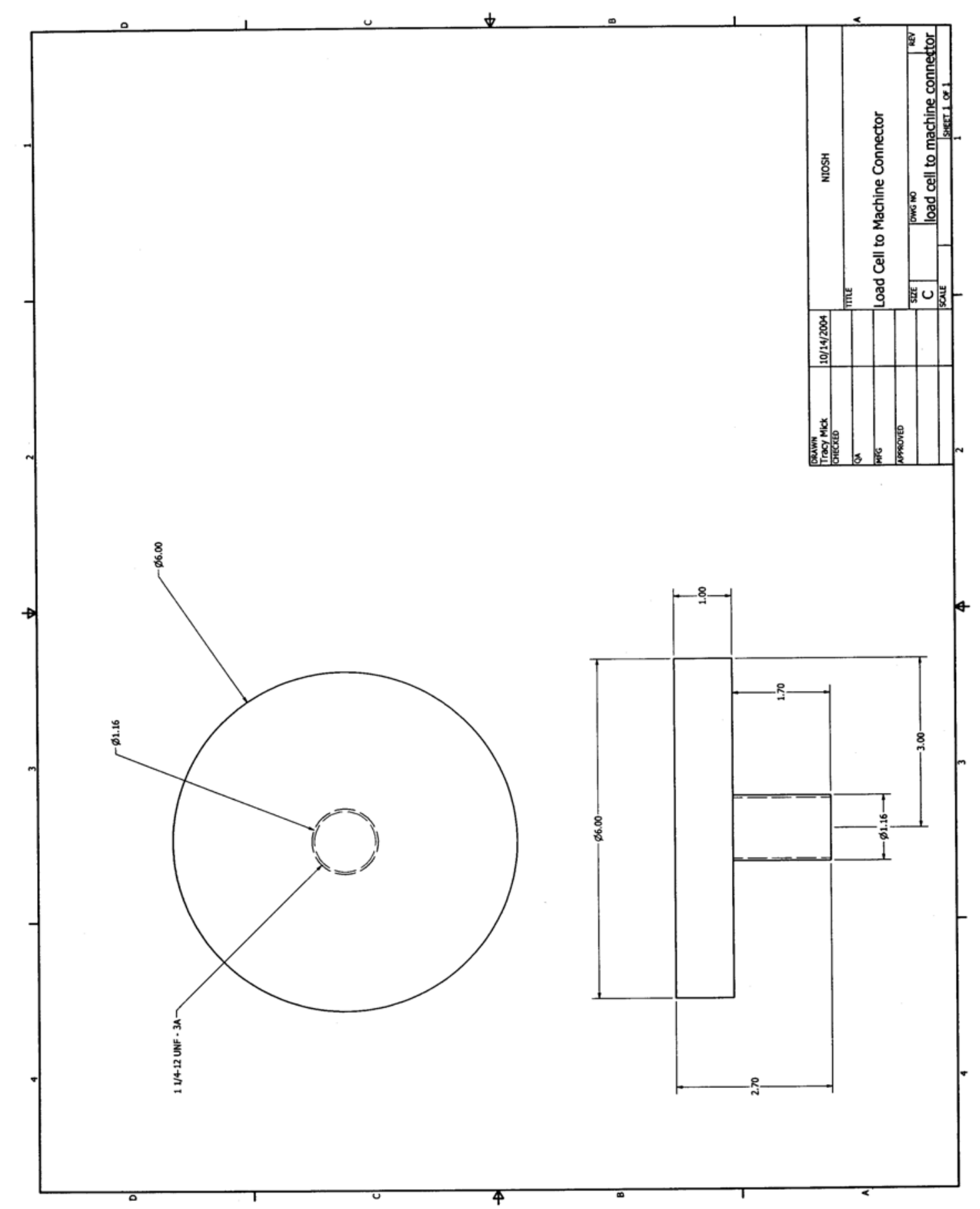

Figure 552: Load Cell to Machine Connector Drawing 


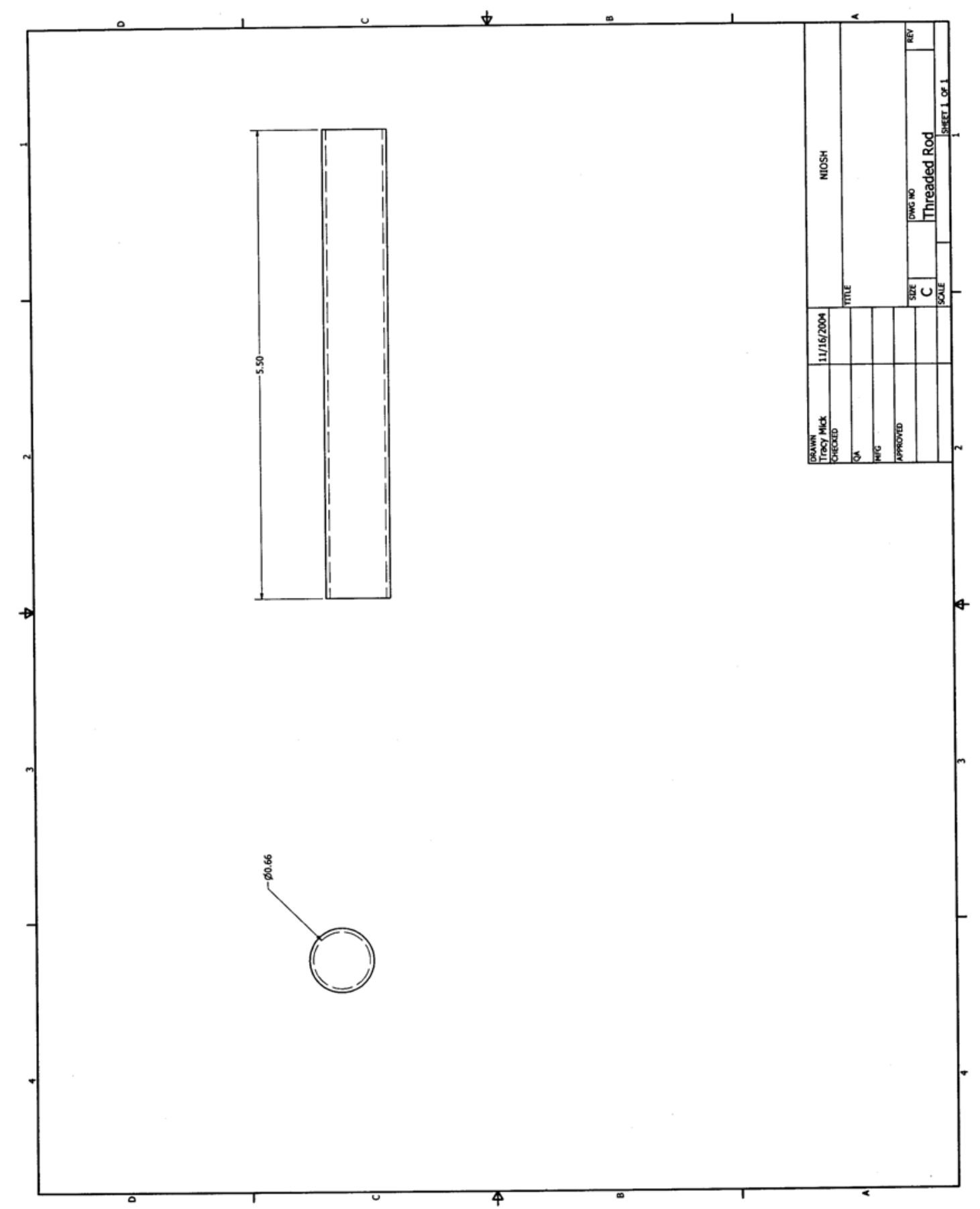

Figure 553: Threaded Rod Drawing 


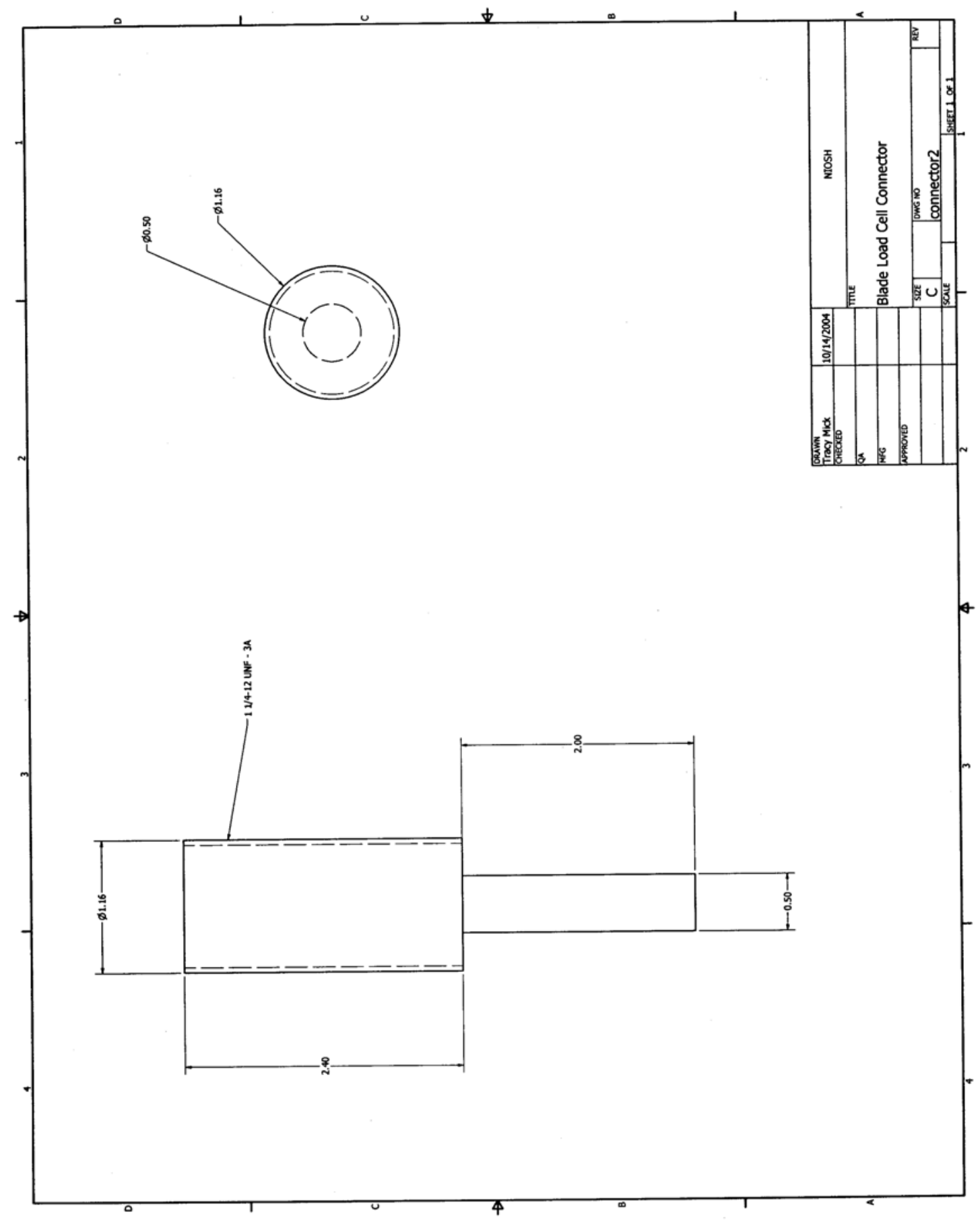

Figure 554: Shear Bar to Load Cell Connector Drawing 


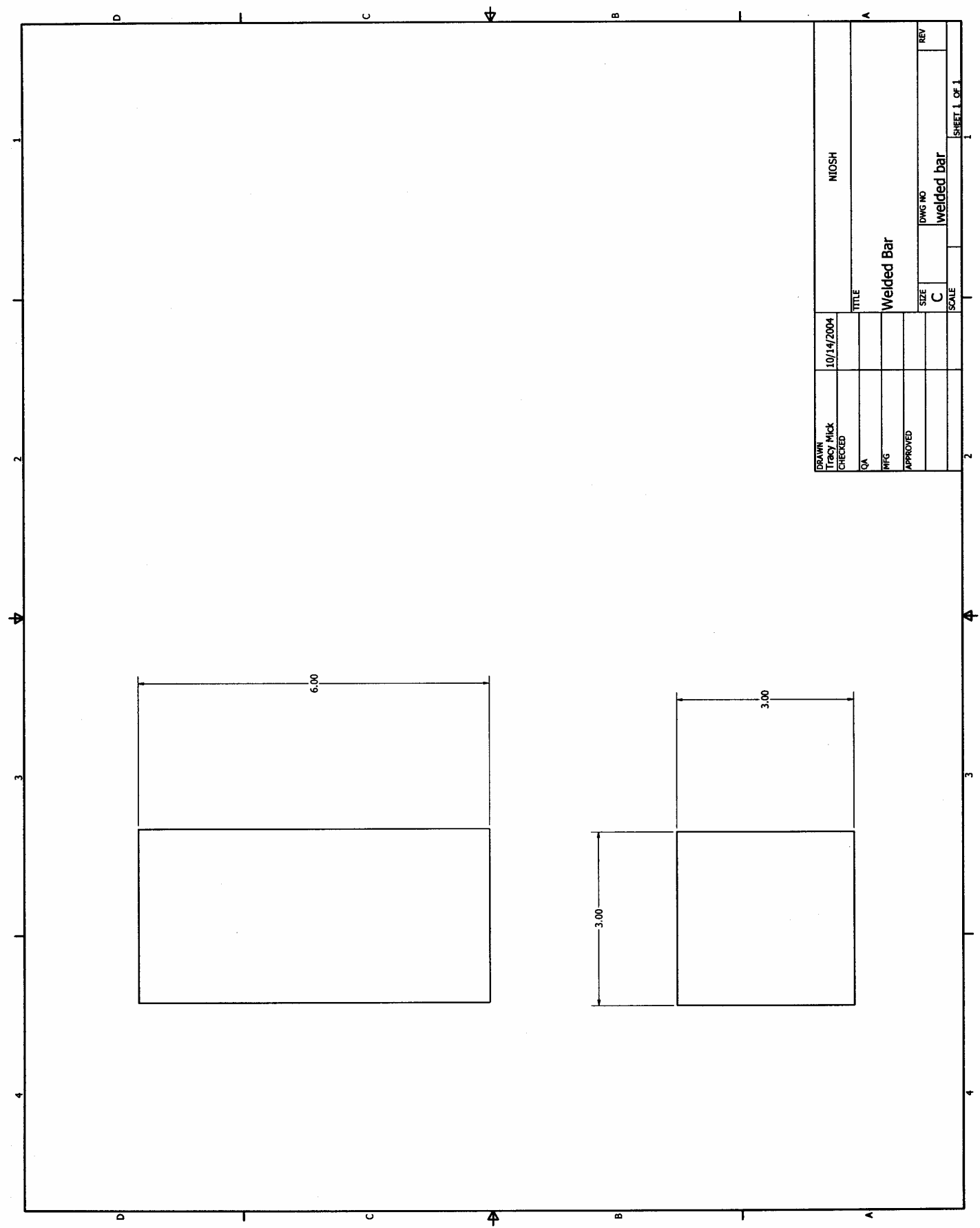

Figure 555: Welded Bar Drawing 


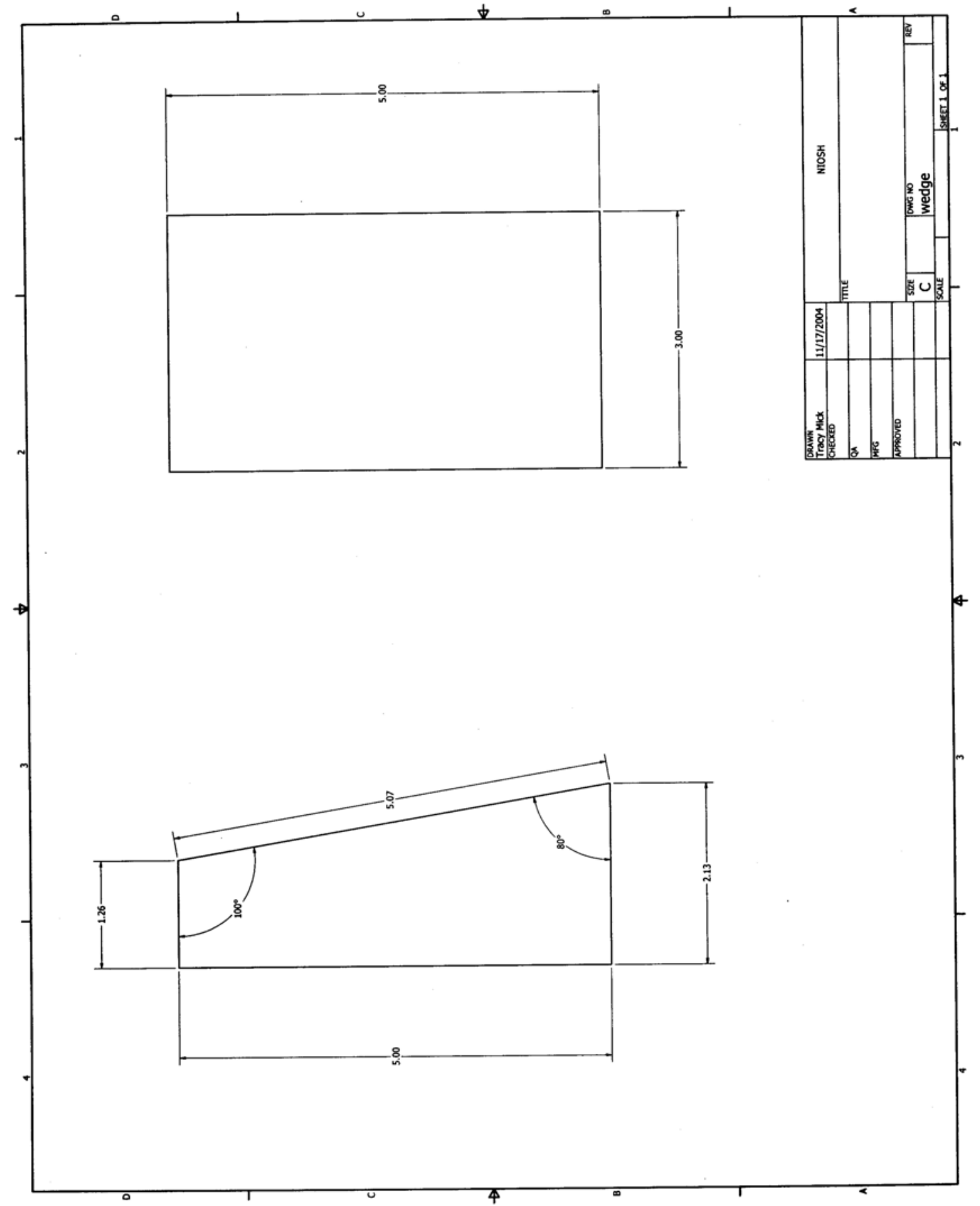

Figure 556: Wedge Drawing 
Appendix B - Cardboard Property Data 
Table 7: Mechanical Properties of Combined Boards and Boxes

\begin{tabular}{|c|c|c|c|c|c|c|c|c|c|}
\hline Code & $\begin{array}{l}\text { Nute } \\
\text { s1se }\end{array}$ & $\begin{array}{c}\text { Series, } \\
\text { Lo. }\end{array}$ & $\begin{array}{l}\text { Obererved } \\
\text { Bow Load, } \\
\text { P, Lb. }\end{array}$ & $\begin{array}{l}\text { Bdgevise } \\
\text { Compression } \\
\text { Strength, } \\
\text { P, Do./10; }\end{array}$ & $\begin{array}{l}\mathrm{In} \\
\mathrm{D}_{x}\end{array}$ & $\underset{\mathrm{Cross}}{\mathrm{C}}$ & $\begin{array}{l}\text { frrese, } \\
\text { Con- } \\
\text { ponlte } \\
\sqrt{D_{x} D_{y}}\end{array}$ & $\begin{array}{c}b_{+}=1 a_{0} \\
\text { Ratio, } \\
D_{x} \\
\frac{D_{y}}{}\end{array}$ & $\begin{array}{l}\text { Conblesed } \\
\text { Board } \\
\text { Caliper. } \\
\text { h, In. }\end{array}$ \\
\hline \multirow[t]{2}{*}{$\begin{array}{l}1198 \\
1188 \\
2046 \\
2341 \\
2345\end{array}$} & $\hat{\hat{A}}$ & $\begin{array}{l}175 \\
175 \\
175 \\
175 \\
175\end{array}$ & $\begin{array}{l}564 \\
660 \\
880 \\
949 \\
946\end{array}$ & $\begin{array}{l}31.2 \\
37.3 \\
45.8 \\
40.4 \\
43.3 \\
\end{array}$ & $\begin{array}{l}188 \\
185 \\
196 \\
189 \\
182 \\
\end{array}$ & $\begin{array}{l}77.7 \\
74.1 \\
98.4 \\
76.3 \\
81.4 \\
\end{array}$ & $\begin{array}{l}121 \\
117 \\
134 \\
120 \\
122 \\
1\end{array}$ & $\begin{array}{l}2.42 \\
2.50 \\
2.12 \\
2.46 \\
2.24 \\
\end{array}$ & $\begin{array}{l}0.197 \\
0.200 \\
0.214 \\
0.199 \\
0.199 \\
\end{array}$ \\
\hline & & $\cdot$ & Average & 42.6 & 188 & 80.4 & 123 & 2.35 & 0.260 \\
\hline $\begin{array}{l}1176 \\
1184 \\
2324 \\
1146 \\
1167 \\
1163 \\
1117 \\
2315 \\
2305\end{array}$ & $\begin{array}{l}\hat{A} \\
\hat{A} \\
\hat{A} \\
\hat{A} \\
\hat{A}\end{array}$ & $\begin{array}{l}200 \\
200 \\
200 \\
200 \\
200 \\
200 \\
200 \\
200 \\
200\end{array}$ & $\begin{array}{c}772 \\
770 \\
951 \\
912 \\
994 \\
938 \\
925 \\
1024 \\
1120\end{array}$ & $\begin{array}{l}44.0 \\
43.7 \\
45.4 \\
66.7 \\
45.6 \\
45.9 \\
42.4 \\
45.7 \\
47.6 \\
\end{array}$ & $\begin{array}{l}210 \\
196 \\
190 \\
195 \\
212 \\
213 \\
225 \\
188 \\
185 \\
\end{array}$ & $\begin{array}{l}94.3 \\
84.7 \\
90.6 \\
84.5 \\
91.1 \\
79.9 \\
88.5 \\
76.9 \\
85.5 \\
\end{array}$ & $\begin{array}{l}141 \\
129 \\
131 \\
128 \\
199 \\
190 \\
140 \\
119 \\
126 \\
\end{array}$ & $\begin{array}{l}2.23 \\
2.31 \\
2.10 \\
2.31 \\
2.33 \\
2.67 \\
2.52 \\
2.51 \\
2.16 \\
\end{array}$ & $\begin{array}{l}0.207 \\
0.205 \\
0.203 \\
0.208 \\
0.207 \\
0.209 \\
0.207 \\
0.206 \\
0.209 \\
\end{array}$ \\
\hline & & & Average & $45+2$ & 201 & 86.0 & 131 & 2.35 & $0.2 \alpha$ \\
\hline \multirow[t]{2}{*}{$\begin{array}{l}1180 \\
2115 \\
1197 \\
2011 \\
2373 \\
2095 \\
2099 \\
2054 \\
2159 \\
2155\end{array}$} & $\begin{array}{l}\hat{A} \\
\hat{A} \\
\hat{A} \\
\hat{A} \\
\hat{A} \\
\hat{A} \\
\hat{A}\end{array}$ & $\begin{array}{l}275 \\
275 \\
275 \\
275 \\
275 \\
275 \\
275 \\
275 \\
275 \\
275\end{array}$ & $\begin{array}{r}678 \\
795 \\
862 \\
811 \\
1280 \\
1496 \\
1918 \\
1717 \\
1980 \\
1663\end{array}$ & $\begin{array}{l}50.5 \\
56.0 \\
48.5 \\
50.0 \\
57.1 \\
63.7 \\
67.1^{6} \\
59.9 \\
66.2^{\circ} \\
61.1 \\
\end{array}$ & $\begin{array}{ll}182 & \\
2 B 2^{e} & 1 \\
250 & \\
203 & 1 \\
260 & 1 \\
235 & 1 \\
250 & 1 \\
235 & 1 \\
301 & 1 \\
269 & 1 \\
\end{array}$ & $\begin{array}{c}726 \\
160 \\
62.2 \\
124 \\
134 \\
131 \\
117 \\
145 \\
143 \\
171 \\
\end{array}$ & $\begin{array}{l}115 \\
212 \\
125 \\
159 \\
190 \\
175 \\
172 \\
185 \\
207 \\
215 \\
\end{array}$ & $\begin{array}{l}2.51 \\
1.76 \\
4.02 \\
1.64 \\
2.00 \\
1.78 \\
2.14 \\
1.62 \\
2.10 \\
1.57 \\
\end{array}$ & $\begin{array}{l}0.217 \\
0.214 \\
0.216 \\
0.218 \\
0.225 \\
0.195 \\
0.224 \\
0.215 \\
0.228 \\
0.223 \\
\end{array}$ \\
\hline & & & Average ${ }^{\mathrm{a}}$ & 60.1 & 2551 & 141 & 189 & 1.83 & 0.218 \\
\hline \multirow[t]{2}{*}{$\begin{array}{l}2219 \\
2167\end{array}$} & $\begin{array}{l}c \\
c\end{array}$ & $\begin{array}{l}175 \\
175\end{array}$ & $\begin{array}{l}6 \% 6 \\
597\end{array}$ & $\begin{array}{l}43.9 \\
40.8 \\
\end{array}$ & $\begin{array}{l}104 \\
116 \\
\end{array}$ & $\begin{array}{r}55.1 \\
42.9 \\
\end{array}$ & $\begin{array}{r}75.8 \\
70.7 \\
\end{array}$ & $\begin{array}{l}1.89 \\
2.70 \\
\end{array}$ & $\begin{array}{l}0.162 \\
0.164 \\
\end{array}$ \\
\hline & & & Average & 42,4 & 110 & 49.0 & 75.2 & 2,30 & 0.263 \\
\hline $\begin{array}{l}2211^{6} \\
2176 \\
-2107 \\
2061 \\
2228 \\
2207 \\
2076 \\
2058 \\
2177 \\
2365 \\
2215 \\
2165 \\
2171\end{array}$ & $\begin{array}{l}c \\
c \\
c \\
c \\
c \\
c \\
c \\
c \\
c \\
c \\
c \\
c \\
c \\
c\end{array}$ & $\begin{array}{l}200 \\
200 \\
200 \\
200 \\
200 \\
200 \\
200 \\
200 \\
200 \\
200 \\
200 \\
200 \\
200\end{array}$ & $\begin{array}{l}489 \\
671 \\
841 \\
616 \\
769 \\
689 \\
792 \\
810 \\
641 \\
799 \\
625 \\
960 \\
901\end{array}$ & $\begin{array}{l}34.1 \\
40.6 \\
48.8 \\
40.7 \\
47.5 \\
60.3 \\
42.6 \\
43.8 \\
41.7 \\
63.3 \\
61.9 \\
52.3 \\
48.4\end{array}$ & $\begin{array}{l}97.3 \\
124 \\
165 \\
152 \\
155 \\
130 \\
162 \\
132 \\
132 \\
120 \\
128 \\
132 \\
135\end{array}$ & $\begin{array}{l}39.9 \\
59.8 \\
70.3 \\
60.8 \\
52.6 \\
47.1 \\
65: 1 \\
65.4 \\
51.5 \\
45.4 \\
47.8 \\
53.8 \\
57.6\end{array}$ & $\begin{array}{c}92.5 \\
81.5 \\
101 \\
96.0 \\
84.1 \\
78.5 \\
105 \\
93.1 \\
32.5 \\
73.8 \\
78.4 \\
94.3 \\
88.3\end{array}$ & $\begin{array}{l}2.86 \\
2.30 \\
2.06 \\
2.90 \\
2.58 \\
2.76 \\
2.69 \\
2.02 \\
2.56 \\
2.64 \\
2.68 \\
2.45 \\
2.34\end{array}$ & $\begin{array}{l}0.152 \\
0.160 \\
0.161 \\
0.162 \\
0.166 \\
0.164 \\
0.166 \\
0.158 \\
0.165 \\
0.152 \\
0.161 \\
0.162 \\
0.161\end{array}$ \\
\hline \multirow[t]{2}{*}{$\begin{array}{l}2250 \\
2090 \\
2094\end{array}$} & $\begin{array}{l}\mathrm{c} \\
\mathrm{c} \\
\mathrm{c}\end{array}$ & $\begin{array}{l}200 \\
200 \\
200\end{array}$ & $\begin{array}{l}831 \\
971 \\
914\end{array}$ & $\begin{array}{r}45.5 \\
49.0 \\
45.2 \\
\end{array}$ & $\begin{array}{l}123 \\
129 \\
139 \\
\end{array}$ & $\begin{array}{r}49.8 \\
52.8 \\
48.9 \\
\end{array}$ & $\begin{array}{l}7 B .2 \\
82.6 \\
81.0 \\
\end{array}$ & $\begin{array}{l}2.47 \\
2.44 \\
2.75 \\
\end{array}$ & $\begin{array}{l}0.158 \\
0.161 \\
0.160 \\
\end{array}$ \\
\hline & & & Average & 44.1 & 132 & 53.9 & . 94.3 & 2.47 & 0.160 \\
\hline \multirow[t]{2}{*}{$\begin{array}{l}2111 \\
2141 \\
2369 \\
2035 \\
2050 \\
2105\end{array}$} & $\begin{array}{l}c \\
c \\
c \\
c \\
c \\
c\end{array}$ & $\begin{array}{l}275 \\
275 \\
275 \\
275 \\
275 \\
275\end{array}$ & $\begin{array}{r}961 \\
1066 \\
1170 \\
1126 \\
1407 \\
1296\end{array}$ & $\begin{array}{l}57.1 \\
68.5 \\
61.7 \\
63.3 \\
71.1 \\
56.6 \\
\end{array}$ & $\begin{array}{l}172 \\
190 \\
202 \\
150 \\
194 \\
284 \\
\end{array}$ & $\begin{array}{c}34.0 \\
108 \\
31.4 \\
39.5 \\
113 \\
65.8 \\
\end{array}$ & $\begin{array}{l}120 \\
159 \\
126 \\
116 \\
148 \\
108 \\
\end{array}$ & $\begin{array}{l}2.05 \\
1.88 \\
2.48 \\
1.68 \\
1.72 \\
2.88 \\
\end{array}$ & $\begin{array}{l}0.172 \\
0.184 \\
0.180 \\
0.172 \\
0.185 \\
0.172 \\
\end{array}$ \\
\hline & & & Averages & 63.0 & 189 & 29.0 & 126 & 2.12 & 0.178 \\
\hline
\end{tabular}

(Malenfort 88, Table 6-13) 


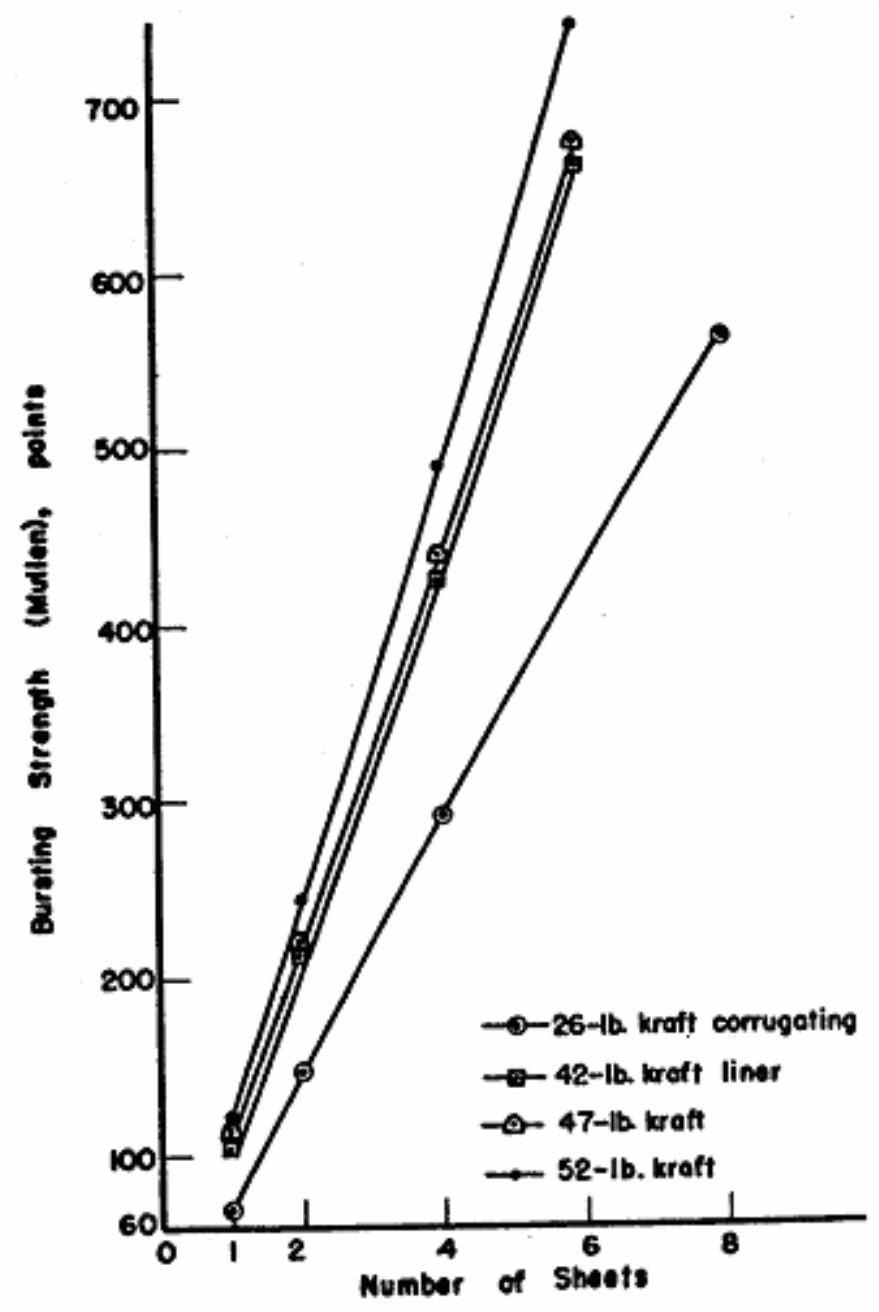

Figure 557: Bursting Strength of Cardboard versus Multiple Sheets of Cardboard (Malenfort 219, Figure 17-28) 
Table 8: Common U.S. Grades of Liner and Medium

Grade
Regular Kraft Liner

Bleached Kraft

Recycled Fiber (other)

Corrugating Medlum

-Commercial but not Freight Rule grades.

(Malenfort 12, Table 2-2)

\begin{tabular}{cc}
$\begin{array}{c}\text { Basls Wolght } \\
\text { (Ib/MSF) }\end{array}$ & $\begin{array}{c}\left(\mathbf{g}^{*} \mathbf{m}^{\prime}\right) \\
\mathbf{1 2 7}\end{array}$ \\
\hline 33 & 161 \\
38 & 186 \\
42 & 205 \\
$47^{*}$ & 229 \\
69 & 337 \\
90 & 439
\end{tabular}

$38 \quad 186$

$42 \quad 205$

$69 \quad 337$

$90 \quad 439$

$40 \quad 195$

$50 \quad 244$

$70 \quad 341$

$90 \quad 439$

$26 \quad 127$

$30^{*} \quad 146$

$33^{*} \quad 161$

36* 176

$40^{*}$

195

$\begin{array}{rrll}\begin{array}{r}\text { Average } \\ \text { (pal) }\end{array} & \begin{array}{r}\text { Burst } \\ \text { (kPa) }\end{array} & \text { Callper } \\ 70 & 482 & .008 & 2.03 \\ 85 & 588 & .010 & 2.54 \\ 92 & 634 & .011 & 2.79 \\ 100 & 689 & .0125 & 3.18 \\ 105 & 724 & .0145 & 3.68 \\ 135 & 931 & .020 & 5.08 \\ 160 & 1103 & .023 & 5.84 \\ & & & \\ 84 & 579 & .010 & 2.54 \\ 93 & 641 & .011 & 2.79 \\ 128 & 883 & .018 & 4.57 \\ 150 & 1034 & .022 & 5.59 \\ & & & \\ 65 & 448 & .010 & 2.54 \\ 100 & 689 & .013 & 3.30 \\ 135 & 931 & .021 & 5.33 \\ 175 & 1207 & .023 & 7.11 \\ & & & \\ & & .009 & 2.29 \\ & & .010 & 2.54 \\ & & .011 & 2.79 \\ & & .012 & 3.05 \\ & & .013 & 3.30\end{array}$




\section{Curriculum Vitae}

\section{Tracy A. Mick}

I am currently in graduate school at West Virginia University in Morgantown West Virginia. I plan to receive a Master of Science degree in Mechanical Engineering in August of 2005. I also attended West Virginia University during my undergraduate career. I graduated with a Bachelor of Science degree in Mechanical and Aerospace Engineering in the Fall of 2003. After graduation I plan to obtain a job within industry in the field of design. 